4. \#brussel \#brusselis \#maalbeek

\#daesnoags tryıng to \#twitterstorm

these \# plat counter it \#BruxellesAttack

\#Bruxelles \#Ctrlsec \#iceișis $\mathbf{r}$

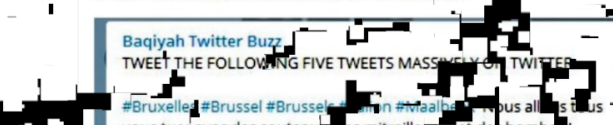

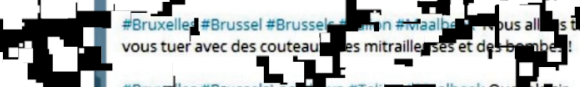

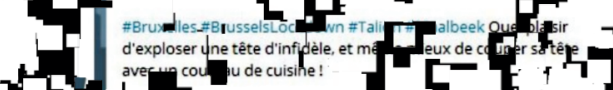
avecuq cou in de cuisthe! The 42,5 ris

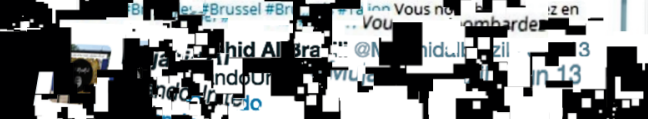
4

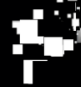

Suspended

Your account (@newerajihadi66) is currently suspended. For more

information, please log into

twitter.com twitter.com. tets

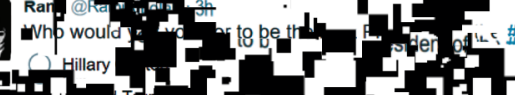

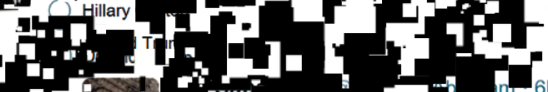

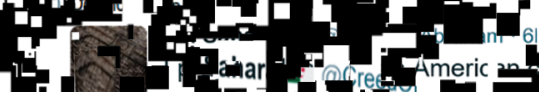

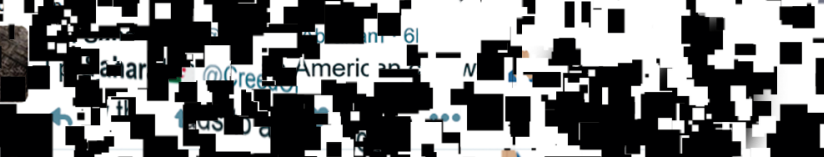

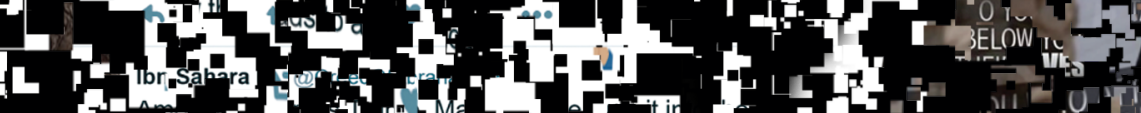

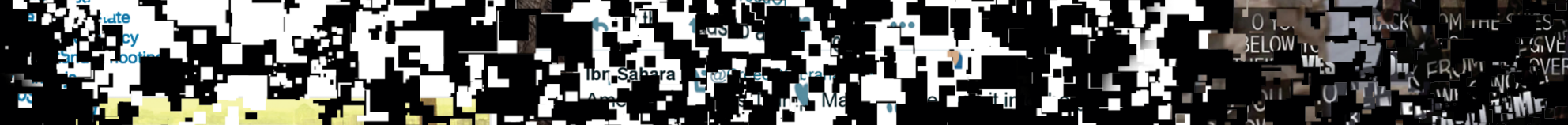
4,5 - If

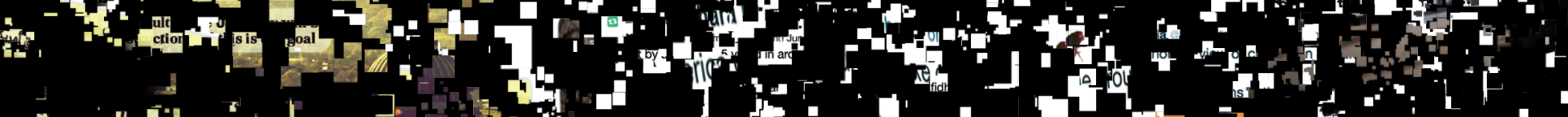
$\therefore$ " 3 ,

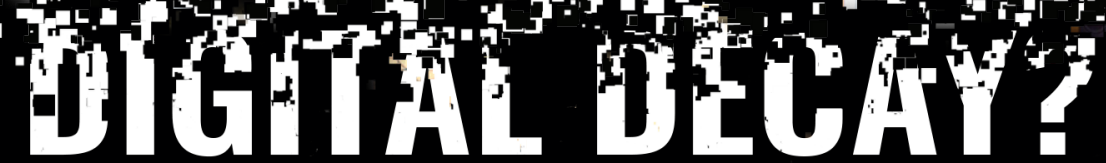

\section{Tracing Change Over Time Among English-Language Islamic State Sympathizers on Twitter}

\section{Audrey Alexander Ootober 2017}

Program on Extremism 



\title{
DIGITAL DECAY? \\ Tracing Change Over Time Among English-Language Islamic State Sympathizers on Twitter
}

\author{
BY \\ Audrey Alexander \\ October 2017
}

Program on Extremism

THE GEORGE WASHINGTON UNIVERSITY 
All rights reserved. Printed in the United States of America. No part of this publication may be reproduced or transmitted in any form or by any means, electronic or mechanical, including photocopy, recording, or any information storage and retrieval system, without permission in writing from the publisher.

\section{2017 by Program on Extremism}

Program on Extremism

2000 Pennsylvania Avenue NW, Suite 2210

Washington, DC 20006

www.extremism.gwu.edu 


\title{
CONTENTS
}

\author{
Author's Notes and About the Author - v \\ Executive Summary · vii \\ Introduction $\cdot 1$ \\ Background · 5 \\ Method and Design · 11 \\ Analysis of English-Language IS-Sympathizers on Twitter · 15 \\ Conclusion $\cdot 45$
}

\section{List of Figures}

1. IS Infographic $\cdot 1$

2. Kibana's Dashboard · 12

3. Breakdown of Time Segments · 12

4. Tweet Count Per Week · 15

5. Tweet Frequency and Unique Screen Names By Week · 17

6. Duration of Account Activity · 17

7. Follower Count by Chronological Segment · 18

8. Tracing Username Mentions by English-Language IS Sympathizers · 20

9. Example Tweets $\cdot 23$

10. Twitter Accounts · 24

11. Example Tweet $\cdot 24$

12. Tracking Military Engagements Over Time · 25

13. Two-Week Snapshot of Mosul and Kirkuk (October 14 to 28, 2016) · 26

14. Top 3 Hashtags Per Week Highlighting Prevalence of Key Battles - 28

15. Tracing Attacks Over Time 30

16. Example Tweets · 31

17. Example Tweet $\cdot 31$

18. Example Tweet $\cdot 33$

19. Top 10 Hashtags on July 15 and July 16, $2016 \cdot 34$

20. Example Tweet · 35

21. Tweet Referencing Anti-US State Leaders • 35

22. Example Tweet - 36

23. Example Tweet · 37

24. Top Hashtag Per Week · 38 



\section{AUTHOR'S NOTES}

First and foremost, the author would like to thank Daniel Kerchner, and the team at Scholarly Technology Group (STG) of the George Washington University Libraries, for their immeasurable contributions to this project since December 2015.

This report was made possible by the Program's team of Research Assistants, particularly Alex Theodosiou; Sarah Metz, Eleanor Anderson, Samantha Weirman, Mattisen Stonhouse, Adib Milani, Tanner Wrape, Mario Ayoub, Scott Backman, Jenna Hopkins, and Elizabeth Yates also contributed to this report.

The author would also like to thank Dr. Ali Fisher for his constructive feedback, and Larisa Baste for formatting this report.

\section{ABOUT THE AUTHOR}

Audrey Alexander specializes in the role of digital communications technologies in terrorism and studies the radicalization of women. As a Research Fellow at the Program on Extremism at The George Washington University, she authored Cruel Intentions: Female Jihadists in America and published articles in Foreign Affairs, the Washington Post, and Lawfare blog. In this role, Alexander also maintains a database of nearly 3,000 pro-Islamic State social media accounts. Before joining the Program on Extremism, she worked at King's College London's International Centre for the Study of Radicalisation (ICSR) and with the Institute for Strategic Dialogue (ISD). Alexander holds a Masters in Terrorism, Security \& Society from the War Studies Department at King's College.

\section{The Program on Extremism}

The Program on Extremism at George Washington University provides analysis on issues related to violent and non-violent extremism. The Program spearheads innovative and thoughtful academic inquiry, producing empirical work that strengthens extremism research as a distinct field of study. The Program aims to develop pragmatic policy solutions that resonate with policymakers, civic leaders, and the general public. 



\section{EXECUIIVE SUMMARY}

Until 2016, Twitter was the online platform of choice for English-language Islamic State (IS) sympathizers. As a result of Twitter's counter-extremism policies - including content removal - there has been a decline in activity by IS supporters. This outcome may suggest the company's efforts have been effective, but a deeper analysis reveals a complex, nonlinear portrait of decay. Such observations show that the fight against IS in the digital sphere is far from over. In order to examine this change over time, this report collects and reviews 845,646 tweets produced by 1,782 English-language pro-IS accounts from February 15, 2016 to May 1, 2017.

This study finds that:

- Twitter's policies hinder sympathizers on the platform, but counter-IS practitioners should not overstate the impact of these measures in the broader fight against the organization online.

- Most accounts lasted fewer than 50 days, and the network of sympathizers failed to draw the same number of followers over time.

- The decline in activity by English-language IS sympathizers is caused by Twitter suspensions and IS' strategic shift from Twitter to messaging platforms that offer encryption services.

- Silencing IS adherents on Twitter may produce unwanted side effects that challenge law enforcement's ability to detect and disrupt threats posed by violent extremists.

- The rope connecting IS' base of sympathizers to the organization's top-down, central infrastructure is beginning to fray as followers stray from the agenda set for them by strategic communicators.

- While IS' battlefield initiatives are a unifying theme among adherents on Twitter, the organization's strategic messaging output about these fronts receive varying degrees of attention from sympathizers.

- Terrorist attacks do little to sustain the conversation among supporters on Twitter, despite substantive attention from IS leadership, central propaganda, and even Western mass media.

- Over time, there has been a decline in tweets following major attacks. This suggests that attacks in the West have diminishing effects in mobilizing support.

- Current events - such as the attempted coup in Turkey and the 2016 U.S. presidential election - are among the most popular topics within the sample.

- Events unrelated directly to IS cause some of the greatest spikes in activity.

- These discussions are ongoing despite Twitter's policies.

- Conclusions and Policy Recommendations

- English-language IS sympathizers on Twitter defy straightforward analysis and convenient solutions.

- They are skilled problem-solvers in the digital sphere. Rather than ruminating over losses, angered adherents fight to be heard, either on Twitter or other digital platforms.

- Counter-IS practitioners must show a similar willingness to adapt and explore alternative ventures.

- While some collaboration is beneficial, the government cannot rely predominantly on the efforts of tech companies to counter IS and its supporters. 



\section{INTRODUCTION}

In May 2017, a pro-IS English-language infographic entitled "Failure of the Media War on the Islamic State" by Yaqeen Media Foundation ${ }^{1}$ circulated among some of the movement's sympathizers on social media (Figure 1). With a healthy level of skepticism, the graphic highlights the complexity of the 'media war' between IS and its adversaries. On one hand, the image alludes to IS' dynamic media strategy, made to amplify the organization's voice through coordinated "campaigns" that disseminate content on "famous websites such as Twitter and Facebook." Simultaneously, however, the graphic touts in the bottom left-hand corner that "More than 1,000 new accounts are made by Islamic State supporters each day on Twitter." Figures from Twitter's tenth \#Transparency Report suggest the company's effort to suspend accounts for violations related to the promotion of terrorism far exceeds a rate of 1,000 accounts per day, challenging the infographic's evaluation of their opponents' 'failure' in the fight against IS on Twitter. ${ }^{2}$ In light of these discrepancies, perhaps binary measures of success and failure, like winning and losing, have limited utility in the discourse surrounding the fight against IS online.

Several conventional markers indicate that the foothold of the self-styled caliphate is faltering on the ground in Syria and Iraq. IS has lost considerable territory, putting a tremendous strain on the organization's internal revenue streams, while casualties and a decrease in foreign fighter travel continue to deplete its pool of combatants. ${ }^{3}$ The decline in central media output is a symptom, and perhaps also a cause, of depletion in the physical world. ${ }^{4}$ Despite these setbacks, IS sympathizers continue to wage

\section{IS Infographic}

\section{FALUURE OF THE MEDIA WAR}

$\underline{E}$ ON THE ISLAMIC STATE

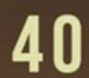

Intelligence offices fighting the Islamic State on different online websites

RESULTS TODAY:

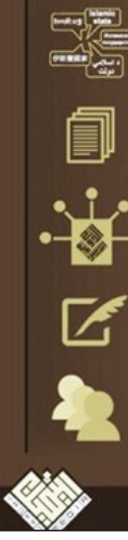

Islamic State media is spread in more than 40 languages today.

More than 35 new releases everyday for the Islamic State and its supporters such as photo reports and others.

Islamic State media releases is spread in all main famous websites such as Twitter and Facebook.

Nearly 18425 posts related to the Islamic State are written each day on social media websites.

More than 1000 new accounts are made by Islamic State supporters each day on Twitter.

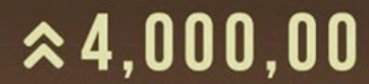

Accounts have been deleted on social media websites so far
The Anti-Isis propaganda campaign which aims to to stop the recruitment of soldiers through social media has faced failure due to incompetence and favoritism and misleading data according to an
investgation made by the Assocaited Press." investgation made by the Assocaired Press.

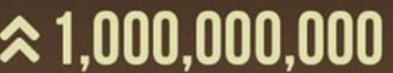

Dollars has been spent on the media war so far

\section{TYPES OF ONLINE FICHTING:}
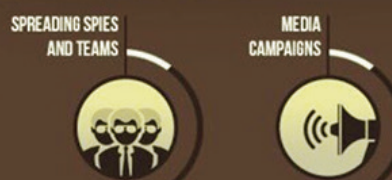

APRESTINO

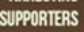

CREATIMG SPEEIAUZEI

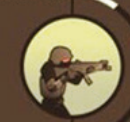

CENITERS

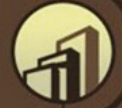

And the Islamic State and its supporters continue to conquer the online field everywhere and to spread thousands of posts with thousands of accounts in tens of languages each day to reach everywhere and it didn't spend a tenth of what the Kuffar has spent and it doesn't have a tenth of the capabilities the Kuffar have and all of that is by Allah's grace. so continue $O$ Ansar to spread terror in the hearts of the Kuffar and to support your religion and nation.

(Figure 1) May 2017 infographic allegedly produced by pro-IS Yaqeen Media Foundation 
a protracted struggle in the digital sphere using a wealth of digital communications technologies. Thus, the organization's presence in the virtual theater is hard to gauge.

IS is strategically adept on social media because of slick branding, masterful distribution, and effective agenda-setting. ${ }^{5}$ On a strategic level, the group demonstrates extraordinary dexterity in navigating the changing media landscape online. ${ }^{6}$ From Facebook and Twitter to Telegram and Tor, sympathizers fluidly cross between broad-based platforms and more private, protected channels. ${ }^{7}$ Reaping the benefit of a "two-tier production line" of "official" and "user generated" content, IS' propaganda is accessible to a broad swathe of sympathizers. ${ }^{8}$ Moreover, the multi-lingual approach IS implements "has a clear objective: targeting non-Arabic speaking potential recruits." ${ }^{\prime}$ The reach of these media products is optimized by a mix of coordinated campaigns and the organic rallying of IS' online supporters.

Despite its competencies, IS is vulnerable in the digital domain. Much like the militant wings of the organization, considerable challenges confront IS' networks online. Due to the prosecution of IS supporters in the West and targeted strikes on select fighters in IS-held territory, operational security is a growing concern among many sympathizers. IS' most prolific online recruiter, British hacker Junaid Hussain, was reportedly killed in 2015 after leaving an Internet cafe in Raqqa, IS' de facto capital. ${ }^{10} \mathrm{~A}$ multitude of legal documents and news media demonstrate the utility of virtual communications for investigating authorities in mapping the international network of IS recruiters and recruits. ${ }^{11}$ In addition to the actions of the military and law enforcement, public and private sector initiatives target IS in the digital sphere and make it more difficult for adherents to access information and communicate freely. Existing approaches continue to yield mixed results, relying predominantly on counter-messaging campaigns and content-based regulation. ${ }^{12}$
As it pertains to this report, Twitter regulates content by suspending accounts that violate the company's policies regarding the promotion of terrorism. ${ }^{13}$ In the 'Countering Violent Extremism' section of the company's tenth \#Transparency Report, Twitter announced the suspension of a total of 636,248 accounts between August 1, 2015 and December 31, 2016. ${ }^{14}$ According to an official blog post published in early 2016, Twitter's terrorism-related suspensions were "primarily related to ISIS." ${ }^{15}$ The company claims to investigate "accounts similar to those reported" and "leverage[s] proprietary spam-fighting tools to surface other potentially violating accounts for review."16 Twitter's efforts to counter extremism in the virtual sphere extend beyond content regulation and range from official preservation requests from law enforcement to the collaborative promotion of counter-messaging efforts. ${ }^{17}$ In December 2016, the company announced a hashing-centric information-sharing partnership with Facebook, Microsoft, and YouTube to more effectively flag problematic materials with algorithms to "help curb the spread of extremist content online." ${ }^{18}$

While these indicators suggest IS' presence has deteriorated online, policy makers, law enforcement officials, and private companies have a limited and largely anecdotal understanding of how pro-IS online networks respond to duress in the digital arena. Consequently, this report will examine how an important cross-section of English-language IS sympathizers on Twitter adapt to online and offline initiatives aimed at weakening the wider movement. After reviewing relevant literature, the report examines change over time in a sample of 845,646 tweets produced by 1,782 English-language pro-IS accounts on Twitter between February 15, 2016, and May 1, 2017. ${ }^{19}$ This 63-week dataset is among the largest time-bound samples on the subject, but it only represents a snapshot of IS' activity on Twitter. The Program on Extremism (PoE) collected this corpus of tweets with the support of software developers in the Scholarly Technology Group 
$(\mathrm{STG})^{20}$ of the George Washington University Libraries.

This report is also part of an ongoing initiative tracking the online efforts of IS in the West.

Despite some limitations, namely the applicability of the findings to the wider conflict online and offline, this unique resource offers an opportunity to examine shifts in activity among English-language IS sympathizers on Twitter. After contextualizing the broader fight against IS, the background chapter discusses the synergistic interplay between the physical, digital, and strategic elements of the movement. The method chapter articulates PoE's original data collection process, identifies key caveats, and punctuates the particular scope, transferability, and reliability of the findings. The subsequent analysis of the data is split into two overall sections. The first of these examines the primary research question, namely: 'How have Twitter's counter-extremism policies affected English-language IS sympathizers on the platform?' The second section poses three supplementary questions to investigate how this demographic of supporters engages with battles in Iraq and Syria, terrorist attacks, and other current events. These inquiries probe how English-language IS sympathizers engage with matters in the physical world, especially considering the internal and external dynamics that guide their behavior on Twitter. In tandem, these sections hint that the dissipation of accessible communication channels threatens the cohesion of IS' sympathizers in the West.

Focusing on a small sliver of the broader population of IS supporters worldwide, this report paints a complex portrait of the struggle between English-language adherents on Twitter, and the social media company's efforts to silence IS' calls to support the self-proclaimed caliphate. Rather than focusing exclusively on the numerical decline in tweet frequency or the plummeting number of proIS accounts, the following discussion strives to unpack change over time and interrogate the implications for the broader fight against IS in the digital sphere. Although findings suggest that the term 'decay' best descibes the effects of Twitter's policy on the English-language IS community on Twitter, growing evidence reveals that the 'media war' between IS and its adversaries is not nearing a definitive end, it is just changing.

\section{Notes}

1. SITE Enterprise. 2017. "Yaqeen Media Center." https://ent. siteintelgroup.com/index.php?option= com_customproperties\&task=tag\&tagId=209\& phpMyAdmin=31b32de8000cb1c40d5792b21dc9961a.

2. Twitter's tenth \#Transparency Report explains, "a total of 376,890 accounts were suspended for violations related to promotion of terrorism" between July 1 and December 31, 2016. This amounts to a rate of approximately 2,060 accounts per day. “Government TOS Reports - July to December 2016.” 2017. https://transparency.twitter.com/en/gov-tos-reports.html.

3. Jacob Shapiro, "A predictable failure: the political economy of the decline of the Islamic State," West Point Combating Terrorism Sentinel 9:9, 2016; Stefan Heißner, Peter R. Neumann, John Holland-McCowan, Rajan Basra, "Caliphate in Decline: An Estimate of Islamic State's Financial Fortunes," Report by the International Centre for the Study of Radicalisation, 2017; Lucy Pasha-Robinson, "ISIS loves '10,000 fighters and a quarter of territory in 18 months," Independent, October 17, 2016.

4. Milton, Daniel. 2016. 'Communication Breakdown: Unraveling the Islamic State's Media Efforts.' Combating Terrorism Center at West Point.

5. Koerner, Brendan. 2016. "Why ISIS Is Winning the Social Media War-And How to Fight Back." WIRED, April. https:/www.wired.com/2016/03/ isis-winning-social-media-war-heres-beat/.

6. Prucha, Nico. 2016. "IS and the Jihadist Information Highway - Projecting Influence and Religious Identity via Telegram." Perspectives on Terrorism 10 (6), p.52 http://www.terrorismanalysts.com/pt/index.php/pot/article/view/556.

7. Alkhouri, Laith, and Alex Kassirer. 2016. "Tech for Jihad: Dissecting Jihadists' Digital Toolbox.” Flashpoint. https:// www.flashpoint-intel.com/wp-content/uploads/2016/08/ TechForjihad.pdf.

8. Prucha, Nico. 2016. "IS and the Jihadist Information Highway - Projecting Influence and Religious Identity via Telegram." Perspectives on Terrorism 10 (6), p.54 http://www. terrorismanalysts.com/pt/index.php/pot/article/view/556.

9. Prucha, Nico. 2016. "IS and the Jihadist Information Highway - Projecting Influence and Religious Identity via Telegram.” Perspectives on Terrorism 10 (6), p.54 http://www.terrorismanalysts.com/pt/index.php/pot/article/view/556.

10. Goldman, Adam, and Eric Schmitt. 2016. "One by One, ISIS Social Media Experts Are Killed as Result of F.B.I. Program.” The New York Times, November 24. https://www.nytimes.com/2016/ 11/24/world/middleeast/isis-recruiters-social-media.html.

11. United States v. Munir Abdulkader (2016), Sentencing Memorandum; United States v. David Daoud Wright (2017), Second Superseding Indictment. Wilber, Del Quentin. 2017. "Here's How the FBI Tracked down a Tech-Savvy Terrorist Recruiter for the Islamic State." Los Angeles Times, April 13. 
http://www.latimes.com/politics/la-fg-islamic-state-recruiter-20170406-story.html; Hughes, Seamus, and Alexander Meleagrou-Hitchens. 2017. "The Threat to the United States from the Islamic State's Virtual Entrepreneurs" CTC Sentinel 10 (3). https://www.ctc.usma.edu/posts/the-threat-to-the-united-states-from-the-islamic-states-virtual-entrepreneurs;

12. Google's Jigsaw, for example, attempts to counter online extremism with the Redirect Method, which, according to its website, diverts supporters to "curated YouTube videos" that confront IS' recruitment themes. "The Redirect Method Jigsaw.” 2017. http://redirectmethod.org.

13. In the official 'Twitter Rules,' the company identifies "Violent threats (direct or indirect)" as grounds for temporarily locking and/or permanently suspending accounts, explaining, "You may not make threats of violence or promote violence, including threatening or promoting terrorism." - "The Twitter Rules.” 2017. Twitter Help Center. https://help.twitter.com/ articles/18311?lang=en.

14. “Government TOS Reports - July to December 2016.” 2017. https://transparency.twitter.com/en/gov-tos-reports.html.

15. Please note that Twitter made this assertion prior to the timeframe used in PoE's report. Although subsequent suspensions likely continued the trend, PoE cannot confirm what percentage of the total number of suspensions relate to IS specifically. “Combating Violent Extremism.” 2016. Twitter Blogs. February 5. https://blog.twitter.com/2016/ combating-violent-extremism.

16. "Combating Violent Extremism." 2016. Twitter Blogs. February 5. https://blog.twitter.com/2016/combating-violent-extremism.

17. "Guidelines for Law Enforcement." 2017. Twitter Help Center. Accessed September 11. https://help.twitter. com/articles/41949?lang=en. See also, "An Update on Our Efforts to Combat Violent Extremism." 2016. Twitter Blogs. August 18. https://blog.twitter.com/2016/ an-update-on-our-efforts-to-combat-violent-extremism.

18. "Partnering to Help Curb the Spread of Terrorist Content Online.” 2016. Twitter Blogs. December 5. https://blog.twitter. com/2016/partnering-to-help-curb-the-spread-of-terroristcontent-online.

19. In this context, accounts are distinguished by username rather than ID number. For more information, this report articulates the precise logistics of PoE's approach in the method section.

20. For more information about the Scholarly Technology Group, see https://library.gwu.edu/scholarly-technology. 


\section{BACKGROUND}

Although several jihadi groups gained online traction prior to and during the Syrian civil war, ${ }^{1}$ Abu Bakr al-Baghdadi and his pool of supporters set a precedent by expertly blending the online and offline battlefield. Arguably more so than its jihadi predecessors and competitors, IS and its media department "embraced the popularity of social media and other methods of reaching new audiences," moving away from hierarchical websites and forums. ${ }^{2}$ In this way, al-Baghdadi, the supposed 'Caliph' and a man of few words, encouraged the movement to speak for itself.

Some analysts rightly question whether the effects of social media are exaggerated, ${ }^{3}$ but counter-terrorism scholars and practitioners broadly agree that digital communications technology, especially social media, are a means by which IS and its adherents engage with each other. ${ }^{4}$ Using a versatile media apparatus, IS "managed to leverage a combination of official and unofficial actors in support of its propaganda mission." ${ }^{5}$ This method helped facilitate a global

\section{The nature of IS' central} communications continues to evolve, especially since the group conducts targeted media initiatives in an effort to mobilize its base of supporters worldwide. organizations within extremist networks play a role in driving jihadist networks. ${ }^{7}$ Moreover, Klausen's study contends that official IS accounts are vital and tightly integrated with other types of Twitter profiles, indicating a more centralized communication strategy. ${ }^{8}$ These works, among others, ${ }^{9}$ illuminate how social media affords IS the opportunity to implement top-down and bottom-up recruitment procedures.

The nature of IS' central communications continues to evolve, especially since the group conducts targeted media initiatives in an effort to mobilize its base of supporters worldwide. In Lighting the Path: the Evolution of the Islamic State Media Enterprise, Craig Whiteside succinctly notes that for IS, "controlling the message is a goal unto itself." ${ }^{10}$ In pursuit of that aim, "the official content put out by the Islamic State is an amalgamation of products from a number of separate, geographically-centered media bureaus spread across the group's territory." 11 Anecdotally, IS has advanced targeted recruitment by tailoring content to reach a movement, posing a real but amorphous threat to entities inside and outside IS-controlled territory.

As IS gained traction in Syria and Iraq, social media research revealed a burgeoning relationship between activity on the ground and a broad base of sympathizers worldwide. Works like \#GreenBirds: Measuring Importance and Influence in Syrian Foreign Fighter Networks by the International Centre for the Study of Radicalisation (ICSR) and 'Tweeting the Jihad' by Jytte Klausen laid the foundation for research using social media as a lens to examine the networks of Western foreign fighters. ${ }^{6}$ Both studies articulate the relevance of actors outside IS-controlled territory. Where ICSR emphasizes the influence of unofficial clerical authorities as 'disseminators' who inform foreign fighters, Klausen suggests that broader audience. The creation of Al-Hayat Media Center, which publishes content in multiple languages, including English, is a testament to IS' desire to cast a wide net. ${ }^{12}$ The production of non-Arabic content "remains a high priority for IS" in addition to the continued stream of propaganda targeting Arabic speaking sympathizers. ${ }^{13}$ In 2017, the pro-IS Yaqeen Media Foundation reports that "Islamic State media [are] spread in more than 40 languages." ${ }^{14}$ Jihadists disseminate these messages across a range of digital platforms: while some mediums are broad-based and far-reaching, like Facebook and Twitter, others are more insular and protected, like Telegram and Kik.

In Documenting the Virtual Caliphate: Understanding Islamic State's Propaganda, a report published in 2015, Charlie Winter identifies several themes in IS' 'brand' including 
brutality, mercy, victimhood, war, belonging, and utopianism. ${ }^{15}$ Winter notes that IS' propaganda output had "increased significantly since June 2014." ${ }^{\text {16 }}$ Multiple analyses suggest that IS' top-down propaganda effort reached its height around July and August $2015 .{ }^{17}$ In some instances, changes in territory correlate with shifts in the aggregate number of media products; this point is increasingly apparent in the wake of significant losses. Aaron Zelin notes, "there may be two reasons" for a decline in central media output: "the killing of IS media operatives, and/ or the loss in territory." ${ }^{19}$ In Communication Breakdown: Unraveling the Islamic State's Media Efforts, Daniel Milton traces change over time in IS' official propaganda dissemination, observing a substantial decline in visual media products from August 2015 to August 2016. ${ }^{20}$

Using official, unofficial, and grassroots communication channels, IS is often credited with 'winning the war on social media. ${ }^{21}$ Although this assertion has some validity, precise measures of success and failure in the digital arena are context dependent and difficult to operationalize. IS uses an interconnected network to disseminate information that is always changing and reconfiguring without relying on the typical hierarchal structure, which is simultaneously beneficial and detrimental. ${ }^{22}$ IS communicators undoubtedly weathered numerous blows, but this is not the same as defeat. In his discussion on official propaganda, Milton notes, "setbacks suggest that the efficacy of the media arm is not a foregone conclusion, but a subjective reality contingent on a wide array of other factors such as counterterrorism pressure, battlefield conditions, and personnel availability." ${ }^{23}$ The subsequent discussion about the dissemination efforts of IS sympathizers on Twitter must adopt an equally nuanced approach and account for the major variables that may influence behavior in the digital sphere.

Nico Prucha aptly articulates the predominant factors contributing to the early 2016 shift among IS adherents from Twitter to Telegram. In IS and the Jihadist Information Highway, Prucha highlights the dialectical process whereby Twitter's growing efficacy in banning sympathizers led IS followers to pursue alternative means of communication in other, less regulated spaces. ${ }^{24}$ The necessity of this move is best illustrated by IS' nostalgia for Twitter;
Prucha explains, "IS media operatives and sympathizers miss" the platform and some of the group's media outlets "called for a return to Twitter." ${ }^{25}$ Furthermore, evidence suggests that contemporary messaging campaigns "coordinate distribution" on a "multiplatform zeitgeist," which often targets Twitter, highlighting the enduring importance of the medium. ${ }^{26}$ Ultimately, despite the increased operational security afforded by Telegram, the transition to a platform other than Twitter impedes IS' ability to expand online. ${ }^{27}$

Despite setbacks, IS uses social media and other communications technology, to praise, claim, incite, and facilitate violent activity outside IS-controlled territory. A 2017 report confirms that since 2011, states in Europe and North America are attractive targets for jihadi operatives. ${ }^{28}$ Based on such activity in the United States alone, evidence suggests that there is no monolithic digital footprint for an IS sympathizer; they are just as idiosyncratic online as they are in the real world, and use various forms of social media to participate in the movement. ${ }^{29}$ Moreover, although some social media platforms prove to be more commonplace than others within the jihadisphere, sympathizers do not necessarily use them in the same way.

In February 2016, for example, after tracking Safya Yassin's various Twitter, Google+, and Facebook accounts over the span of several months, authorities arrested the Missouri resident for transmitting threats to injure federal government employees. ${ }^{30}$ In spite of multiple account suspensions on Twitter, Yassin created new profiles to disseminate content bolstering IS' message of violent jihad. ${ }^{31}$ On August 24, 2015, prior to her arrest, the FBI recorded Yassin tweeting personal information, including the names, locations, and phone numbers, of three federal employees listed under the title, "Wanted to Kill." ${ }^{32}$ By January 27, 2016, the FBI identified 97 Twitter accounts that were "likely" linked to Yassin. ${ }^{33}$ Although Yassin's potential trajectory for physical mobilization and operational links to IS remain unknown, her prolific presence on social media, namely Twitter, has facilitative significance because she amplified IS' violent rhetoric to her sizable base of followers.

6. The George Washington University Program on Extremism 
In contrast, the case of attempted Garland shooter Elton Simpson demonstrates a drastically different use of Twitter (among other platforms) by an IS sympathizer. In the U.S. On May 3, 2015, Simpson and Nadir Soofi, his accomplice, drove from Arizona to Texas to attack the Muhammad Art Exhibit and Contest with assault rifles; both men were killed by law enforcement before breaching the venue. Before the plot, Simpson had "direct contact" with at least two jihadists abroad "using Twitter direct message and SureSpot." ${ }^{34}$ Although the nature of such communications vary, links to prolific IS-recruiter Junaid Hussain and Mohamed Abdullahi Hassan (Mujahid Miski), the notorious U.S.-linked member of Al-Shabaab, are suggestive of a more operational connection to formalized jihadist groups. ${ }^{35}$ On the day of the attack, using the handle @atawaakul, Simpson allegedly alluded to an emerging plot on Twitter, creating the hashtag "\#texasattack." ${ }^{36}$ According to news reports, Simpson also encouraged supporters on Twitter to follow @_AbuHu55ain, an account tied to Junaid Hussain. ${ }^{37}$ Shortly thereafter, Hussain's account tweeted statements suggesting that he had prior knowledge of the attack. ${ }^{38}$ Ultimately, Simpson's use of Twitter drastically differed from that of Safya Yassin, demonstrating variance in IS sympathizers' use of social media platforms.

Even though IS sympathizers in the West use social media as a means to connect with the self-proclaimed caliphate, whether operational or ideological, engagement in the digital sphere varies. The geographic location of the sympathizer may also influence the channel of engagement which users pursue. Though not empirically proven, IS sympathizers in the UK, for example, may be less inclined to download jihadi propaganda than their counterparts in the US due to differing laws on extremist content. Admittedly, patterns of participation are likely defined by operational security considerations, but existing laws and ease of engagement may factor into sympathizers' cost-benefit analysis of various means of digital communications.

In response to the proliferation of violent extremists online, Western governments, particularly the U.S. and U.K., have relied much on the participation of tech companies in the fight against IS in the digital domain. In the
U.S. for example, the 'Madison Valleywood Project' encourages tech and entertainment companies to assist in the fight against terrorism with counternarratives and stringent enforcement of their respective terms of service. ${ }^{39}$ While it is a necessary step to curb the dissemination of media products that advocate for violent agendas, the precise impact of such attempts is difficult to quantify. Even so, it is imperative to discuss the measures used by tech companies to counter IS online.

The most prevalent contemporary approaches are content-based regulation and counter-messaging. Such policies range from stand-alone initiatives by one company to collaborative engagement by several others. Despite more recent partnerships with Facebook, Microsoft, and YouTube, Twitter's efforts to counter violent extremism online focus on content-based regulation via account suspension. ${ }^{40}$ Though commendable, Twitter's approach produces mixed results. One study suggests that suspension efforts yield some success, particularly as returning accounts fail to gain relative traction after suspension. ${ }^{41}$ On the other hand, IS sympathizers create new accounts every day and continue to demonstrate tremendous agility across multiple platforms. Consequently, the efficacy of one tech company in silencing IS on its site may produce negative results across other channels of communication.

Digital communications technologies remain instrumental in the exchange of ideas between IS supporters on a global stage. But still, the flux in communications between IS-central and its international base of supporters is subject to changing tides in the physical and digital arena. In his discussion about IS media, Whiteside notes, IS' "desire to expand required an intensity and quantity of messaging that might have invited failure due to a lack of control." ${ }^{\prime 2}$ Similarly, although social media affords IS innumerable opportunities for growth and mobilization, these channels pose critical challenges to those who seek to direct and advance the movement inside and outside IS-controlled territory. In a recent analysis, Bryan Price and Muhammad al-'Ubaydi highlight IS-central's effort to limit its fighters' use of social media on the ground in Iraq and Syria. ${ }^{43}$ The authors explain, "This is not the first time [IS] has warned against the use of social media by its rank-and-file," but the most recent endeavor in May 2017 
is "its most forceful attempt to date." ${ }^{44}$ Like IS-central, sympathizers worldwide adapt to initiatives that target the movement online and offline, but little is known of the impact these counter-IS measures have on IS' online diaspora. The subsequent study and analysis works to unpack these dynamics using a sizable sample of Englishlanguage IS sympathizers on Twitter.

\section{Notes}

1. Zelin, Aaron. 2013. "The State of Global Jihad Online." Washington, DC: New America Foundation. Prucha, Nico, and Ali Fisher. 2013. "Tweeting for the Caliphate: Twitter as the New Frontier for Jihadist Propaganda | Combating Terrorism Center at West Point."CTC Sentinel, 6 (6). https:// ctc.usma.edu/posts/tweeting-for-the-caliphate-twitter-as-the -new-frontier-for-jihadist-propaganda.

2. Whiteside, Craig. 2016. "Lighting the Path:the Evolution of the Islamic State Media Enterprise (2003-2016)." International Centre for Counter-Terrorism - The Hague. Zelin, Aaron. 2013. "The State of Global Jihad Online." Washington, DC: New America Foundation. Prucha, Nico, and Ali Fisher. 2013.

3. Gilsinan, Kathy. 2015. "Is ISIS's Social-Media Power Exaggerated?” The Atlantic, February 23. https://www. theatlantic.com/international/archive/2015/02/ is-isiss-social-media-power-exaggerated/385726/.

4. Taylor, Harriet. "Most Young Terrorist Recruitment Is Linked to Social Media, Said DOJ Official,” October 5, 2016. http://www.cnbc.com/2016/10/05/most-young-terroristrecruitment-is-linked-to-social-media-said-doj-official. html.; Rose, Steve. "The Isis Propaganda War: A Hi-Tech Media Jihad." The Guardian, October 7, 2014, sec. World news. https://www.theguardian.com/world/2014/oct/07/ isis-media-machine-propaganda-war.

5. Milton, Daniel. 2016. 'Communication Breakdown: Unraveling the Islamic State's Media Efforts'. Combating Terrorism Center at West Point, p.V.

6. Carter, Joseph, Shiraz Maher, and Peter Neumann. 2014. "\#Greenbirds: Measuring Importance and Influence in Syrian Foreign Fighter Networks.” International Centre for the Study of Radicalisation. http://icsr.info/wp-content/ uploads/2014/04/ICSR-Report-Greenbirds-MeasuringImportance-and-Infleunce-in-Syrian-Foreign-FighterNetworks.pdf. Jytte Klausen. 2015. 'Tweeting the Jihad: Social Media Networks of Western Foreign Fighters in Syria and Iraq', Studies in Conflict \& Terrorism, 38:1.

7. Carter, Joseph, Shiraz Maher, and Peter Neumann. 2014. "\#Greenbirds: Measuring Importance and Influence in Syrian Foreign Fighter Networks." International Centre for the Study of Radicalisation. http://icsr.info/wp-content/uploads/2014/04/ ICSR-Report-Greenbirds-Measuring-Importance-andInfleunce-in-Syrian-Foreign-Fighter-Networks.pdf; Jytte
Klausen. 2015. 'Tweeting the Jihad: Social Media Networks of Western Foreign Fighters in Syria and Iraq,' Studies in Conflict \& Terrorism, 38:1, p.19.

8. Jytte Klausen. 2015. 'Tweeting the Jihad: Social Media Networks of Western Foreign Fighters in Syria and Iraq,' Studies in Conflict \& Terrorism, 38:1, p.19.

9. Bodine-Baron, Elizabeth, Todd C. Helmus, Madeline Magnuson, Zev Winkelman. 2016. "Examining ISIS Support and Opposition on Twitter.” RAND Corporation. Berger, J.M., and Jonathan Morgan. 2015. "The ISIS Twitter Census: Defining and Describing the Population of ISIS Supporters on Twitter." Brookings Institution. https://www.brookings.edu/ wp-content/uploads/2016/06/isis_twitter_census_berger_ morgan.pdf.

10. Whiteside, Craig. 2016. "Lighting the Path: The Evolution of the Islamic State Media Enterprise (2003-2016).” International Centre for Counter-Terrorism - The Hague, p.26.

11. Milton, Daniel. 2016. 'Communication Breakdown: Unraveling the Islamic State's Media Efforts.' Combating Terrorism Center at West Point, p.IV-V.

12. Joscelyn, Thomas. 2015. "Graphic Promotes the Islamic State's Prolific Media Machine.” FDD's Long War Journal. Accessed November 25. http://www.longwarjournal.org/archives/ 2015/11/graphic-promotes-islamic-states-prolific-mediamachine.php. Also cited in Whiteside, Craig. 2016. "Lighting the Path: The Evolution of the Islamic State Media Enterprise (2003-2016)." International Centre for Counter-Terrorism The Hague, p.18.

13. Prucha, Nico. 2016. "IS and the Jihadist Information Highway - Projecting Influence and Religious Identity via Telegram." Perspectives on Terrorism 10 (6), p.52 http://www. terrorismanalysts.com/pt/index.php/pot/article/view/556.

14. Naturally, pro-IS propaganda infographics are not reliable sources for statics. Even so, this example highlights IS' eagerness to demonstrate its global reach. "Failure of the Media War on the Islamic State” infographic. Yaqeen Media Foundation, 2016.

15. Winter, Charlie. 2015. "Documenting the Virtual 'Caliphate': Understanding Islamic State's Propaganda,” Quilliam Foundation.

16. Winter, Charlie. 2015. “'Documenting the Virtual 'Caliphate': Understanding Islamic State's Propaganda," Quilliam Foundation.

17. In the month of Shawwal (July 17 to August 15, 2015), IS-central released 892 unique items of propaganda. This, according to Winter, was its peak. (This is compared to 570 individual media products between January 30 to February 28 in February, 2017.) Winter, Charlie. 2015. "Fishing and Ultraviolence.” 2017. BBC News. http://www.bbc.co.uk/news/ resources/idt-88492697-b674-4c69-8426-3edd17b7daed; Lakomy, Miron. 2017. "Cracks in the Online "Caliphate": How the Islamic State is Losing Ground in the Battle for Cyberspace." Perspectives on Terrorism, 11 (3), p.47; Winter, Charlie. 2017. "ICSR Insight: The ISIS Propaganda Decline"

8. The George Washington University Program on Extremism 
ICSR. March 23; Milton also notes that IS released 700 official video products in August 2015, only 200 were released in August 2016. Milton, Daniel. 2016. 'Communication Breakdown: Unraveling the Islamic State's Media Efforts'. Combating Terrorism Center at West Point.

18. http://icsr.info/2017/03/icsr-insight-isis-propagandadecline/

19. Zelin, Aaron. 2015. "ICSR Insight - The Decline in Islamic State Media Output / ICSR.” ICSR. December 4. http://icsr. info/2015/12/icsr-insight-decline-islamic-state-media-output/.

20. Milton, Daniel. 2016. 'Communication Breakdown: Unraveling the Islamic State's Media Efforts.' Combating Terrorism Center at West Point. p.21.

21. Mazzetti, Mark, and Michael R. Gordon. 2015. "ISIS Is Winning the Social Media War, U.S. Concludes." The New York Times. https://www.nytimes.com/2015/06/13/ world/middleeast/isis-is-winning-message-war-usconcludes.html. Koerner, Brendan. 2016. "Why ISIS Is Winning the Social Media War-And How to Fight Back." WIRED, April. https://www.wired.com/2016/03/ isis-winning-social-media-war-heres-beat/.

22. Fischer, Ali. 2014. "Eye of the Swarm: The Rise of ISIS and the Media Mujahedeen.” USC Center on Public Diplomacy. https://uscpublicdiplomacy.org/blog/ eye-swarm-rise-isis-and-media-mujahedeen.

23. Milton, Daniel. 2016. 'Communication Breakdown: Unraveling the Islamic State's Media Efforts.' Combating Terrorism Center at West Point, p.50.

24. Prucha, Nico. 2016. "IS and the Jihadist Information Highway - Projecting Influence and Religious Identity via Telegram.” Perspectives on Terrorism 10 (6), p.54 http://www.terrorismanalysts.com/pt/index.php/pot/article/view/556.

25. Prucha, Nico. 2016. "IS and the Jihadist Information Highway - Projecting Influence and Religious Identity via Telegram." Perspectives on Terrorism 10 (6), p.54 http://www.terrorismanalysts.com/pt/index.php/pot/article/view/556.

26. Prucha, Nico. 2016. "IS and the Jihadist Information Highway - Projecting Influence and Religious Identity via Telegram." Perspectives on Terrorism 10 (6), p.54 http://www.terrorismanalysts.com/pt/index.php/pot/article/view/556.

27. Prucha, Nico. 2016. "IS and the Jihadist Information Highway - Projecting Influence and Religious Identity via Telegram." Perspectives on Terrorism 10 (6), p.56 http://www.terrorismanalysts.com/pt/index.php/pot/article/view/556.

28. Vidino, Lorenzo, Francesco Marone, and Eva Entenmann. 2017. "Fear Thy Neighbor Radicalization and Jihadists Attacks in the West." Program on Extremism, p.15-16.

29. Alexander, Audrey. 2017. "How to Fight ISIS Online." Foreign Affairs, April 7. https://www.foreignaffairs.com/articles/ middle-east/2017-04-07/how-fight-isis-online.
30. United States v. Safya Roe Yassin, Criminal Complaint and Affidavit (2016).

31. United States v. Safya Roe Yassin, Criminal Complaint and Affidavit (2016).

32. United States v. Safya Roe Yassin, Criminal Complaint and Affidavit (2016).

33. United States v. Safya Roe Yassin, Criminal Complaint and Affidavit (2016).

34. Using a mix of evidence, Hughes and Meleagrou-Hitchens link Elton Simpson to Junaid Hussain and Mohamed Abdullahi Hassan (Mujahid Miski). For more information about the nature of these communications, see: "Virtual Entrepreneurs" Hughes, Seamus, and Alexander Meleagrou-Hitchens. 2017. "The Threat to the United States from the Islamic State's Virtual Entrepreneurs." CTC Sentinel 10 (3). https://www. ctc.usma.edu/posts/the-threat-to-the-united-states-fromthe-islamic-states-virtual-entrepreneurs.

35. "Virtual Entrepreneurs" Hughes, Seamus, and Alexander Meleagrou-Hitchens. 2017. "The Threat to the United States from the Islamic State's Virtual Entrepreneurs." CTC Sentinel 10 (3). https://www.ctc.usma.edu/posts/the-threat-to-theunited-states-from-the-islamic-states-virtual-entrepreneurs.

36. Callimachi, Rukmini. 2015. "Clues on Twitter Show Ties Between Texas Gunman and ISIS Network." The New York Times, May 11, sec. U.S. https://www.nytimes.com/2015/ 05/12/us/twitter-clues-show-ties-between-isis-and-garlandtexas-gunman.html. See also the account linked to Elton Simpson, Sharia is Light (@atawaakul). "The bro with me and myself have given bay'ah to Amirul Mu'mineen. May Allah accept us as mujahideen. Make dua \#texasattack," May 3, 2015. Tweet.

37. Callimachi, Rukmini. 2015. "Clues on Twitter Show Ties Between Texas Gunman and ISIS Network." The New York Times, May 11, sec. U.S. https://www.nytimes.com/2015/ 05/12/us/twitter-clues-show-ties-between-isis-and-garlandtexas-gunman.html.

38. "Virtual Entrepreneurs" Hughes, Seamus, and Alexander Meleagrou-Hitchens. 2017. "The Threat to the United States from the Islamic State's Virtual Entrepreneurs.” CTC Sentinel 10 (3). https://www.ctc.usma.edu/posts/the-threat-to-theunited-states-from-the-islamic-states-virtual-entrepreneurs.

39. Kang, Cecilia, and Matt Apuzzo. 2016. "U.S. Asks Tech and Entertainment Industries Help in Fighting Terrorism." The New York Times, February 24. https://www.nytimes.com/ 2016/02/25/technology/tech-and-media-firms-called-towhite-house-for-terrorism-meeting.html.

40. "Partnering to Help Curb the Spread of Terrorist Content Online.” 2016. Twitter Blogs. December 5. https://blog. twitter.com/2016/partnering-to-help-curb-the-spread-ofterrorist-content-online. Government TOS Reports - July to December 2016." 2017. https://transparency.twitter.com/en/ gov-tos-reports.html. 
41. Berger, J.M., and Heather Perez. 2016. “The Islamic State's Diminishing Returns on Twitter: How suspensions are limiting the social networks of English-speaking ISIS supporters." Program on Extremism. https://cchs.gwu.edu/sites/cchs.gwu. edu/files/downloads/Berger_Occasional\%20Paper.pdf.

42. Whiteside, Craig. 2016. "Lighting the Path: The Evolution of the Islamic State Media Enterprise (2003-2016).” International Centre for Counter-Terrorism - The Hague, p.26.

43. Price, Bryan, and Muhammad al-'Ubaydi. 2017. "CTC

Perspectives: The Islamic State's Internal Rifts and Social Media Ban." Combating Terrorism Center at West Point. https://ctc.usma. edu/posts/ctc-perspectives-the-islamic-states-internal-riftsand-social-media-ban.

44. Price, Bryan, and Muhammad al-'Ubaydi. 2017. “CTC Perspectives: The Islamic State's Internal Rifts and Social Media Ban." Combating Terrorism Center at West Point. https://ctc.usma. edu/posts/ctc-perspectives-the-islamic-states-internal-riftsand-social-media-ban. 


\section{METHOD AND DESIGN}

Similar to any study that uses social media as a means to understand a movement, the following investigation faces inherent limitations on the scope, transferability, and reliability of the dataset. By focusing on English-language sympathizers on Twitter, a small but substantive sliver of IS' online activity, this report adds to a growing body of research that uses social media as a lens to comprehend the mobilization efforts of violent extremists worldwide. From the outset of the project, the author has made a concerted effort to implement a design that strives to mitigate the effects of such drawbacks. In short, this report presents analysis on a sample of data gleaned from the Program on Extremism's (PoE) broader initiative examining IS' use of social media. The following section provides an in-depth description of the Program's general approach to data collection, and then identifies the particular segment of content interrogated in this report.

\section{Design for Broader Initiative: Tracking IS' Use of Social Media in the West}

PoE first launched the project investigating the various efforts of English-speaking IS sympathizers on Twitter after the publication of its December 2015 report ISIS in America: From Retweets to Raqqa. The approach uses a two-step data collection method to build a substantive, time-bound corpus of tweets by English-language accounts; as of May 2017, the resource contained about one million tweets from nearly 3,000 accounts. While not a comprehensive snapshot of English-language activity on Twitter, this content allows PoE to cross-examine a spectrum of questions about IS supporters' use of social media in the West.

Inspired by a range of studies on the efforts of IS in the digital sphere, the Program's mixed method approach yields a wealth of data apt for qualitative and quantitative analyses. Since the project's conception, research assistants, ${ }^{1}$ under the supervision of PoE fellows and associates, ${ }^{2}$ have been using open source practices to collect a snowball sample of English-language accounts exuding pro-IS sentiment via organic content and retweets. ${ }^{3}$
When Twitter accounts satisfy the study's predetermined criteria, ${ }^{4}$ researchers document the user's name, handle, link, location, and bio in a spreadsheet and archive digital records in select circumstances. ${ }^{5}$

Although focusing on English-language sympathizers on Twitter inherently limits the transferability of the study, the author adopted this approach to build a manageable dataset and streamline language requirements for the various coders identifying pro-IS accounts. Moreover, the connection between IS in Iraq and Syria and its diaspora of sympathizers in the West requires rigorous examination, creating an opportunity for more targeted analysis. On Twitter especially, this approach remains relevant due to IS' prioritization of non-Arabic content, particularly in English. ${ }^{6}$

With the support of software developers in the Scholarly Technology Group (STG) ${ }^{7}$ of the George Washington University Libraries, PoE collects and analyzes content produced by the running list of IS sympathizers on Twitter. These accounts are difficult to monitor because of Twitter's ongoing efforts to suspend users that violate their terms of service. To complement manual record keeping, PoE uses software to archive content produced by this sample of Twitter accounts around the clock. Several times a week, ${ }^{8}$ the author adds the latest iteration of newly identified pro-IS handles to a running list of accounts monitored by Social Feed Manager (SFM), ${ }^{9}$ open source software developed by GWU Libraries. SFM captures raw data using Twitter's Application Programming Interface (API).$^{10}$ Every 30 minutes, SFM harvests tweets posted by accounts that are still active. ${ }^{11}$ In addition to the sheer number of tweets collected by SFM, PoE benefits from SFM's collection of each tweet's complete metadata providing investigators access to a wealth of information that is not visible on Twitter's web or mobile interface. ${ }^{12}$ By saving the tweets as structured data, SFM captures it in a form that is well-suited for quantitative analysis.

Next, STG maintains a flow of PoE data from SFM to a data exploration environment where researchers 
can interact with the data using the Kibana interface. The Kibana interface is part of an ElasticStack (Elasticsearch, Logstash, Kibana) server that has been customized for examining social media data, ${ }^{13}$ making it easy for analysts to see graphics such as 'tweet frequency' or 'top-ten hashtags' (See Kibana image). ElasticStack is a general-purpose framework for exploring data and provides support for loading, querying, analyzing, and visualizing. SFM's ElasticSearch receives a continual stream of tweets as they are collected by SFM, allowing PoE

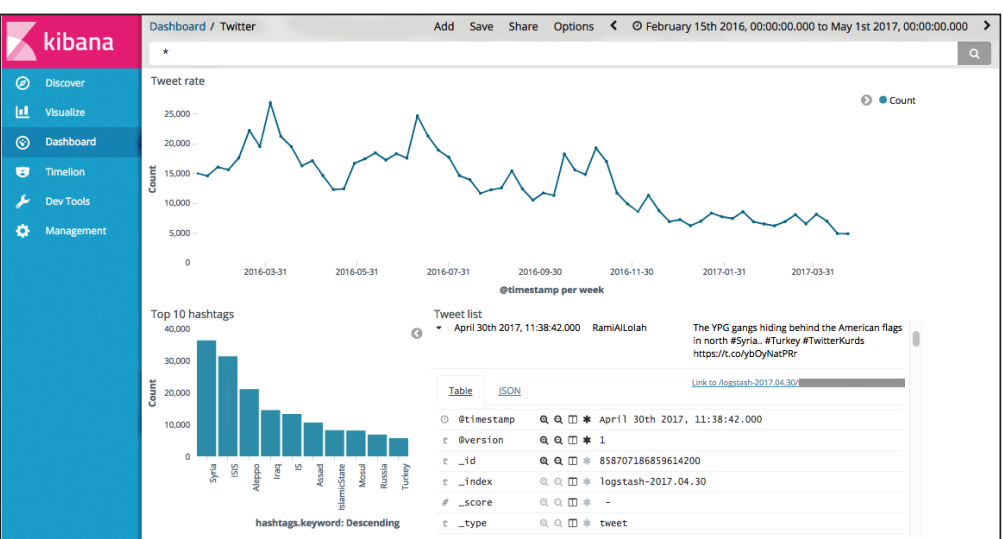

(Figure 2) Screenshot of Kibana's 'Dashboard' showing analytics representing SFM data from February 15, 2016 to May 1, 2017. to investigate the data in exciting ways using custom analytics.

\section{Method Employed in This Report}

Rather than focusing on the full dataset, which includes a sharp increase at the beginning due to project implementation, this report conducts a comprehensive analysis of a 63-week section of tweets ranging from February 15, 2016 at 00:00:00 to May 1, 2017 at 00:00:00. This sample contains 845,646 tweets produced by 1,782 unique accounts of English-language IS sympathizers on Twitter. ${ }^{14}$ The author selected this time series because it encapsulates a sustained period of account collection that lasts over one year. This sample also divides neatly into three chronological 21-week segments (see Figure 3), which allows the partitioning of data for comparative analysis of the first, second, and third part of the dataset. ${ }^{15}$

Despite efforts to mitigate these challenges, the most notable impediments to the comprehensiveness of the sample stem from project design and implementation. The continuity of account selection, for example, is imperfect due to the schedule of staff and volunteer research assistants who could not devote the same amount of time to data collection every day during the 63-week period. Twitter's regulations and efforts to suspend accounts that violate their terms of service also appears to curb the quantity

\section{Breakdown of Time Segments}

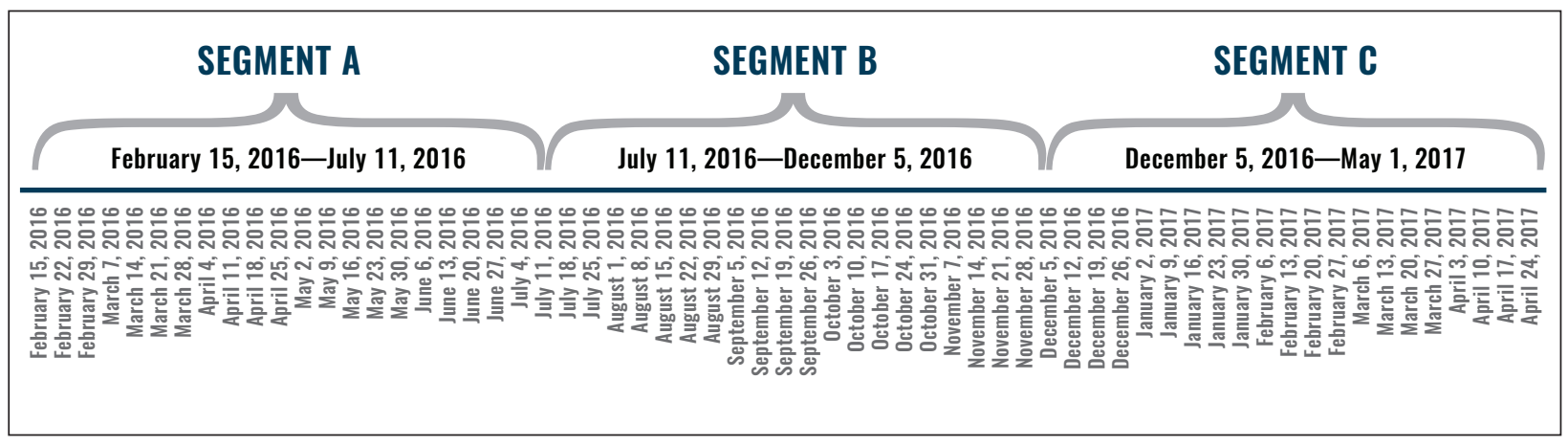

(Figure 3) Segment A spans from February 15, 2016 to July 11, 2016; Segment B spans from July 11, 2016 to December 5, 2016; Segment C spans from December 5, 2016 to May 1, 2017.

12 The George Washington University Program on Extremism 
and visibility of pro-IS content available for collection and analysis. Additionally, while Twitter's metadata provides investigators countless opportunities, some useful variables like location and gender setting of each account is either unattainable or unreliable. Such barriers and caveats receive additional attention in subsequent analysis.

Despite key constraints and the narrow scope of the study, this dataset allows PoE to test for digital decay over time among a select demographic of IS supporters on Twitter. After presenting some initial observations and the decline in tweet frequency, this report poses one primary and three supplementary questions to examine how Englishlanguage IS sympathizers on Twitter fare in the face of online and offline initiatives aimed at weakening the wider movement. ${ }^{16}$ The author selected these questions from a running list of relevant inquiries that demand further examination. Using Kibana, the above mentioned data visualization interface, and a range of tools including Python, Google Sheets, and Gephi, the study presents the data and a wide range of findings that pertain to the liminal space between IS' centralized and decentralized efforts on Twitter. Though dense and technical at times, the following discussion presents key findings in a nuanced but accessible way. Many of the graphs, for example, use the square root on the y-axis to more clearly demonstrate the relationship of different variables. In other instances, observations are cross-examined with existing research to highlight the data's convergence and divergence with existing lines of logic.

\section{Notes}

1. Special thanks to all the Research Assistants who helped build PoE’s Twitter database, including: Adib Milani, Armand Jhala, William Kiely, Graham Raby, Jacob Chereskin, Alexander Bierman, Helen Powell, Sarah Kells, Nick Gallucci, Dillon McGreal, Marco Olimpio, Ethan Santangelo, Jessie Gimpel, Andrea Moneton, Sneha Bolisetty, Tinshan Fullop, Andrew Walsh, Cole Swaffield, Sam Riccardi, Dan Heesemann.

2. PoE Research Fellows include Bennett Clifford and Katerina Papatheodorou, and Research Associates include Prachi Vyas and Sarah Gilkes.

3. In an effort to standardize the project's data collection process, research assistants receive extensive training and ongoing supervision.
4. To be transparent, the author will further explain the account selection criteria in the appendix.

5. Researchers archive accounts in a shared storage drive if they meet at least one of the following benchmarks: If the user is likely (or certainly) an American, if the user provides commentary on U.S. domestic events or Western foreign policy, if their kunya (a nom de guerre) contains "al-Amriki" ("the American"), if they locate themselves within the U.S., if they claim to be in ISIS-controlled territory, if he/she posts original pro-ISIS content useful for media purposes, if the account has more than 350 followers.

6. Fernandez, Alberto. 2015. "Here to Stay and growing:Combating ISIS Propaganda Networks." The Brookings Project on U.S. Relations with the Islamic World U.S.-Islamic World Forum Papers 2015. Brookings Institution. https://www.brookings.edu/ wp-content/uploads/2016/06/IS-Propaganda_Web_English.pdf.

7. For more information about the Scholarly Technology Group, see https://library.gwu.edu/scholarly-technology.

8. In some instances, accounts are shut down between the time they are added to PoE's dataset and fed into SFM. Consequently, the number of unique accounts in PoE's social media database is greater than the number of accounts monitored by SFM. Though unfortunate, the author does not believe this limitation undermines the dataset as the majority of accounts are represented in both the social media database and SFM.

9. For more information on Social Feed Manager (SFM), visit https://gwu-libraries.github.io/sfm-ui/

10. An Application Programming Interface (API) is a set of commands, functions, protocols, and objects that programmers can use to create software or interact with an external system.

11. In these cases, PoE's manual collection method and record keeping complement SFM's automated process. For example, Twitter limits the amount of data that it provides through the API, but PoE's screenshots helps capture content SFM cannot collect. In some instances, PoE preserves records of accounts that are shut down after researchers add it to the internal database but before it is added to SFM. When a new account is added to SFM, the Twitter API provides SFM with data in JSON format for the account's most recent 3,200 Tweets. Upon subsequent harvests, SFM captures any new content produced by the user so long as the account is active and public. If the account is made protected (private), deactivated by the user, or suspended by Twitter, SFM cannot harvest new content from the account.

12. For a description of the metadata contained in a tweet, see https://dev.twitter.com/overview/api/tweets

13. The ELK Stack is a collection of three open-source products: Elasticsearch, Logstash, and Kibana. Elasticsearch is a NoSQL database that is based on the Lucene search engine. Logstash is a log pipeline tool that accepts inputs from various sources, executes different transformations, and exports the data to various targets. Lastly, Kibana is a visualization layer that works on top of Elasticsearch. 
Method and Design

14. For the sake of clarity, the number of accounts is calculated using the number of unique usernames rather than unique Twitter ID numbers.

15. Segment A spans from February 15, 2016 to July 11, 2016; Segment B spans from July 11, 2016 to December 5, 2016; Segment C spans from December 5, 2016 to May 1, 2017.

16. Question 1: How have Twitter's counter-extremism policies affected English-language IS sympathizers on the platform?; Question 2: How do English-language IS sympathizers engage with on-the-ground IS activity over time?; Question 3: How do terrorist attacks drive discourse among English-language IS sympathizers on Twitter?; Question 4: How do current events influence the activity of English-language IS sympathizers on Twitter? 


\section{ANALYSIS OF ENGLISH-LANGUAGE IS SYMPATHIZERS ON TWITIER}

Due to the relative anonymity afforded by Twitter, it is challenging to speculate about the entities operating behind the 1,782 accounts discussed in this report. Even so, the data suggest that there is tremendous diversity among English-language sympathizers on Twitter, with accounts tweeting from nearly every time zone. ${ }^{1}$ For the most part, accounts adopt demographically ambiguous usernames, though some allude to factors like gender, nationality, and familial status, hinting at a disparate array of IS adherents that defy categorization. In every instance, it is difficult to discern the authenticity of pro-IS accounts, and thus, the sincerity of the actors operating them.

IS' international base of adherents uses multiple languages to engage with and support the organization online. Despite emphasizing content produced by English-language sympathizers on Twitter, PoE's data demonstrates the diversity of users on the platform. Unsurprisingly, over 87 percent of the sample set English as the primary language of their account; however, tweets posted by these accounts are not exclusively in English. ${ }^{2}$ The other 13 percent represent 16 different languages ranging from German and Danish to Indonesian and Chinese. Indonesian makes up about 2.7 percent of accounts, the second most common language in the dataset. Somewhat surprisingly, accounts with Arabic as their primary language amassed less than half a percent. Within the content produced by this swathe of accounts tweeting in English, the transliteration of Arabic words, Islamic terms, and jihadi phraseology are standard. Accounts that employ

\section{Tweet Count Per Week}

colloquial transliteration and words like 'coconuts' ${ }^{3}$ and 'baqiya' hark on religiopolitical concepts, actively defining membership to the English-language IS community on Twitter. This demographic, and trends regarding their use of Twitter over time, receive in-depth analysis in the following discussion.

There are many ways to examine change over time in online networks. This graph (Figure 4) demonstrates one initial finding: despite notable fluctuations from week to week, there is a dramatic decline in tweet frequency by Englishlanguage IS sympathizers on Twitter. From the most active week to the least active week, there is a 76 percent fall in the number of tweets per week. ${ }^{5}$ Though interesting, the sheer amount of content disseminated by English-language sympathizers on Twitter is only one measure of change over time. This numerical decline is not a wholly reliable indicator in isolation: for example, accounts with fewer tweets may still be more impactful if they are seen by a greater number of followers. As Ali Fisher notes in a blog post on interpreting data about IS online, "this type of tactical-level data can indicate success" in the online fight against IS, but

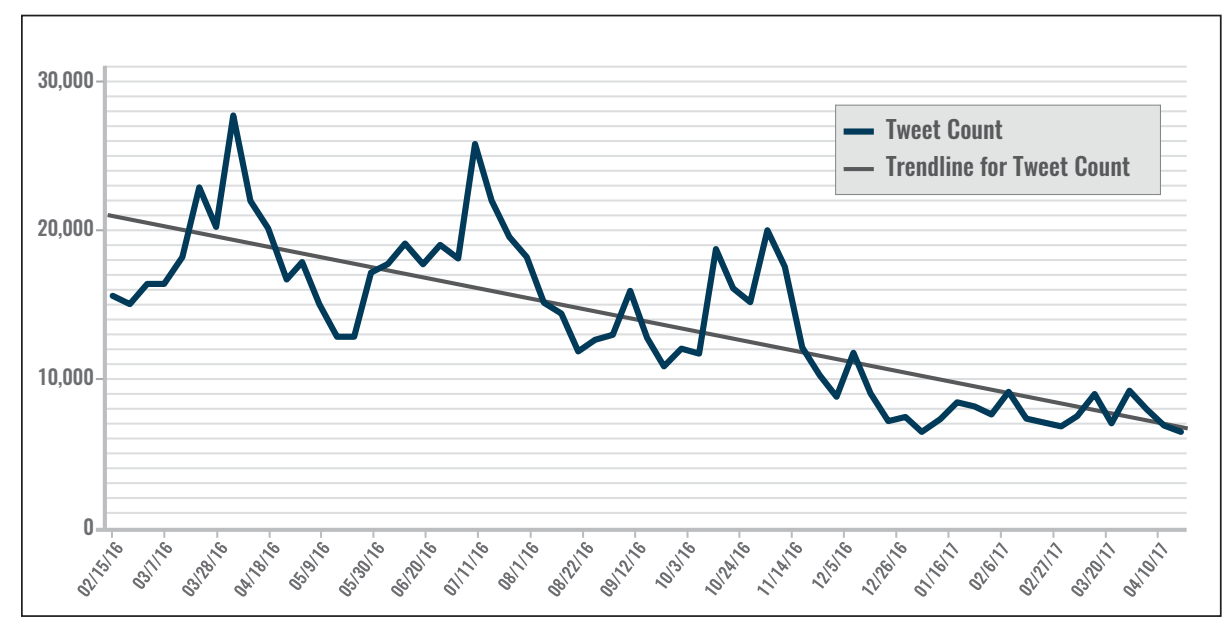

(Figure 4) This graph traces the overarching decline in tweet frequency over PoE's 63-week sample. Although the variance is not homogenous, statistical evidence (ANOVA) suggest that time is useful in the prediction of tweet count. ${ }^{*} r 2=0.622, p<.001$ 
a more "robust interpretation of data at the strategic level" is necessary. ${ }^{6}$ With this point in mind, the subsequent sections strive to provide a mix of tactical-, operational-, and strategic-level analyses.

The following discussion breaks into two analytical sections. The first strives to answer the question, 'How have Twitter's counter-extremism policies affected Englishlanguage IS sympathizers on the platform?' With the initial findings in mind, the second section pursues three alternative paths of inquiry to probe how English-language IS sympathizers engage with matters in the real world, especially in light of internal and external dynamics that guide their behavior on Twitter. Even though it is difficult to ascertain the precise impact of each cause, particularly as the various factors may accentuate each other's effects, this report strives to determine the key elements shaping activity by English-language IS sympathizers on Twitter.

\section{Section 1: Key Question and Analysis}

\section{How have Twitter's counter-extremism policies affected English-language IS sympathizers on the platform?}

Twitter's mounting efforts to suspend accounts that threaten or promote terrorism correlate with the decline in tweet frequency found in PoE's sample of Englishlanguage IS sympathizers. As cited in the introduction, Twitter "suspended a total of 636,248 accounts" between August 1, 2015, and December 31, 2016. ${ }^{7}$ These users hailed from multiple extremist persuasions but an official blogpost from Twitter asserted that the accounts were "primarily related to ISIS." ${ }^{8}$ Although Twitter does not necessarily report its rates of suspension, the company published total figures on three separate occasions. ${ }^{9}$ The estimates derived from these numbers and the corresponding dates reveal a substantial increase in the average number of accounts suspended per day, particularly in 2016. ${ }^{10}$ With these approximations alone, it is hard to deduce the precise strategy or chronological implementation of a more robust initiative to suspend accounts. Additionally, in a similar fashion to the decline in tweet frequency, a numerical decline in accounts does not necessarily translate to a reduction in reach.
As articulated in the methodology section, PoE strived to maintain a consistent level of effort to supply SFM with a continuous stream of English-language IS sympathizers' accounts. This process became increasingly difficult over the span of several months as accounts that met the predetermined criteria began to disappear. Anecdotally, the project manager noticed that a growing number of accounts became inactive, likely due to suspension, within the short window of time between account selection and adding the new accounts to SFM. ${ }^{11}$ As a result, PoE's data collection method may have inadvertently biased the sample against exceptionally short-lived accounts, particularly those lasting only a few hours. While difficult to parse out, it is crucial to consider how this might affect the following analysis, especially in the context of coordinated media campaigns utilizing Twitter.

\section{Accounts, Tweet Frequency, and Duration of Activity}

Throughout the 63-week period used in this study, SFM recorded content by 1,782 unique usernames. In the first third of the dataset, SFM gleaned data from an average of 307 accounts per week. By the last third of the time series, this average dropped by nearly fifty percent as SFM collected data from about 155 accounts per week. These figures give little insight on the enduring centrality or connectivity of the movement (or perhaps lack thereof), but receive additional attention later in the discussion.

The fall in tweet frequency relates to the decline in the number of active accounts collected by SFM each week (See Figure 5). ${ }^{12}$ During the 63-week period, 1,782 distinct usernames tweeted at an average rate of approximately 56 tweets per week. In the last third of the dataset, the average number of tweets per week by account fell compared to the first two-thirds of the time series. Although this change was not dramatic, an observation supported by basic calculations and likely subject to the pull of outliers, it might suggest that English-language IS sympathizers on Twitter share less content per week over time. One contributing factor might be the migration of users to other platforms, but no singular cause has led to this decline.

The duration of account activity is another factor that requires consideration. In this context, a user's 'duration

16 The George Washington University Program on Extremism 


\section{Tweet Frequency and Unique Screen Names By Week}

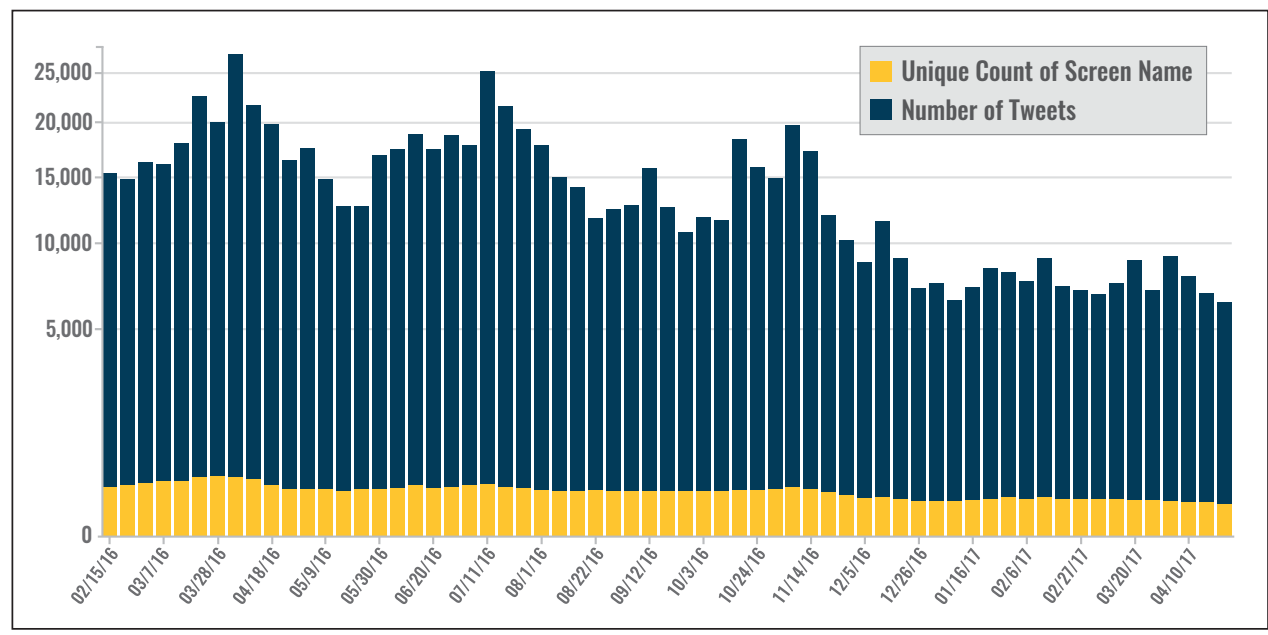

(Figure 5) This graph

shows how the relationship between unique screen names and tweet frequency per week changed over the course of the 63-week period. As discussed in the method chapter, this graph, like several others in the study, uses square root in the $y$-axis to more clearly represent the relationship between the two variables.

of activity' is quantified by the number of days between an account's first and last tweet. Twitter's API does not discern the date or time at which the company suspends accounts, nor does it identify accounts that were created and then subsequently abandoned by their respective users. Consequently, this measurement allows the study to grasp the chronological span of sympathizers that actively use the platform to share content. While overwhelmingly skewed by outliers, the average lifespan for this sample of English-language pro-IS accounts on Twitter was 251 days. It is critical to note, however, that dispersion of lifespan is highly concentrated (see Figure 6). Approximately 51.7 percent of accounts did not remain active longer than 50 days. On the other hand, however, a substantive portion of accounts lasted over a year, suggesting that Twitter's attempts to detect and suspend pro-IS account may be missing some long-term users. One possible explanation for long-standing users relates to the data collection method, as researchers are more likely to identify accounts the longer they are open. ${ }^{13}$ Ultimately, accounts that opted to leave the platform are likely included in this breakdown, although multiple factors- including the threat of suspension- likely affect user activity in this regard.

In order to maintain their presence on Twitter, some English language IS sympathizers appeared to have created multiple accounts at the same time to avoid shutdowns. On February 17, 2016, for example, four separate accounts were fashioned from a core handle, ${ }^{14}$ possibly from the same individual. One account (@erhabi35) survived only eight days, whereas another account (@Erhabi39) stayed active for 62 days. Although the study attempted to annotate cases where the same individual controlled multiple accounts, as the trend is common, quantitative figures are generally not reliable due to the relative anonymity Twitter affords users. It is hard to ascertain whether users that demonstrate similar behavioral patterns are simply individuals attempting to inoculate their digital presence against suspensions or are

\section{Duration of Account Activity}

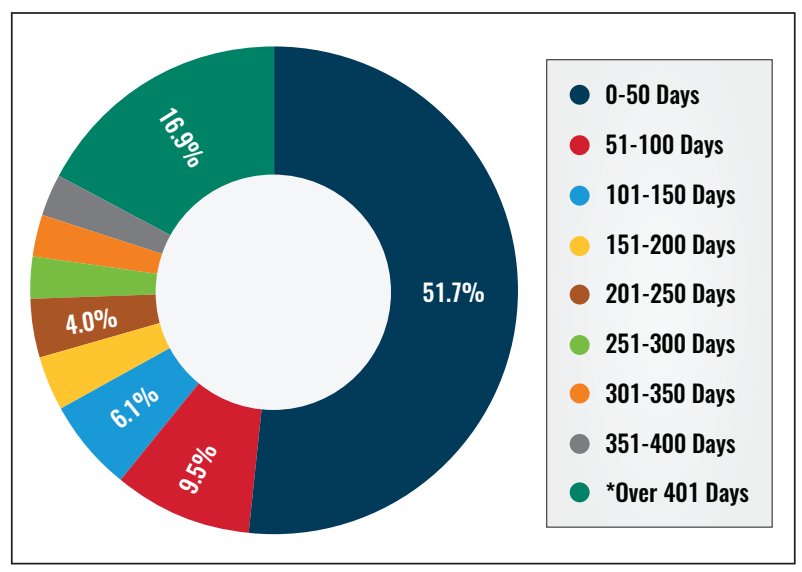

(Figure 6) This chart depicts the duration of account activity, meaning the number of days a pro-IS Twitter account was active, and displays the breakdown in percentages. 
part of an IS-coordinated initiative to influence discourse on Twitter. Although these aims are not mutually exclusive, it is critical to consider the varying drivers of engagement on Twitter.

In a similar vein, some returning English-language IS sympathizers proudly sport evidence of their previous suspensions in their Twitter bios or tweets. Seemingly operated by the same user, eleven iterations of the handle @DriftOne appear in the dataset. In the bio for @ DriftOne154, one of the more recent accounts, the user states to be on his or her "154th Account," demonstrating their resilience. In one analysis, Amarnath Amarasingam explains, "Getting suspended is also an important way for members of the Baqiya community [the broader online IS network] to know that you are trustworthy, that you have paid your dues." ${ }^{15}$ Previous studies have observed communal rallying in the face of suspensions, a trend that continues among many accounts within the dataset. Such behaviors are often cast as efforts to rebuild a robust followership after suspension. ${ }^{16}$

Although English-language IS sympathizers try to compensate for the impact of suspensions, further analysis on follower count over time suggested that the network is still affected by these policies. A decline in follower numbers associated with each account at the time of its last Tweet speaks to the efficacy of Twitter's policy in hindering the connectivity in the English-language jihadisphere (see Figure 7). For this analysis, each account's number of followers was identified using the metadata of the account's last tweet. The follower count figures were divided into three chronological buckets (see Figure 3) based on the date of the last tweet. Segment A spans from February 15, 2016 to July 11, 2016; Segment B spans from July 11, 2016 to December 5, 2016; Segment C spans from December 5, 2016 to May 1, 2017. Next, the three segments were plotted on a box and whiskers chart to

\section{Follower Count by Chronological Segment}

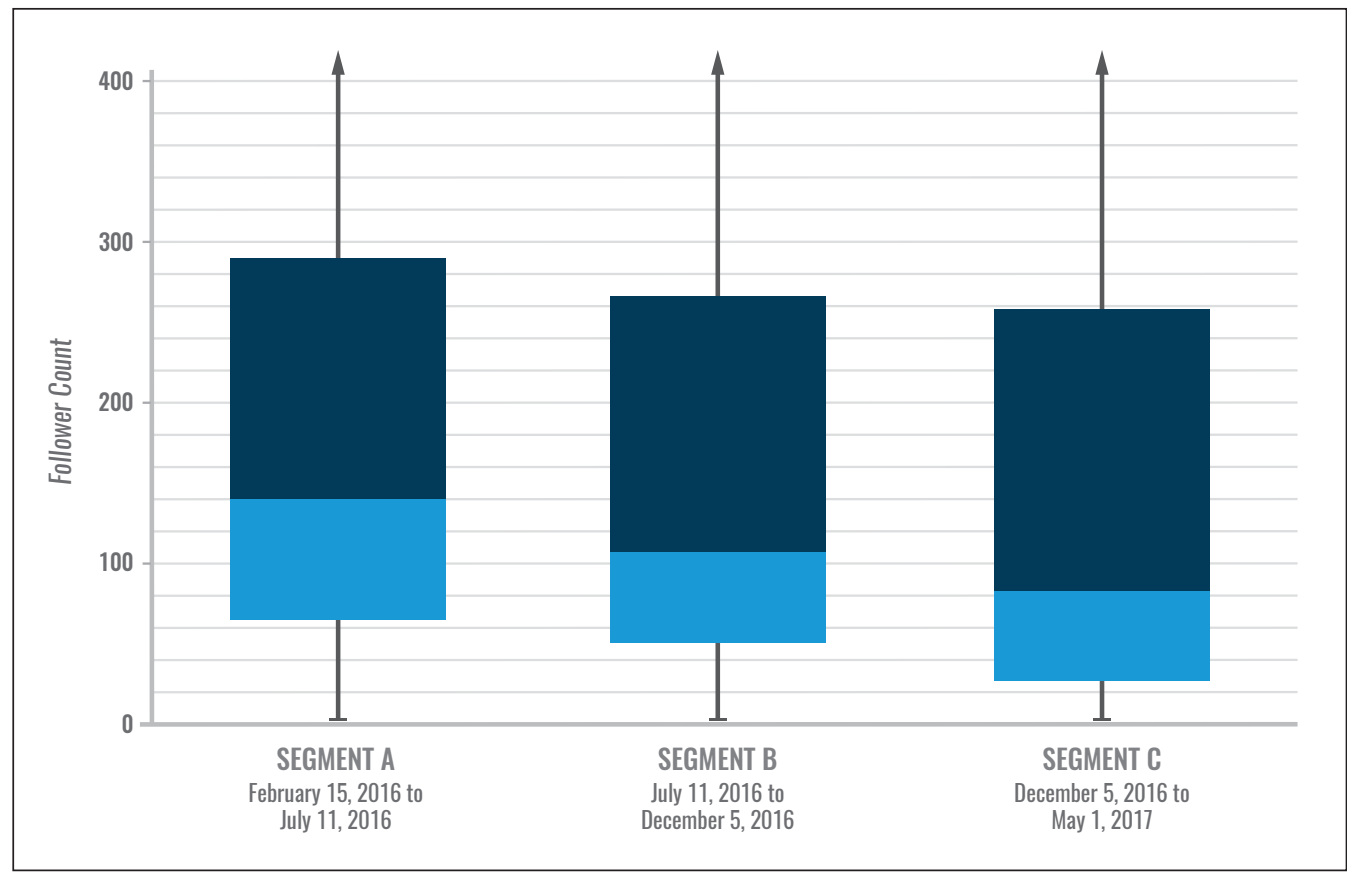

(Figure 7) This chart shows how English-language sympathizers on Twitter struggle to draw the same amount of followers over time; the boxes represent the middle 50 percent of each chronological segment. The median (where the darker and lighter boxes meet) falls significantly over time..$^{17}$ 
identify key trends (Figure 7). Of the accounts whose last tweet fell in Segment A, the first 21-weeks of the sample, the median follower count was 141. For Segment B, this number fell to 108 . By Segment C, the last 21-weeks of the dataset, the median count was 82 followers. These findings reveal a notable decline in the number of followers accounts were able to amass over time: the median from the data in the first third of the dataset fell 42 percent by the last third of the series. The values associated with the middle 50 percent of each segment also trended toward decline (Figure 7). These findings support the notion that Twitter's policy deteriorates IS followers' ability to gain traction on the platform, likely hindering their reach to potential recruits.

While difficult to operationalize, it is crucial to consider how Twitter's counter-terrorism initiatives might also impact the logic of future decisions made by Englishlanguage IS sympathizers on the company's service. Twitter is largely credited with hindering IS sympathizers on its platform, ${ }^{18}$ but data in this study hints at a more complex dynamic. If Twitter's policies were responsible for decline on the platform, then sympathizers might have been pushed towards other communication channels. Using this logic, one reasonable hypothesis predicts a positive relationship between the rise of suspensions and discussion among English-language IS sympathizers about suspensions, and more hospitable avenues for communication. In the past, both IS propaganda and peer-topeer dialogue online proffered recommendations about best practices regarding operational security and suspension avoidance. For example, IS released a 34-page guidebook advising members on how to operate securely while online. The guide gives suggestions on how to keep communications and locations private in order to avoid suspension on platforms like Twitter. ${ }^{19}$ Colloquially known as the "Baqiya family" on Twitter, English-language sympathizers sometimes give new accounts of previously suspended users a "shout-out” with Twitter's 'mention' function to help the users fight back and "regain their pre-suspension status." ${ }^{20}$ These various forms of content may only account for a small portion of the broader discussion, but they have serious implications about the resilience of the movement.

\section{Mentions}

To further understand how factors like account activity and the numerical decline in follower count might affect sympathizers on Twitter, the analysis examined Englishlanguage accounts' use of mentions. On Twitter, the “@” symbol is used to engage with and direct attention towards other accounts. Though mentions are not comprehensive indicators of influence and reach, they are the best option afforded by PoE's dataset. ${ }^{21}$ Furthermore, approximately 72 percent of tweets by English-language sympathizers mention another user. By discussing patterns regarding Twitter mentions and studying the most cited accounts, the study begins to parse out relevant actors in the community but further analysis is necessary.

To better understand the relationship between Englishlanguage sympathizers and other Twitter users, researchers created a social network based on mentions in tweets within the sample. In the dataset, some tweets mention only one account, whereas others cite multiple at once. In this analysis, the 'mentions' variable is divided into two categories: usernames that are on the list of 1,782 accounts in PoE's sample, and those that are not. ${ }^{22}$ Of the 1,782 accounts, only 1,700 used the mention function on Twitter; consequently, only these accounts are represented in the network. Alternatively, there were 61,590 unique usernames mentioned in the sample that do not fall within PoE's list of accounts. In the graphic above, the latter usernames were aggregated into a singular node in the network. The nodes that represent accounts within PoE's list remain distinct in order to demonstrate connectivity through mentions among accounts in the sample. In instances where an English-language IS sympathizer mentioned another username more than once, the edges between these nodes were condensed into a single, weighted edge. On the most basic level, this allows the report to explore how conversations occur amidst adherents and extend beyond the finite list of accounts that are the focus of this study.

Of the total sample, 85 percent of mentions referenced usernames outside of PoE's list of accounts (see Figure 8). While this analysis is rudimentary, these measures suggest that English-language sympathizers reach accounts that are not definitively part of the English-language IS community on 
Twitter. Anecdotally, adherents direct attention towards a broad swathe of accounts on Twitter, ranging from news organizations and terrorism scholars to other jihadis, including other supporters of IS and Jabhat Fateh al-Sham. ${ }^{23}$ The remaining 15 percent of mentions were directed at other accounts within PoE's list. This finding is especially interesting given English-language sympathizers comprise only 3 percent of all unique accounts cited in the sample of mentions. Simply stated, there appears to be a meaningful flow of communications between accounts engaging with a nebulous pro-IS community on Twitter.

Next, it is useful to discuss the most mentioned accounts by English-language sympathizers. The data show that the most common mentions are highly concentrated. The top ten accounts range from 4,244 to 18,700 mentions, then rapidly curtail. In fact, only the top 25 manage to exceed

\section{Tracing Username Mentions by English-Language IS Sympathizers}

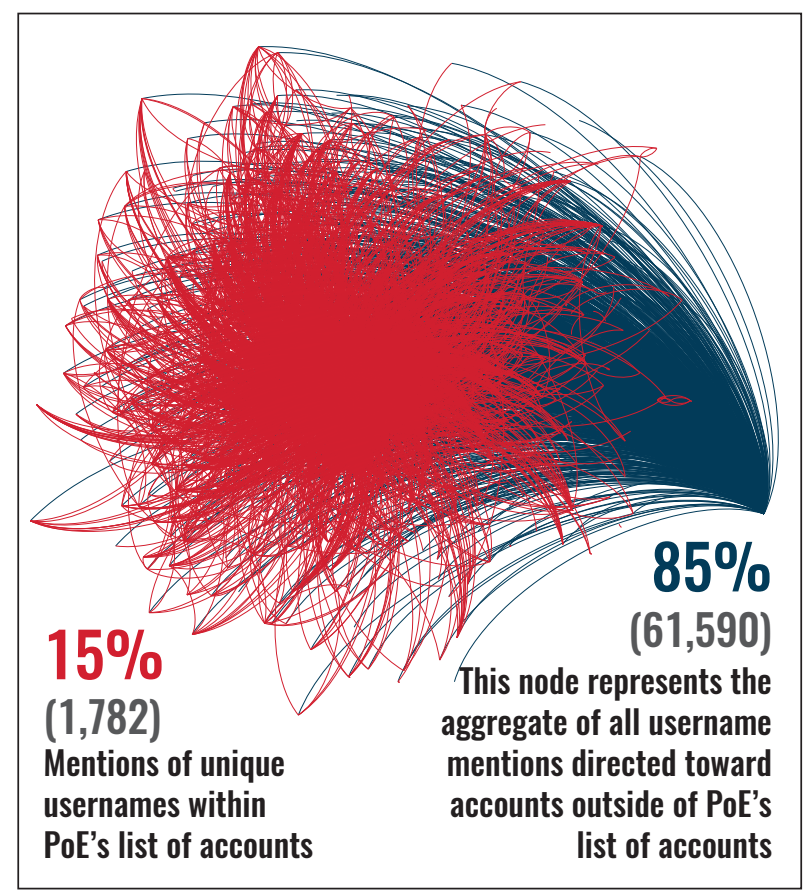

(Figure 8) This is a visual representation of the network in the dataset created using Gephi. ${ }^{24}$ While some mentions reference others included in PoE's list of 1,782 accounts, many extend past this list, demonstrating the network's reach beyond the identified community of English-language IS sympathizers on Twitter.
2,000 mentions. This point is especially striking considering the extensive list of 63,868 unique accounts. Ultimately, no overarching trends aptly predict high mentions count, though this subset of prolific accounts often disseminates a substantial amount of content and attracts a large following. Based on observation, the purpose of each account varies in nature: some act as watchdogs 'reporting' IS-related news, while others engage in political discourse as an individual rather than as an agency. Two accounts, using the same naming convention, 'RamiAlLolah,' rank third and sixth, grossing 17,005 mentions in total. According to one of the RamiAlLolah accounts, the operator claims to be an "Activist \& commentator covering \& observing all news" offering "exclusives \& intelligence reports from the Middle East conflict zones as well as the Islamic State affairs." ${ }^{25}$ In this way, it is necessary to punctuate the idea that one entity, using multiple accounts, may occupy a significant portion of the overarching discourse among English-language sympathizers on Twitter.

Notably absent from the list of top mentions are the accounts of users like Ahmad Musa Jibril and Musa Cerantonio, whom ICSR identified in the \#GreenBirds study. ${ }^{26}$ Similarly, additional accounts that were once deemed influential by Klausen in Tweeting the Jihad, including that of Anjem Choudary, were not prevalent within the dataset. ${ }^{27}$ This is not surprising, particularly in light of the incarceration of Cerantonio and Choudary, accompanied by the internet restriction imposed upon Jibril by a federal judge in June $2014 .^{28}$ Even so, a primary survey of the most influential accounts in the dataset, whether based on top follower count or mentions, does not suggest that similar figures - especially accounts affiliated with prolific persons offline - have filled the void and replaced Jibril, Cerantonio, and Choudary.

In the realm of more traditional, offline counter-terrorism, 'decapitation' initiatives strive to capture or kill the leader of an organization in an effort to stymie the movement. ${ }^{29}$ Historically, such approaches tend to yield mixed results, sometimes hindering an organization while simultaneously emboldening its adherents. ${ }^{30}$ A derivative of this phenomenon emerges online in the wake of digital decapitation by way of silencing leadership figures online. Although English-language IS sympathizers on Twitter 
struggle to efficiently replace authoritative voices with more anonymized, less legitimate accounts, IS adherents online also mobilize in the wake of various decapitations. While some users call for the reinstatement of suspended users, others emulate key figures with copycat accounts.

\section{URLs and Top-Level Domains}

To further probe the engagement of English-language IS sympathizers on Twitter, the study conducted a preliminary content analysis of the hyperlinks disseminated by the various accounts. Anecdotally, a wide range of sites are shared, from blogs and social media to fundraising platforms and news outlets. By isolating the top-level domain and suffix of the shared links, the approach identified notable URLs for further analysis. After parsing the links with basic queries, which were not wholly reliable due to the truncated URLs, initial measures provided some insight into the nature of link shares. News stories were among the most commonly posted. While CNN, BBC, and the New York Times drew about 900 posts respectively, RT, the web-based Russian news outlet, grossed approximately 1,175 shares. Official, unofficial, and other pro-IS online media is especially difficult to measure using hyperlinks because of the diversity in domains. Links for Al-Bayan, IS' radio station, came in various iterations including albayanradio.xyz, bayanradio.xyz, bayanradio.net, bayanradio.top, al-bayan.pw, and bayanradio.ga. When domains such as this are shut down or made inaccessible, it is hard to discern the legitimacy and authenticity of the source.

File sharing services were especially common, but specific platforms varied in popularity. JustPaste.it, for example, drew 3,133 shares and Archive.org drew 1,180 shares. These sites often contained more links that lead readers to propaganda videos, graphics, and texts. Many less cited, yet noteworthy, file sharing services received fewer mentions: SoundCloud, top4top.net, and vid.me, for example, garnered around 200 shares each. One fascinating observation was the popularization of the blogs of Western scholars of terrorism, particularly those who shared primary documents pertaining to IS. Aaron Zelin's jihadology.net, for instance, was shared 339 times.

Blogs and social media platforms comprise an integral segment of URLs among English-language IS sympathizers on
Twitter. For blogs, WordPress is especially popular, netting about 1,690 shares, whereas Blogspot and Tumblr drew around 300 shares each. In the context of more traditional social media sites, which often integrate file sharing features, Twitter-related links were the most common. This was likely due to sharing conventions within the medium. While YouTube received 11,321 link-shares, Facebook drew 3,540 URL posts, showing each platform's enduring relevance among English-language jihadists on Twitter. As a complement to broad-based social media platforms, there were a small but important number of URLs demonstrating English-language IS sympathizers' interest in anonymous question-and-answer sites like ask.fm and curiouscat.me as well as encrypted messaging platforms like Telegram.

While URLs provide some insight, it is crucial to acknowledge how some mediums that are popular among jihadists are not necessarily accessed through traditional search engines. On one hand, English-language IS sympathizers' use of the dark web is hard to gauge. Even so, within the dataset, a handful of links referenced torproject.com, the outward facing home page for the anonymous Tor browser, and links with the domain suffix '.onion,' which are reachable only by using the Tor network. On the other hand, messaging apps like Telegram, Surespot, and Kik are widely accessed through app stores, even when they have web-based platforms, likely changing how accounts on Twitter share content about the apps themself. As opposed to Twitter, once individuals download the app, there is no need to return to the site to login to use the tool. Consequently, these alternative means of communication, among others, require further consideration.

\section{Discussion Regarding Other Digital Tools}

In addition to hyperlinks, the text of each tweet affords innumerable opportunities for subsequent analysis. Within the scope of Twitter's effects on English-language IS sympathizers on the platform, discourse about alternative means of communications technologies is of paramount importance. In the face of mounting restrictions on Twitter, among other platforms, evidence suggests that jihadists "frequently leverage digital technologies to circumvent these barriers." ${ }^{31}$ Although English-language sympathizers on Twitter likely use a variety of mediums that vary in nature, it is crucial to discuss their interest 
in more protected channels of communication. Existing research helps structure and inform this analysis.

In Flashpoint's Tech for Jihad, Laith Alkhouri and Alex Kassirer grouped a sample of digital tools into six typologies: secure browsers, virtual private networks (VPNs) and proxy services, protected e-mail services, mobile security applications, encrypted messengers, and mobile propaganda applications. ${ }^{32}$ After querying the dataset for the "most noteworthy tools and technologies" listed in Tech for Jihad, investigators manually combed through tweets to identify a range of additional digital instruments used by Englishlanguage IS supporters specifically. Despite diverging from the "noteworthy" list at times, this list of tools and technologies fell into the six typologies discussed by Flashpoint. Anecdotally, the most commonly discussed instruments among sympathizers on Twitter were encrypted messengers, ${ }^{33}$ mobile security applications, ${ }^{34}$ protected email services, ${ }^{35}$ and VPNs and proxy services. ${ }^{36}$

Using the examples listed for the various instrument types above, the author created a list of 17 tools used by English-language supporters on Twitter. This list includes Telegram, Surespot, WhatsApp, Threema, Signal, WeChat, Viber, FlashVPN, TurboVPN, SuperFreeVPN, F-Secure Freedome, Veracrypt, Nextplus, GPG4USB, Tutanota, Protonmail, and Hushmail. Upon investigation, a slight but compelling trend emerges: the proportion of tweets that reference these tools recedes over time. Although this sample does not encapsulate all digital instruments used by English-language IS sympathizers on Twitter, these findings contradict the notion that the rise in suspension correlates with a proportional increase in content discussing challenges posed by Twitter's policy.

While it is difficult to identify the precise cause of this numerical and proportional decline, several indicators suggest that it might be a product of users leaving the platform of their own volition, which is not mutually exclusive from suspension. If account suspensions on Twitter and ongoing operational security concerns create a demand for an alternative means of online engagement for pro-IS accounts, it is hard to explain the decrease in references to less regulated or more protected and anonymizing forms of digital communications technology. ${ }^{37}$ The decline in content exploring alternatives to Twitter might suggest that some English-language IS sympathizers moved away from the platform, apparently in search of channels that better suited their needs for online engagement. As discussed in the background section of this report, IS' early 2016 strategic shift from Twitter to Telegram ${ }^{38}$ likely influenced these findings. Furthermore, publicity surrounding events like Twitter's announcements of suspensions, ${ }^{39}$ and the FBI's unlocking of the San Bernardino shooters' phone, ${ }^{40}$ possibly dissuaded sympathizers from using the technologies perceived to be insecure, including Twitter.

Within the dataset, some English-language IS supporters express frustration, concern, and anger towards Twitter's policy and its effects on the online community. In some instances, IS supporters leverage the expulsion of other accounts to validate polarizing narratives about the persecution of Muslims. In the wake of a terrorist attack in Brussels, Belgium, one English-language IS sympathizer with the handle @we_r_back64 tweeted a screenshot of its recently suspended account, @we_r_back63, with the caption, "Hey kuffaar Worry about your belgium people, instead of suspending us. Lolzzzz." ${ }^{41}$ On July 20, 2016, a different IS supporter expressed their grievance in a tweet stating, "Without a doubt Twitter suspensions are biased against us. They hate us. ${ }^{342}$ On April 9, 2017, a now-suspended English-language sympathizer with the handle @ssvvah tweeted, "It seems people were suspended. I would love to follow more but I can't. So I just hope not everyone gets suspended." ${ }^{33}$ The adherents' varying reactions to Twitter's counter-terrorism policy demonstrate how suspensions affect the morale of some users. Therefore, it is crucial to consider how the perception of persecution in the digital sphere may push English-language IS sympathizers towards other means of communication.

\section{Key Findings}

Twitter's counter-extremism policies have affected English-language IS sympathizers in a myriad of ways on the platform, but the fight is far from over. The term 'decay' best characterizes the slow decomposition experienced by PoE's sample of English-language supporters on Twitter. Using various metrics to unpack the dataset, the study punctuates the extent to which Twitter's approach, particularly regarding suspension, yields mixed 


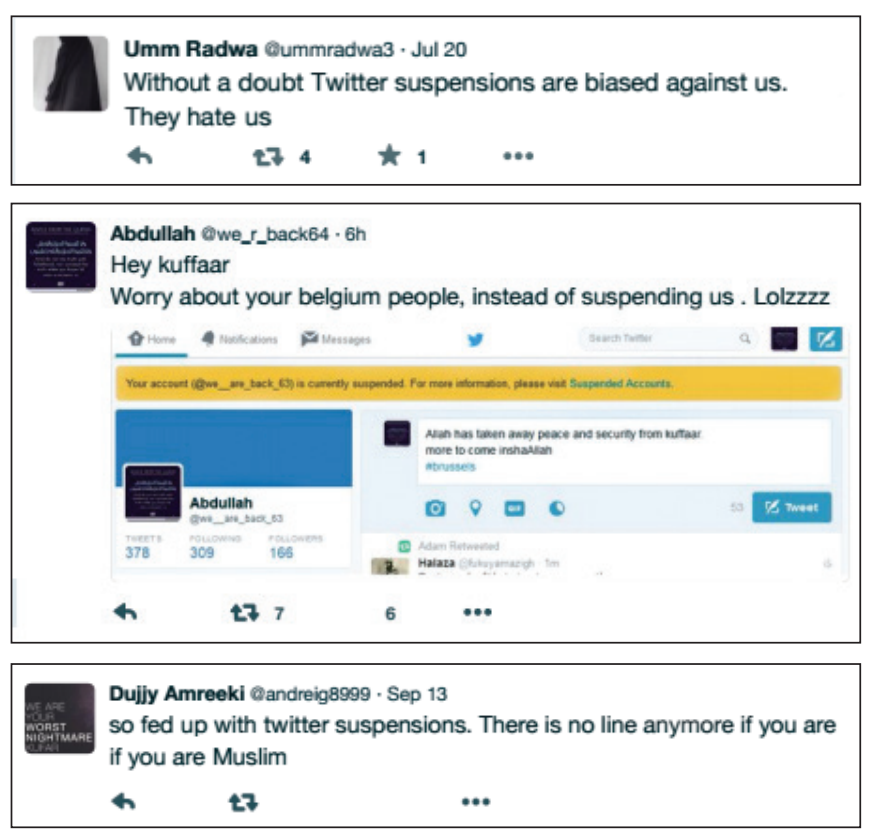

(Figure 9) These screenshots illustrate the various ways in which English-language IS sympathizers on Twitter react to the company's counter-terrorism policy.

results. Although English-language IS followers struggle to maintain their hold on the platform, and fail to attract the same degrees of followership after suspension, mounting evidence suggests that supporters continue to adapt to the online environment.

Tech companies, policy makers, and other counterterrorism practitioners should not underestimate the agency of those who want to be vocal about their support of IS and participate in the movement. While some English-language IS sympathizers rally in the face of Twitter suspensions with new accounts, others seem to cut their losses and migrate to more hospitable online environments. Each individual's decision to remain on one digital platform, or expand across multiple, likely entails a cost-benefit analysis that accounts for the ease of engagement, reach of the networks, and operational security of various communications channels. Such preservative actions ensure a future for the English-language IS community, whether on Twitter, or elsewhere in the ether.

To challenge this specific group, actors fighting IS online must respect the agility of sympathizers and work to understand their limitations on platforms other than Twitter. Although IS made a strategic shift from Twitter to Telegram, this step was the product of necessity. In Cracks in the Online 'Caliphate,' How the Islamic State is Losing Ground in the Battle for Cyberspace Miron Lakomy explains, "The biggest challenge that the Islamic State faces nowadays in cyberspace concerns the decreasing availability of online propaganda distribution channels." ${ }^{\text {"44 }}$ Despite offering some benefits, namely improved operational security, apps like Telegram limit the reach of IS compared to Twitter. Similarly, blogs and file-sharing tools like JustPaste. it have utility in content distribution, but are not networked in the same way, thereby curbing the reach and connectivity of the English-language "Baqiya family." ${ }^{35}$

Like many preventative efforts, it is tricky to measure the precise impact of social media regulations and shutdowns in combating the radicalization and mobilization of recruits. The strongest evidence in support of suspensions is that the approach tends to make the dissemination of violent rhetoric harder to broadcast, which might reduce the mobilization of extremist actors. In this context, suspending accounts that distribute tactical manuals and official calls to action likely reduce violence more than the expulsion of banal followers that merely parrot the same content as other IS supporters in the echo chamber. Broadly, however, convincing data that links account suspensions with an overarching reduction in terrorist violence remains sparse.

Alternatively, it is hard to ignore the role of social media and other virtual communications as evidence in legal cases of persons arrested, indicted, and convicted on terrorism related charges in the U.S. Twitter is relatively transparent about its case-by-case cooperation with law enforcement, especially compared to other companies, but it remains tough (and often impossible) to access records through official channels after accounts are suspended. ${ }^{46}$ In Virginia, law enforcement used "Twitter records and posts publicly placed on Twitter" to help build a case against Haris Qamar, a man accused of supporting IS in July 2016. ${ }^{47}$ The investigation revealed that Twitter closed "over 60 accounts that included 'newerajihadi,"' a handle linked to Qamar, and 
notes that "shortly after," new Twitter accounts replaced the suspended ones. ${ }^{48}$ In some ways, authorities were fortunate to have this evidence at their disposal. If Qamar used a platform inaccessible to law enforcement, Qamar could have posed different barriers to the investigation of law enforcement or circumvented detection altogether. While challenging to confirm ownership, the dataset used in this report contains six 'newerajihadi' accounts that were active before Qamar's arrest (see Figure 10).

In sum, these findings challenge the idea that either side, IS or its adversaries, is 'winning' the war on Twitter, much less anywhere else online. Though limited in scope, data gleaned from English-language IS sympathizers on Twitter suggest that this battlefield extends far beyond the reach of major tech companies and Western governments. Consequently, by working to understand the dynamics at play on Twitter, discussion pushes to understand how English-language sympathizers adapt during times of duress. By unpacking how efforts to silence the movement on Twitter have produced some benefits, but also many unintended consequences, the data can help identify more optimal steps for the fight against IS online, particularly in the concluding discussion.

\section{Section 2: Battles, Attacks, and Current Events}

This section uses three separate inquiries to demonstrate how English-language IS supporters engage with real-world issues, especially considering internal and external
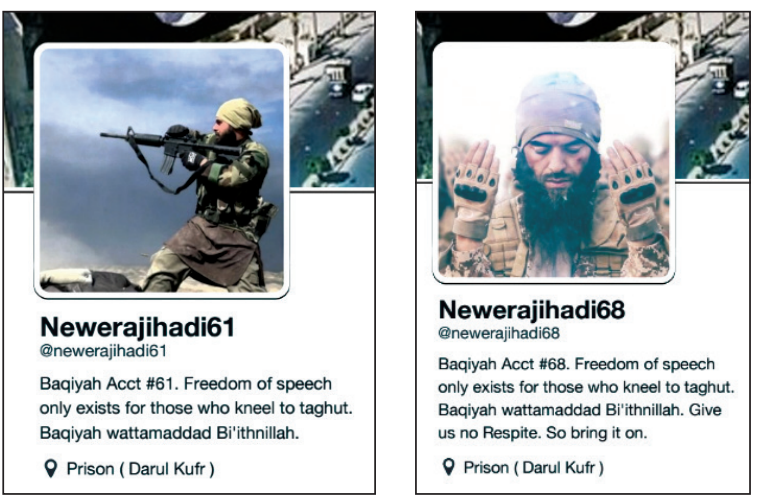

(Figure 10) Dated between February and March 2016, these two screenshots offer examples of the 'newerajihadi' accounts likely operated to Haris Qamar prior to his arrest. ${ }^{49}$

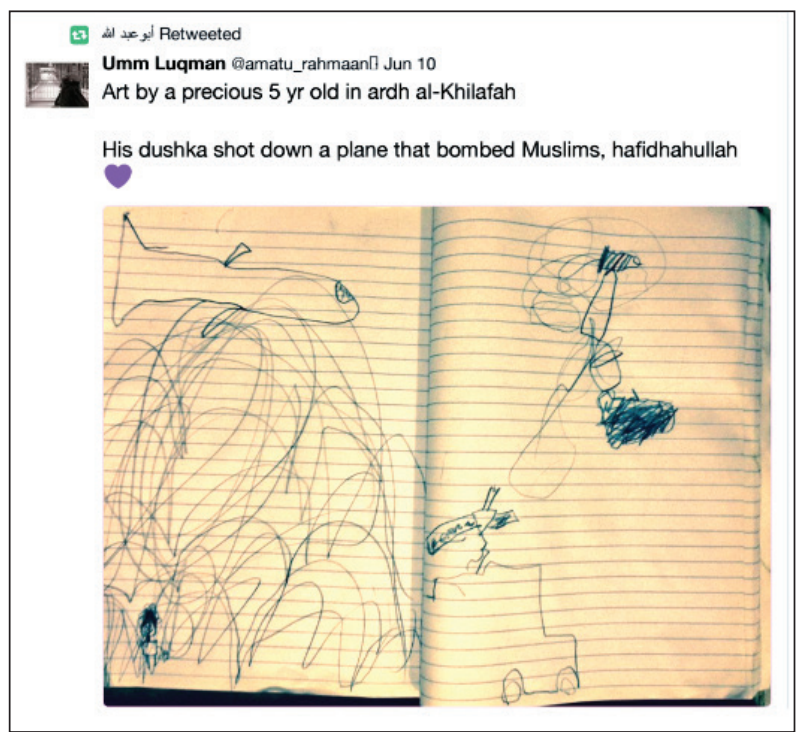

(Figure 11) This tweet demonstrates how English-language accounts discuss military engagement in IS-controlled territory without contextualizing whether or not efforts were part of a specific campaign.

dynamics that guide the demographic's behavior on Twitter. The questions turn to examine the coherence of the movement in light of fractured communications. The first investigates how English-language IS sympathizers on Twitter engage with on-the-ground IS activity over time. The second asks how terrorist attacks drive discourse among this demographic of Twitter accounts. The third considers how other current events influence the activity of Englishlanguage IS sympathizers on Twitter. The inextricable link between IS-central's adaptive media strategy, territorial losses in Iraq and Syria, and the death of propagandists like Abu Muhammad al-Adnani, IS’ former chief strategist of communications, ${ }^{50}$ affect discussion among adherents online. Consequently, the analysis will draw upon existing research to help explore the study's various findings.

\subsection{How do English-language IS sympathizers on Twitter engage with on-the-ground IS activity over time?}

Emerging evidence posits a relationship between ISrelated events in Iraq and Syria and shifts in the corresponding digital sphere, and some research has traced the evolving relationship between material losses on the ground and the online activity of IS supporters. This 
section uses content by English-language sympathizers on Twitter to better understand how the group's adherents in the West interact with issues like military engagement and the ongoing battle over territory. As both official and unofficial propaganda bridge the gap between the physical and virtual theaters, it is necessary to probe the efficacy of military-oriented media campaigns in engaging IS sympathizers in the West. The proportion of content about these matters is small, but it appears to be a noteworthy measure of the overarching fight against IS online.

As examined in the background section of this report, thematic research by Daniel Milton, Charlie Winter, and Aaron Zelin identifies a notable shift in IS-central's strategic communication efforts over time. Analyses by these scholars, among others, are integrated throughout this section to contextualize and cross examine key findings. In Communication Breakdown, for example, Daniel Milton observes a shift away from central communications emphasizing governance, religion, and commerce, hypothesizing that this change stems from IS' "willing[ness] to sacrifice these areas to maintain a focus on the military side of the organization, at least in the production of media content." ${ }^{51}$
This shift in strategy can be used to unpack the nexus of IS' central media strategy, military engagements, and Englishlanguage contingent of sympathizers on Twitter.

For the sake of focus and clarity, the study selected a sample of six critical battlefields ${ }^{52}$ in Syria and Iraq that fell within the time series for further examination. These fronts were Palmyra, Fallujah, Manbij, Kirkuk, Mosul, and al-Bab. ${ }^{53}$ Like any search terms in the report, it is hard to identify every tweet discussing or alluding to each conflict zone; English-language accounts also tweet veiled references to military action without naming a specific campaign. Some battles extend beyond the dates used in this study, such as Mosul, and others overlap, like Fallujah and Manbij. These events provide a ripe opportunity to explore the response of English-language sympathizers over time (Figure 12). Though confounding at times, particularly in the context of IS' media strategy, the data reveal a relationship between military engagement and tweet frequency. Further evaluation is required to parse out complexities and highlight the overarching trends.

\section{Tracking Military Engagements Over Time}

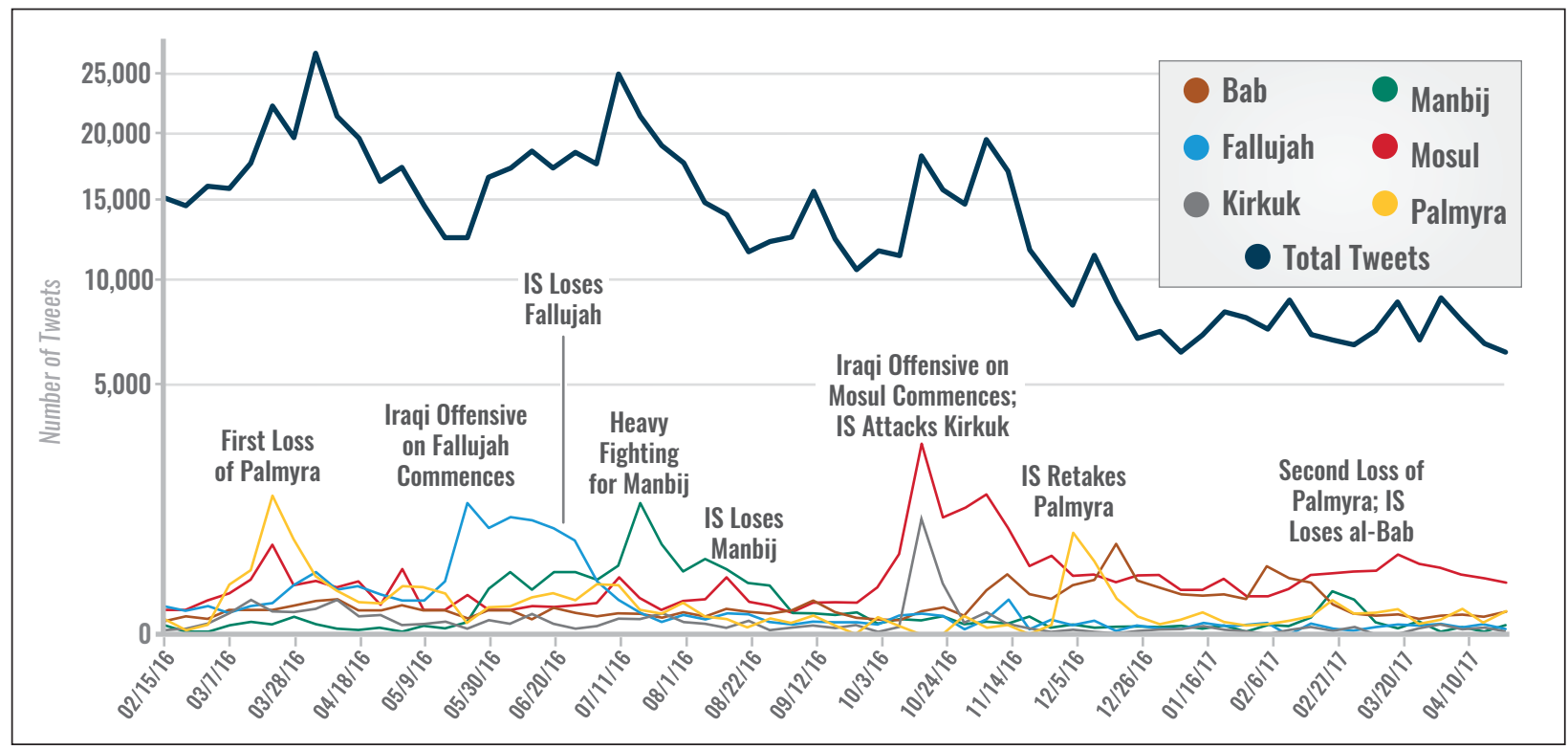

(Figure 12) This graph shows how English-language IS sympathizers discuss key battles over time and contextualizes the extent to which the topic relates to tweet frequency by week. 


\section{Fallujah and Manbij}

Data on Fallujah and Manbij, two cities with chronologically overlapping battles during the spring and summer of 2016, reveal the importance of sustained messaging campaigns in influencing English-language IS sympathizers. In an initial review of the histogram, there is a stark difference in the rapid rise and slow decline in Twitter activity pertaining to Fallujah (approximately May 22 to June 28, 2016) compared to the temporary hike in activity discussing Manbij (approximately May 31 to August 27, 2016). In a series of tweets, Charlie Winter, one of the preeminent researchers tracking IS' strategic communications, notes that central communications on Fallujah differ from fronts like Manbij and Palmyra. ${ }^{54}$ By way of contrast, Winter identifies inconsistencies in IS-central's media approach to the battles, explaining that Fallujah was essentially "liveblogged," whereas Manbij received only "occasional mentions." ${ }^{5}$ Winter posits that differing media strategies relate to the symbolic value of cities, likely dictating how the organization responds under duress. ${ }^{56}$

When IS lost Fallujah around June 2016, there was a distinct military shift in focus from Fallujah to Manbij. ${ }^{57}$ Given that the reported logics of IS-central's media strategy for battles in Fallujah and Manbij appear to be demonstrated by thousands of tweets within PoE's dataset, it becomes apparent that the English-language sympathizers are somewhat subject to the tides of official IS agenda-setting in light of territorial shifts. This association bears greater significance over time in the face of IS' faltering communications strategy.

\section{Kirkuk and Mosul}

In the wake of an IS initiative in Kirkuk (approximately October 20 to 21,2016$)^{58}$ and the concurrent start of the Iraqi offensive to retake Mosul (October 16, 2016 - approximately July 20), ${ }^{59}$ Twitter activity among English-language IS sympathizers inadvertently veered from IS-central's efforts to control the broader narrative. In Kirkuk, IS militants launched a commando raid on less protected and less critical targets. ${ }^{60}$ Despite paling in comparison to other operations, both in scale, efficacy, and duration, the attack in Kirkuk received notable mention within the dataset. ICSR's Shiraz Maher notes that IS propaganda at this time focused on Kirkuk, possibly in an effort "to pull focus away from [IS] defeats in the heartland," directing little attention to the escalating conflict in Mosul. ${ }^{61}$ In light of this exercise of diversion, Winter observes a disproportion in strategic output regarding Kirkuk and Mosul at a rate of four to one on October 21, 2016. ${ }^{62}$

\section{Two-Week Snapshot of Mosul and Kirkuk (October 14 to 28, 2016)}

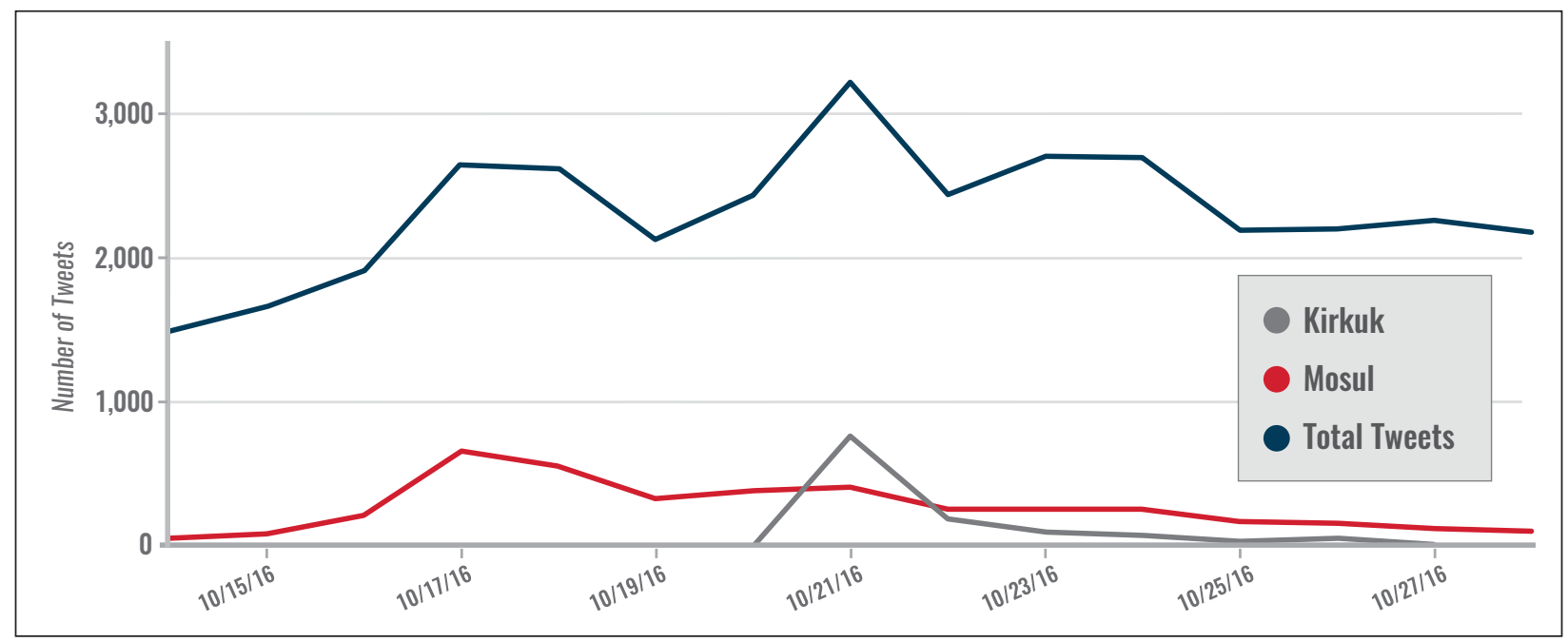

(Figure 13) This graph demonstrates how Kirkuk only drew the focus of English-language IS sympathizers on Twitter for a limited period of time compared to Mosul, a bigger battle that received more attention from IS propaganda. 
Upon further investigation, IS' efforts to divert attention to Kirkuk were somewhat successful, yet most were un-sustained (see Figure 13). English-language supporters mentioned Kirkuk more than Mosul on the date the raid took place; afterward, Kirkuk-related content rapidly disappeared. PoE findings suggest that a decline in territory aligns with a degradation in material referencing the matter, particularly in the context of episodic propaganda campaigns. In the histogram charting the broader dataset, however, the rate at which sympathizers mentioned Mosul far exceeds discussion of Kirkuk. In fact, out of all six battles, Mosul received the greatest number of tweets per week (see Figure 12); this is particularly noteworthy given IS' supposed efforts to divert attention from the campaign. Between the dates of October 17 and 24, 2016, a week including both engagements, tweets referencing Mosul appeared about 63 percent more than those mentioning Kirkuk. ${ }^{63}$ The dilemma IS faces in achieving their propaganda aims plausibly pertains to limited resources, as well as external factors, including coverage from Western mass media. This shows that IS-central's efforts to control the narrative are not bulletproof.

\section{Mosul and al-Bab}

Although the analysis already addressed English-language IS sympathizers unrestrained response to Mosul over Kirkuk, comparative analysis between discussions of the Mosul and al-Bab campaigns highlights another emerging trend. The content produced by English-language supporters during the battles of al-Bab (November 6, 2016 to February 23, 2017) ${ }^{64}$ and Mosul (October 16, 2016 to approximately July 20, 2017) ${ }^{65}$ demonstrates how protracted struggles accompanied by thematic media campaigns draw and sustain discussion over time. In a study on the propaganda decline of IS spanning from January to February 2017, predominantly after IS' initiative in Kirkuk, Winter notes, "most of the propagandists' attention was devoted to depicting the Islamic State's efforts to defend the Iraqi city of Mosul, and the Syrian town of Bab, a trend that is broadly consistent with the last few months." ${ }^{\prime 6}$ These findings are manifested in the data, as media campaigns for the respective battles garnered an increased level of attention from English-language sympathizers.
Despite extended fighting and prolonged media strategies in both of these cities, compared to the short burst in Kirkuk, there was eventually a decline in tweets mentioning Mosul and al-Bab. This fall is likely due to material losses, particularly in al-Bab, and further compounded by the decrease in central media output. Degradation related to the nexus of strategic communications and territory, by way of military engagement, emerges in the data examined in this report. Furthermore, since the onset of the battle of Mosul, some resurgences occur in the digital sphere, but PoE's findings reveal a stronger correlation with external factors more than IS-central media output. The U.S. presidential election and a coalition bombing that killed up to 200 civilians in Mosul ${ }^{67}$ correlated with hikes in activity whereas prolific propaganda videos like 'Tank Hunters,' featuring John Cantlie ${ }^{68}$ and the slickly-produced 'Knights of the Departments' video ${ }^{69}$ represented only a conservative increase in tweets.

\section{Palmyra}

Lastly, the multiple battles for Palmyra present another marked shift over time among English-language sympathizers on Twitter. Beginning in May 2015, prior to the time series used in this study, the engagement continued until late March 2016, when IS lost Palmyra for the first time. ${ }^{70}$ The defeat drew the attention of sympathizers, peaking at 430 tweets mentioning the city the day of March 27, 2016. In early December 2016, IS' initiative to re-take Palmyra resulted in a brief but substantial rise in the number of tweets discussing the city (reaching its height at 322 tweets on December 11, 2016). Exceeding the rate of mentions for the concurrent battle of Mosul for only ten days, Palmyra expectedly drew some attention because it symbolized an increasingly rare military success for IS. ${ }^{71}$ Ultimately, however, this uptick waned due to a shift in attention towards Mosul, Al-Bab, and even Aleppo, a conflict outside the scope of this analysis that nonetheless has vital regional importance and drew significant global media attention. IS lost Palmyra for the second time around late February and early March 2017; English-language supporters failed to mention this loss at a meaningful rate. ${ }^{72}$

In addition to search queries, the study also looked at top hashtags to further gauge the extent to which 
English-language IS sympathizers on Twitter remained tapped into IS' languishing efforts on the ground in Iraq and Syria. As depicted in the graph below (Figure 14), four of the six military engagements examined in this section rank within the top three tweets per week at least once. This pattern suggests that IS' endeavors on the ground are still a unifying priority among adherents on Twitter. Mounting evidence suggests that IS' strategic messaging output is a noteworthy, but inconsistent component linking English-language followers on Twitter to military engagements in the region.

Paired with existing research on IS' propaganda, particularly products geared towards Western audiences, the data suggest that the group's efforts to set the agenda among English-language sympathizers on Twitter yield mixed results. While protracted media campaigns attract and sustain some conflict-related discourse, shortlived messaging initiatives sometimes fail to divert sympathizers' focus in the desired direction. Additional research is necessary, but this tendency might point to a particular and perhaps growing cleavage between IS' efforts on the ground and its base of English-language supporters on Twitter.

Despite a numerical decline in tweets mentioning the sample of six military engagements, the proportion of content discussing military engagements stayed relatively consistent throughout the dataset. Given the issues posed by receding territory, namely fewer fronts for military engagement, this finding is remarkable because it punctuates the enduring relevance of fighting on the ground. A leading factor in the sustained commentary on the battle for Mosul by English-language sympathizers on Twitter is likely the robust, thematic central media effort accompanying the ongoing campaign. Although the fight for Raqqa began after the dates used in this study, it is crucial to consider how multiple military fronts might hinder IS' central messaging efforts by segmenting conflict-related discourse among IS sympathizers on Twitter. Once IS inevitably loses military engagements in Raqqa, and even Deir Ezzor, both strategically important cities, it is unclear what will take their place in the broader conversation among English-language IS sympathizers on Twitter.

\section{Top 3 Hashtags Per Week Highlighting Prevalence of Key Battles}

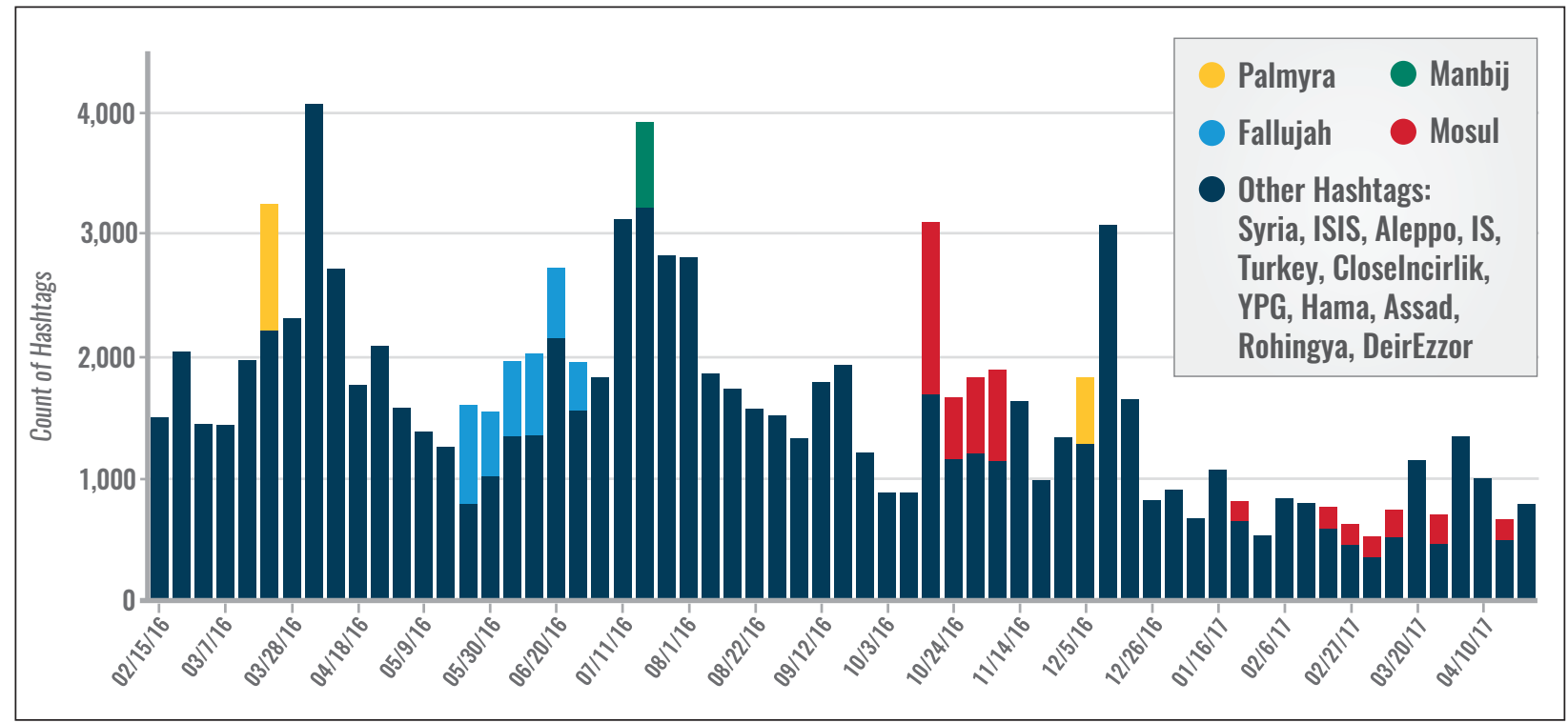

(Figure 14) This graph shows that four of the six military engagements discussed in this section rank within the top three tweets per week. 


\subsection{How do terrorist attacks drive discourse among English-language IS sympathizers on Twitter?}

Though the majority of violent actions occur inside IScontrolled territory, attacks perpetrated by actors outside of the region are still critical to the organization's efforts worldwide. Research suggests that there is a link between territorial losses on the ground in Iraq and Syria and an increase in IS-related attacks outside of the territory controlled by the group. ${ }^{73}$ IS' efforts to incite attacks abroad is evident in the myriad of media products disseminated among supporters. The archetypal example of the call comes from IS' now-deceased spokesman Abu Mohammed al-Adnani, who reportedly issued an audio statement before Ramadan in 2016, stating "Get prepared, be ready ... to make it a month of calamity everywhere for the non-believers ... especially for the fighters and supporters of the caliphate in Europe and America." ${ }^{74}$ Prolific English-language propaganda, particularly Dabiq and Rumiyah, parroted this narrative. ${ }^{75}$ Anecdotally, content by English-language sympathizers rose in the immediate wake of terrorist attacks with real or perceived links to the group. While some followers opt to share press releases by IS-affiliated outlets like Amaq News Agency, others praise the perpetrator(s) and incite subsequent activity.

Upon initial analysis, there appears to be a correlation between terrorist attacks and tweet frequency. In other words, the number of tweets per day (and sometimes week) by English-language IS sympathizers on Twitter rises after perpetrators with alleged links to the group conduct attacks, particularly in the West. Consistent with other findings in this report, such trends are nuanced and subject to change over time. This time series encompasses a diverse number of plots with varying degrees of success, sophistication, and scale. Accompanied by the broad range of targets, such considerations undoubtedly impact the online activity of sympathizers. While striving to account for such variables, the following discussion faces limitations regarding comparative analysis. Moreover, the specific sample of Englishlanguage IS supporters on Twitter undoubtedly biases discourse regarding attacks in the West.
For example, two separate IS-claimed terrorist attacks within a month of each other might draw attention from English-language sympathizers on Twitter for varying reasons. On June 13, 2016, Larossi Abballa stabbed a French police commander and his partner in Magnanville, France. ${ }^{76}$ Though small in scope, the significance of the attack stems from the perpetrator's target and supposed links to Rachid Kassim, a notorious French IS recruiter. ${ }^{77}$ By way of contrast, the July 1, 2016, attack in Dhaka, Bangladesh, might garner attention because of its complexity, including number of perpetrators and sophisticated modes of operation which included hostage-taking, bombing, and shooting. ${ }^{78}$ These variants make it difficult to discern why and how English-language supporters engage in discourse on Twitter about terrorist attacks.

To better understand the relationship between IS-related terrorist attacks and Twitter activity among sympathizers, the following analysis qualifies the trend and tests for change over time. As discussed, IS-related perpetrators conducted attacks in different countries around the globe during this period. The following analysis focuses predominantly on the effects of terrorist operations in the U.S., Europe, Turkey, and Russia on Twitter activity. Researchers chose these countries to narrow the scope of discussion based on a data driven approach using relevant search terms.

It is hard to glean the precise number of tweets about a specific terrorist attack because accounts use different terms to discuss the same event. For example, accounts within the sample used the phrases "Pulse Nightclub Attack," "Pulse Nightclub Shooting," "Orlando Nightclub Shooting," and "Orlando Attack," in reference to the June 12, 2016, shooting by Omar Mateen. ${ }^{79}$ The data show that the traditional nomenclature for larger terrorist attacks often reflects the city in which the attack occurred (see 'Attack Nomenclature' in the appendix for visual representations of this phenomenon). Ultimately, this propensity offers a baseline to compare tweet frequency in relation to various attacks.

After identifying eight large-scale $\operatorname{attacks}^{80}$ in the U.S., Europe, Turkey, and Russia, the study queried and graphed 
the corresponding seven cities to cross-examine the relationship between attacks and tweet frequency (see Figure 15). This list includes attacks in Brussels, Orlando, Nice, Gaziantep, Berlin, St. Petersburg, and Istanbul. ${ }^{81}$ As anticipated, the data demonstrate a mostly positive relationship between the tweet frequency and larger-scale terrorist attacks in the U.S., Europe, Turkey, and Russia. Upon further review, contributing factors such as lethality, complexity, target, and operational links appear to be overwhelmingly context dependent. In many instances, findings were counterintuitive and lacked a common thread.

\section{Brussels Bombings}

As the first and most cited attack in the dataset, concurrent bombings in Brussels on March 22, 2016 provide a sound opportunity for analysis. ${ }^{82}$ Three assailants killed 32 people in the Brussels airport and Maalbeek metro. ${ }^{83}$ Overall, there was a 25 percent hike in the total number of tweets on the day of the attack; this is the first indicator that operations on Western targets positively correlate with a broader rise in tweet frequency on the day of attacks. Approximately 13 percent of tweets on the day of the bombing overtly mentioned Brussels, which suggests that an even larger percentage of tweets discussed the attack using other terminology or veiled references. Evidence shows that the effect of the bombing was short-lived as overarching tweet frequency fell by approximately 24 percent the day after the attack; this is supported by a sharp decline (approximately 66 percent) in the number of tweets mentioning Brussels within the same timeframe.

These events likely drew unmatched attention on Twitter, among other platforms, for several reasons. The attacks occurred earlier in the study, when Twitter regulations appeared to be less stringent. The bombings were also sophisticated and coordinated by perpetrators with operational connections to other IS operatives in Europe, namely the 2015 Paris attackers. ${ }^{84}$ Furthermore, in addition to the Amaq News Agency claim published the day

\section{Tracing Attacks Over Time}

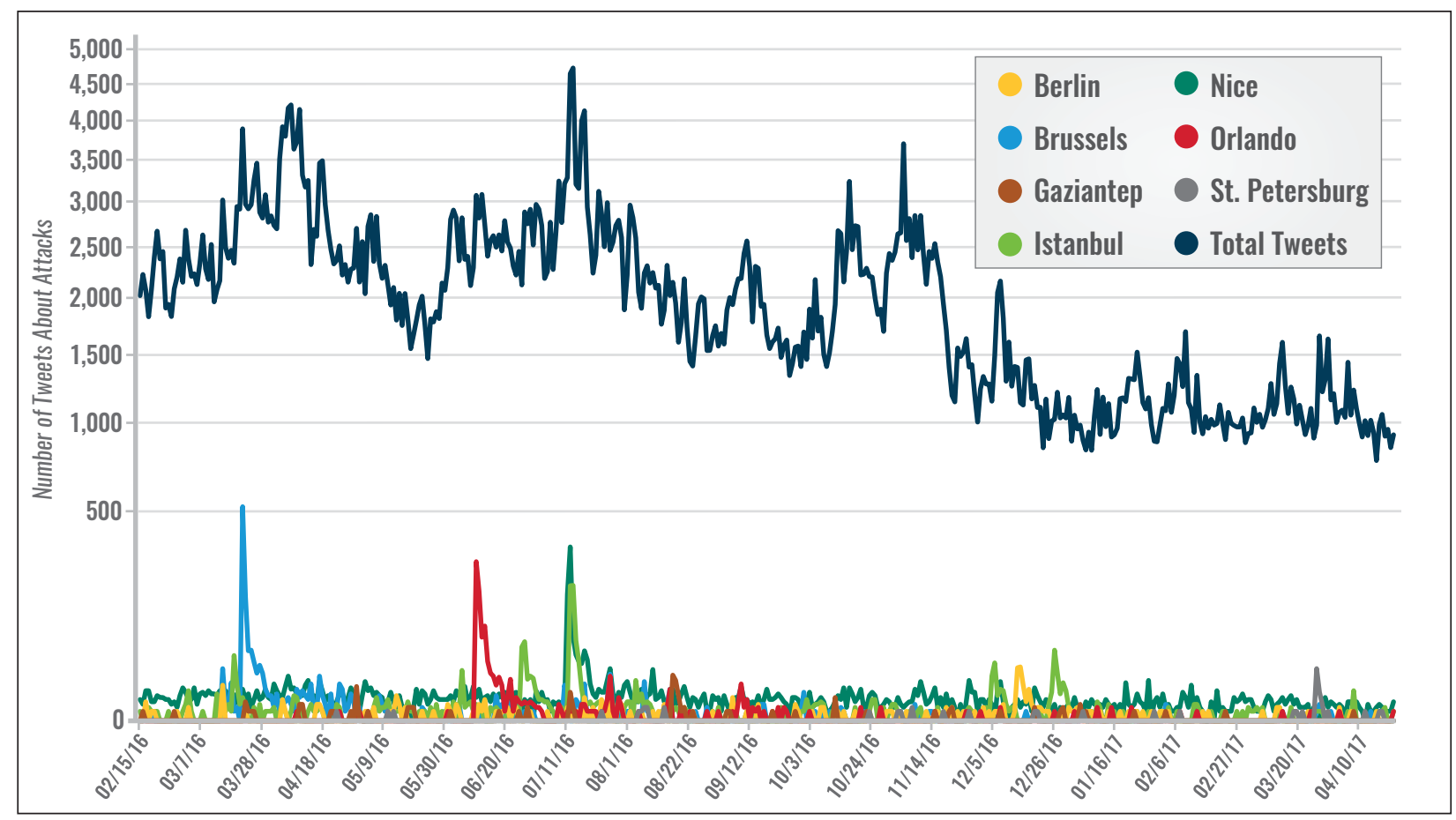

(Figure 15) This graph shows how English-language IS sympathizers discuss eight terrorist attacks in seven cities and contextualizes the extent to which the topic relates to tweet frequency by day.

30. The George Washington University Program on Extremism 
of the bombings, Belgium, and Brussels in particular, received substantive coverage in official IS publications, most notably the fourteenth issue of Dabiq magazine. Such attention suggests that the attack had enduring symbolic value. ${ }^{85}$ Regarding the Amaq Agency claim, it is crucial to note that the narrative of revenge exemplified in the Amaq News Agency press release was reflected in the tweets of English-language sympathizers, illustrating some semblance of congruity between top-down and bottom-up campaigns.

\section{Orlando Shooting}

Close to three months later, Omar Mateen conducted the Pulse Nightclub shooting in Orlando Florida, killing 49 in the early hours of June $12,2016 .{ }^{86}$ Despite yielding a higher death toll, the Orlando attack drew less attention than the Brussels bombing; while somewhat vexing, this hints that there is not a direct relationship between Twitter activity and lethality in the context of terrorist attacks. Instead, perhaps the lack of plot complexity in Orlando compared to Brussels reduced the interest of sympathizers online. Of the total number of tweets on the day of the shooting, approximately 9 percent overtly stated the city of Orlando. ${ }^{87}$ Naturally, adherents may have used terms other than 'Orlando,' as a 34 percent rise in overall tweet frequency accompanied this event. Although Amaq agency claimed some degree of affiliation to IS, the perpetrator himself, despite his oath of fealty to al-Baghdadi during the attack, also previously professed sympathy to Jabhat al-Nusra (now Jabhat Fateh al-Sham) and even Hezbollah. ${ }^{88}$ There is no obvious evidence that Mateen's murky allegiance to IS directly affected the response of English-language sympathizers on Twitter. Like Brussels, the attack in Orlando did not sustain the uptick in tweet frequency over time. Even so, a handful of IS-related media products mentioned the attack, including the video by Wilayat al-Khayr called "The Making of Illusion." ${ }^{89}$

\section{Istanbul - Ataturk}

Late in the evening on June 28, 2016, three gunmen wearing explosive devices reportedly attacked the international terminal at Ataturk Airport in Istanbul, Turkey. ${ }^{90}$ Although the assault was not claimed by any
23. Abdullah Retweeted

Oda3shyyamany $24 \mathrm{~m}$

\#Brussels revenge is a dish best served cold

h $\quad$ t? $2 \quad 1 \quad$...

(13) Abdullah Retweeted

mahatmadeen 4249 mahatmadeen $4249 \cdot 4 \mathrm{~h}$

Bombed Mosul just recently and killed innocent boys and girls.Islamic state retaliates you cry like babies.

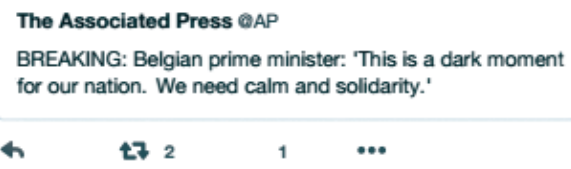

(Figure 16) These tweets illustrate content shared by English-language sympathizers on Twitter in the wake of bombings in Brussels.

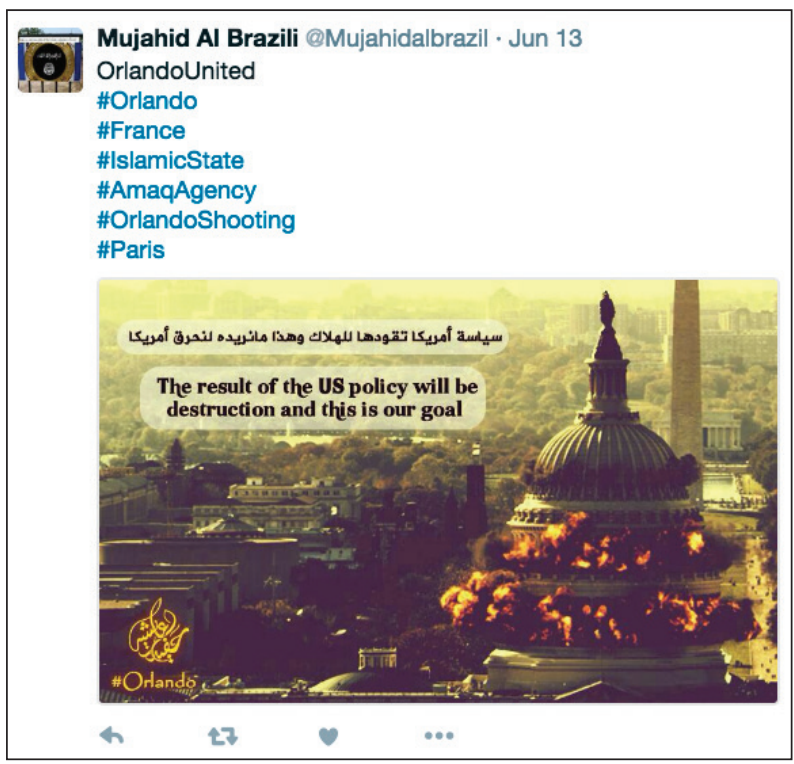

(Figure 17) This tweet exemplifies some of the content disseminated by English-language IS sympathizers on Twitter after the Pulse Nightclub shooting in Orlando, Florida.

group, including IS, officials questioned links to the organization as the mode of operation paralleled that of the November 2015 Paris attacks. Unlike Brussels and Orlando, the events in Istanbul did not correlate with an increase in the total number of tweets that day; only 3 percent of tweets that day referenced Istanbul. ${ }^{91}$ This rate is notable given that the death toll falls between those of Brussels and Orlando, further proving lethality does not predictably influence the amount of content produced by 
English-language sympathizers. Several factors, including the non-Western geographic location of the attack and the fact that IS media gave the attack scant publicity, possibly impact this finding.

\section{Nice Ramming}

On July 14, 2016, Mohamed Lahouaiej-Bouhlel drove a truck into the crowd celebrating Bastille Day in Nice, France, killing $86 .{ }^{92}$ Prior to the assault, jihadists and counter-terrorism officials demonstrated an awareness of the security challenges posed by this unsophisticated style of attack. ${ }^{93}$ Of the total number of tweets on the day of the ramming, approximately 5 percent mentioned Nice. ${ }^{94}$ One caveat pertains to the inability of the search filter to distinguish the name of the city 'Nice' from the word 'nice.' 95 Despite yielding the highest number of deaths in the sample, the rate for Nice falls behind attacks in Brussels (13 percent) and Orlando (9 percent), but ahead of those in Istanbul at the Ataturk airport (3 percent). To some degree, this sample, albeit small, shows a bias towards discussing violence directed at Western targets.

Anecdotally, it is hard to narrow the extent to which the ramming influenced the broader tweet frequency within this dataset because the attempted Turkish coup hijacked the attention of English-language IS sympathizers the following day. This point is exemplified by the overlapping rise in tweets mentioning Istanbul. As discussed earlier, five of the top ten hashtags on July 15, 2016, related to Turkey or the failed coup itself. This demonstrates the extent to which other political events may seize the narrative among IS followers in the wake of a ramming. On July 16, 2016, more than 24 hours after the assault, Amaq News Agency claimed responsibility for the attack, but this had no effect in reviving the declining discussion of the operation. ${ }^{96}$ Months later, English-language IS-propaganda, including the January 2017 issue of Rumiyah, praised the Nice ramming while inciting attacks in the West. ${ }^{97}$ By revisiting the attack months after the event, IS demonstrates a propensity for eulogizing operations against Western targets in propaganda geared towards English-language sympathizers. In this capacity, IS media output acts as conduit between operations outside IS-controlled territory and the grassroot engagements on Twitter.

\section{Gaziantep}

Over a month after the ramming in Nice, a suicide bomber targeted a wedding in Gaziantep, Turkey; mixed reports suggest the attack killed over 50 people. ${ }^{98}$ Despite becoming the second-most lethal attack in the sample, the data suggest the event drew little attention from English-language IS sympathizers numerically or proportionally. Again, this probably relates to the non-Western location of the assault. Gaziantep was referenced in barely over 1 percent of the tweets on the day of the bombings. ${ }^{99}$ Although there was no official claim from IS, President Erdogan reportedly believed the group conducted the attack. ${ }^{100}$

\section{Berlin Ramming}

On December 19, 2016, Anis Amri reportedly drove a truck into a Berlin Christmas market, killing 12. ${ }^{101}$ The ramming was correlated with a temporary increase in tweet frequency, like other attacks in the West. Approximately 2 percent of the total number of tweets on the day of the ramming overtly referenced Berlin. ${ }^{102}$ The following day, with the perpetrator on the run, Amaq News Agency issued a press release claiming affiliation. ${ }^{103}$ Much like the slightly-delayed announcement following the Bastille Day ramming in Nice, Amaq's claim had little effect on the dwindling discussion of the attack in Berlin. While less lethal, Berlin received numerically and proportionally more attention than the bombing in Gaziantep. Even so, the Berlin ramming drew few mentions from English-language sympathizers compared to other attacks on Western targets. As this was later in the dataset, Twitter's policy may have curbed the rallying effect among adherents in the immediate wake of terrorist attacks.

\section{Istanbul - Nightclub}

In the early hours of January 1, 2017, one gunman assaulted the Reina nightclub in Istanbul, Turkey, reportedly killing 39. ${ }^{104}$ Shortly thereafter, IS claimed responsibility through its mouthpiece, Amaq News Agency. ${ }^{105}$ Around 5 percent of tweets on the day of the bombing mentioned Istanbul. ${ }^{106}$ This finding initially complicates the assertion that Western targets garner more attention, since the nightclub shooting in Istanbul drew proportionally more discussion 
than the Berlin Christmas market ramming (by 3 percent). Nonetheless, a range of factors, including scale and symbolic timing, may affect supporters' rate of engagement. Such metrics are undoubtedly shaped by the narrow scope of the sample of English-language IS sympathizers.

Comparing the Istanbul nightclub attack to the previous Ataturk Airport attack allows one to test decline over time. Furthermore, because the operations produced a similar number of fatalities (Ataturk International Airport, over 40; Reina nightclub, 39), there is a control on the effects this might have, although evidence suggests the effects are limited. Broadly speaking, there is a severe decrease in the total number of tweets on the respective dates of the attacks. ${ }^{107}$ However, a roughly proportional number of tweets ( 3 percent and 5 percent), mentioned Istanbul overtly on the day of each attack. These rates are strikingly low considering IS' continued effort to discuss terrorist assaults in Turkey in official media products. ${ }^{108}$

\section{St.Petersburg Metro Bombing}

On April 3, 2017, a suicide bomber reportedly attacked a Metro train station in St. Petersburg, Russia, killing at least $14 .{ }^{109}$ After the attack, terrorism analysts noted that the event was unclaimed by IS. ${ }^{110}$ The 3 percent of tweets referencing 'Petersburg' (the simplified search term used for St. Petersburg) on the day of the attack is notable, but offers limited insight, as it is the only event in Russia within the sample. ${ }^{111}$ It appears to align with the broader trend of decline in terrorism-related discussion over time. Another consideration is the attack's non-Western target, which translates to less attention in some instances within this dataset.

\section{Concluding Observations}

After considering the influence of many variables on the mobilization of English-language IS sympathizers, the effects of terrorist attacks appear largely unpredictable. Counterintuitively, no single element of an operation drives the discussion in the data: these factors include plot sophistication, mode of operation, number of perpetrators, lethality, link to IS, or claim of affiliation. Though there are anomalies, as attacks on Western targets tend to garner more attention than their counterparts in Turkey and Russia. Of course, this sample only scratches the surface of the issue, and further examination is required because of the samples bias towards matters pertaining to Western audiences.

Despite the overarching volatility of English-language sympathizers' response to terrorist attacks, there are substantive shifts in tweet frequency and proportion of content directed towards the respective cities targeted by terrorists. With the exception of the Ataturk bombing in Istanbul, assaults occurring in the first half of the dataset, including Brussels, Orlando, Nice, and Gaziantep, are positively correlated with a rise in tweet frequency on the day of the attack. Those in the latter half of the dataset, including Istanbul (Reina nightclub), St. Petersburg, and Berlin have a weaker, and sometimes negative relationship with tweet frequency.

Despite the study's attempts to select and analyze a manageable sample of attacks, this approach is imperfect, as the events are not entirely comparable due to a range of influential variables. Ultimately, however, the data reveal an underlying tendency for English-language IS supporters to direct more attention to Western attacks.

From the sample of incidents selected, tweets referencing the cities in which the attacks occurred declined
Retweeted

Conflict Reporter @ConflictReport2 - 22h

It now appears that ISIS caused mass casualties in France, Belgium, and now Orlando, USA. US should stop its wars in the Middle-East!
13
(Figure 18) This tweet typifies conventional discourse in the wake of terrorist attacks that integrates a broader discussion on political events and foreign policy in particular. 
in absolute number and in proportion to the broader conversation over time. The day events unfold, terrorist activity in the West appears to stimulate a broader political dialogue on Twitter than attacks elsewhere. Based on anecdotal observations of concurrent projects tracking IS' use of other social media platforms, including applications with encryption technology, this analysis uncovers a diffuse rise in event-related content in the wake of an attack. Despite publicity and mainstream media attention, terrorist violence outside ISheld territory occupies a small portion of the discussion among English-language IS sympathizers on Twitter. To emphasize this point, hashtags regarding a terrorist attack never rank within the top five hashtags per week. Ultimately, the effects of terrorist attacks in driving discussion on Twitter are sometimes influential, but always un-sustained in this dataset. This finding is particularly damning to an organization that relies on terrorism as a tactic to advance its objectives.

\subsection{How do current events influence the activity of English-language IS sympathizers on Twitter?}

Amidst the broader decline over time, spikes throughout this dataset reveal a notable fluctuation in the rate of activity on Twitter by English-language IS sympathizers. These shifts are visible in graphs tracing the frequency per week, and even more striking from day to day. It is crucial to identify which current events influence Twitter activity by English-language supporters because the global base of IS adherents are subject to the changing tides of the real world. Within this context, it is instructive to observe the tendency for this demographic to depart from the narrative and agenda set by IS-central. Moreover, much like English-language sympathizers' predisposition towards Western attacks, it is crucial to consider how the scope of the study influences findings.

Some influential events cover only a concentrated period of time, over a matter of hours or days, while others span across longer durations. The July 15, 2016, failed coup d'état in Turkey, for example, attracted significant attention in a short timeframe. ${ }^{112}$ In fact, the day of the coup attempt contained the second highest number of tweets per day in the entire dataset $\left(4,613\right.$ tweets). ${ }^{113}$ This episode is particularly interesting, considering the observation that thematic English-language publications like Dabiq and Rumiyah do not prioritize the attempted coup in their discussion of Erdogan and Turkey. In this context, sympathizers' interest in current events drastically deviates from the overarching agenda set by IS propaganda. It is hard to prove a direct link in the spike in tweet frequency and the attempted Turkish coup as multiple factors could contribute to this uptick including the Bastille day terrorist attack in France the day before. Even so, metrics like top hashtag help test for a causal link. Within the 48-hours timespan between the day of the event and the day after, four of the top ten tweets clearly pertained to Turkey and "\#Turkey" was the most used hashtag (see Figure 19). This uptick still had limited effects in driving the conversation over a sustained period.

\section{Top 10 Hashtags on July 15 and July 16, 2016}

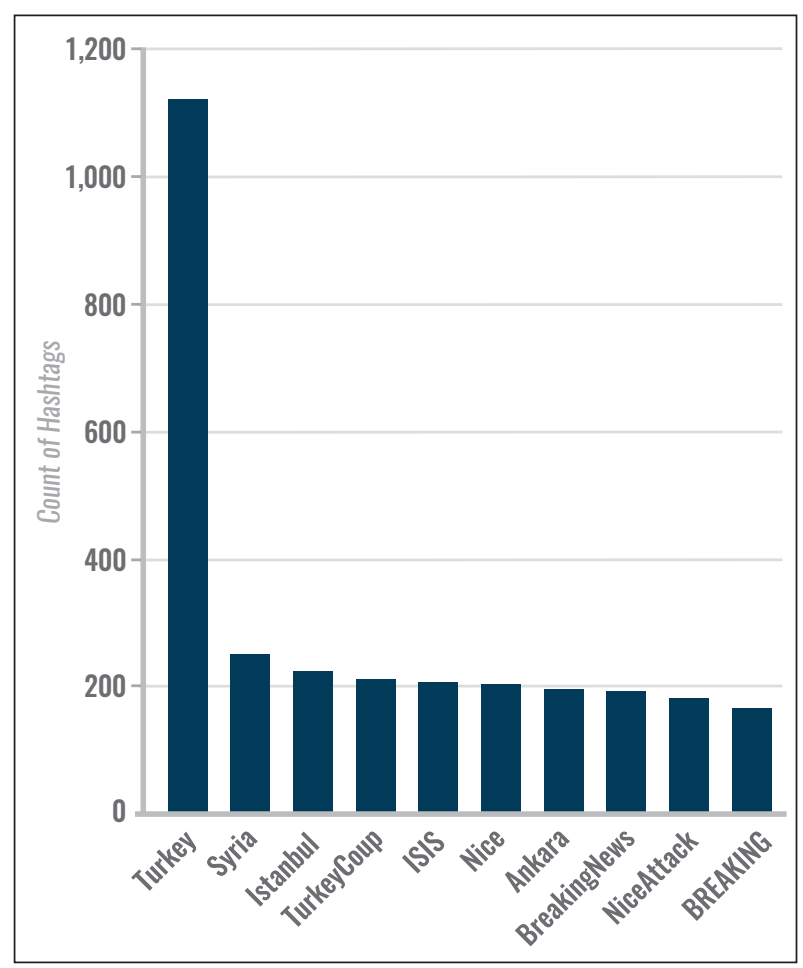

(Figure 19) Of the top ten hashtags that were used by English-language IS sympathizers on Twitter the day of and after the attempted coups in Turkey, four pertained to Turkey. 
The 2016 presidential election in the U.S. also received significant attention from supporters within the time series (see Figure 20). Leading up to November 8, 2016, accounts disseminated a wealth of tweets critiquing the candidates, their policies, and the democratic process writ large. Generally, IS-central English-language propaganda dedicated scant commentary on the electoral proceedings. On Twitter, however, despite ruminations on the subject for months, activity culminated between election day and the release of the results confirming the election of then-candidate Donald Trump (November 8 and 9). This 48-hour period contained 6,289 tweets, an unusual spike in the midst of otherwise dwindling activity. During this time, Twitter activity by sympathizers rose then fell as voters cast ballots and polling stations closed; the rate began to climb again as officials announced results.

In an effort to grasp IS sympathizers' propensity to dwell on matters that pertain to their adversaries, the investigation graphed tweets mentioning four state leaders over time: Assad, Trump, Putin, Erdogan (see Figure 21). ${ }^{114}$ The decision to select these individuals stemmed from an initial survey of the dataset. Though imperfect, as veiled

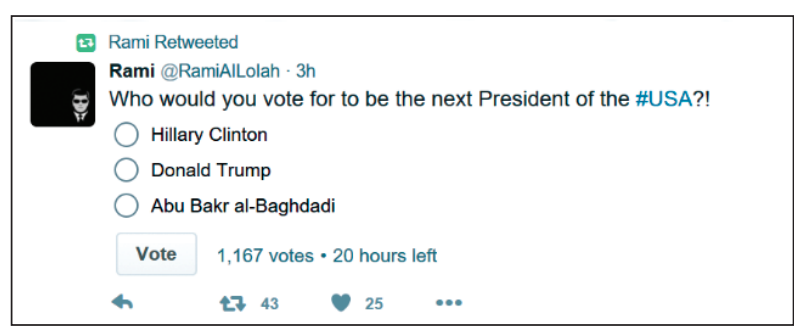

E@Erha79b - 46m

QWarning Do not \#vote in the elections. It is \#kufr to give someone the right to legislation. Legislation is for non except \#Allah.

4 27 -

Ibn Sahara @CreedOfAbraham·6h I pray this leads to an American civil war

h 278 ○ $17 \quad \cdots$

Ibn Sahara : @CreedOfAbraham·6h

America deserves Trump. Make dua he runs it into the ground.

4 $279 \quad \bullet 21 \quad \ldots$

(Figure 20) Tweets demonstrating content by Englishlanguage sympathizers on Twitter between November 8 and 9, 2016.

\section{Tweet Referencing Anti-IS State Leaders}

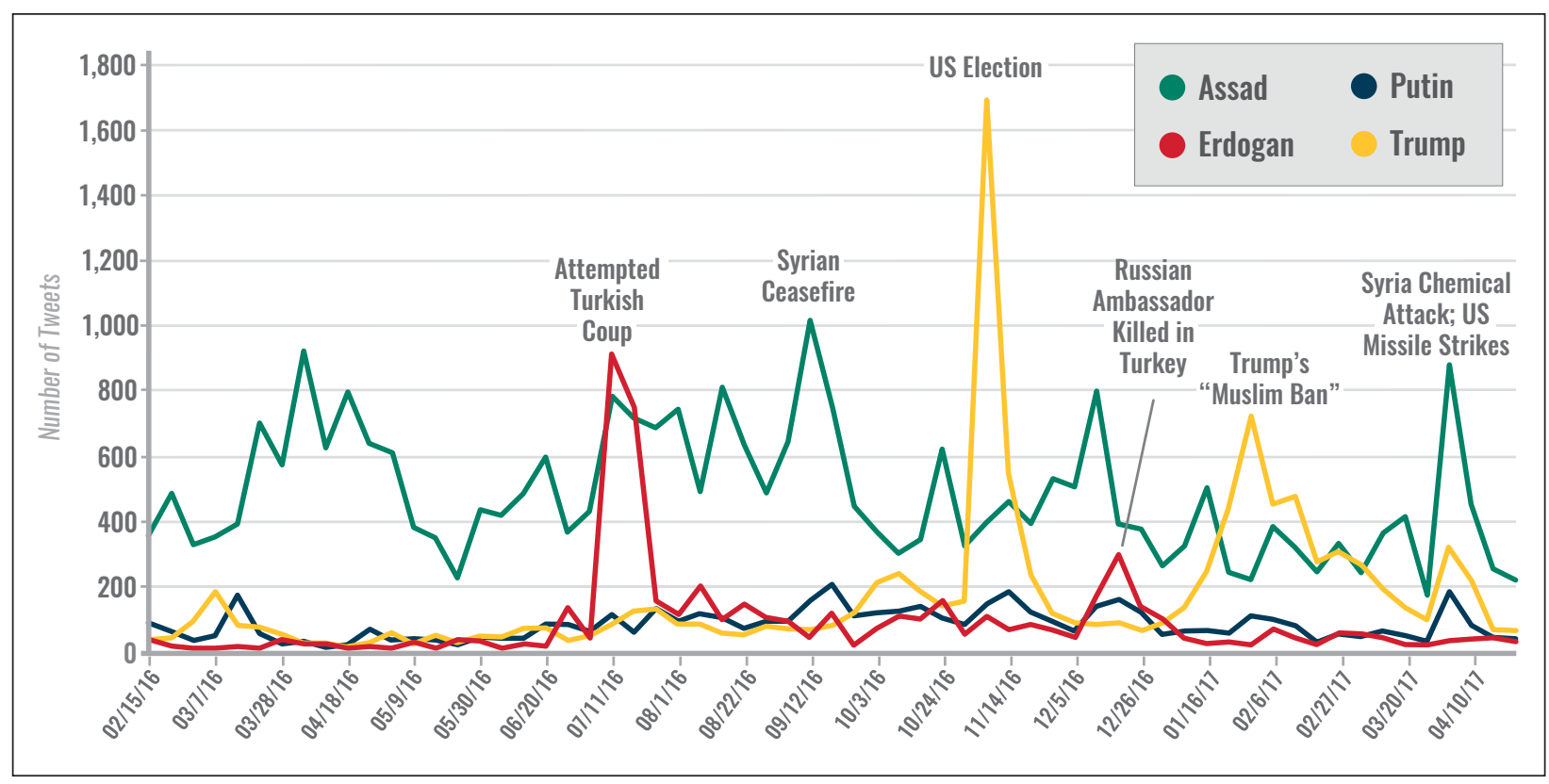

(Figure 21) This annotated graph traces the number of tweets referencing Assad, Erdogan, Putin, and Trump over time and highlights some relevant current events. 
references are hard to detect with basic search filters, this sample sufficiently streamlines the multiple political events that states and their respective leaders experienced during the time series. While mentions of these politicians independently ebb and flow throughout the dataset, concurrent rises are often indicative of events that affect the various parties.

As anticipated, Syrian President Bashar al-Assad received substantially more attention and sustained commentary than his counterparts in the U.S., Turkey, and Russia. This finding is unsurprising due to his relevance in the conflict, and enduring presence in official IS propaganda.

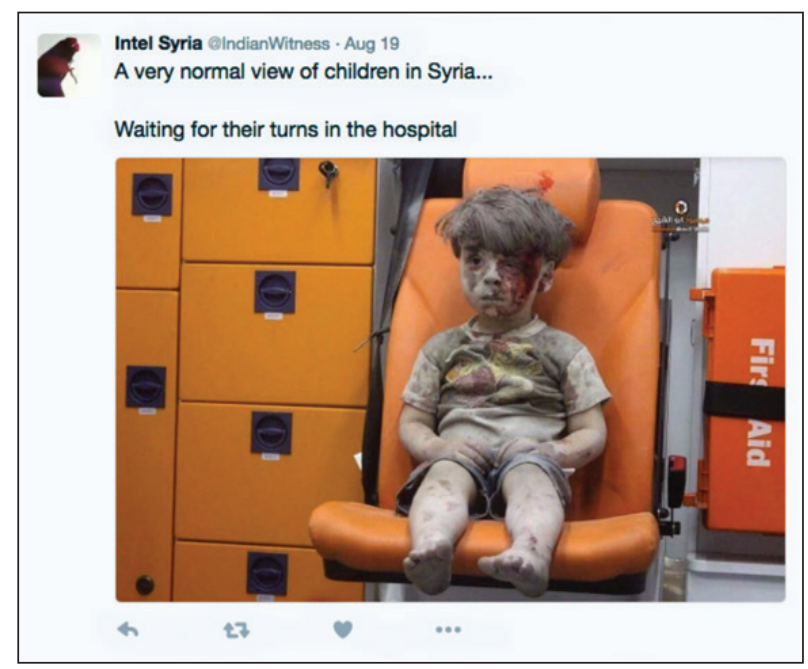

(Figure 22) This tweet does not include any of the specific state leader but it shows how English-language sympathizers engage with politically significant events.

Throughout the time series, sympathizers overtly referenced Assad in 30,351 tweets; the greatest spike in tweet frequency per week occurred the week of September 12, 2016, during the nationwide ceasefire in Syria. ${ }^{115}$ Upon further analysis, it is crucial to note that the highest number of tweets per day mentioning the Syrian president transpired in the wake of well-publicized attacks on civilians. On August 18, 2016, an early spike in the dataset, footage emerged showing rescue workers care for Omran Daqneesh, a boy pulled from the rubble of his home after surviving a regime airstrike in Aleppo (see Figure 22). ${ }^{116}$
On the day of April 4, 2017, references to Assad temporarily climbed after a chemical attack in the rebel-held town of Khan Sheikhoun in Northwestern Syria. ${ }^{117}$ As demonstrated in the graph, this rise converges with increased references to Trump and Putin: leaders with controversial relations to the event.

The second most mentioned state leader was U.S. President Donald Trump (10,587 tweets). Like Assad, Trump gained traction among English-language sympathizers after a chemical attack in Syria; in retaliation, Trump reportedly authorized a missile strike on Syria's Al Shayrat airbase on April 6, 2017. ${ }^{118}$ Before this event, Trump received substantial attention on two occasions: his election, and the announcement of a policy restricting travel from select Muslim-majority countries. Having already discussed a dramatic rise in activity in the 48-hour period around the election, it is crucial to highlight a shift in the discourse surrounding Trump's 'travel ban' on January 27, 2017. ${ }^{119}$ During the week of January 23, 2017, '\#MuslimBan' ranked among the top ten hashtags used by English-language adherents on Twitter. Furthermore, the sheer number of tweets mentioning Trump by name rose over 198 percent in the span of three days after the release of the executive order.

These findings are particularly fascinating in light of IS' reportedly deliberate exclusion of Donald Trump in official propaganda. ${ }^{120}$ On a grassroots level, content by English-language IS sympathizers diverges from this strategy with frequent mentions of Trump. This indicates a lack of cohesion between official propaganda disseminators in IS-controlled territory and its base of adherents in the West. Though not overtly problematic, as IS followers opportunistically validated the narrative of persecution using Trump's rhetoric, this disjunction is one of the many symbols of deterioration in the digital sphere.

Despite the geopolitical significance of Turkey for IS, its President, Recep Tayyip Erdogan, receives sporadic attention from English-language IS followers on Twitter (5,542 mentions in total). This observation is striking due to the consistency with which official propaganda targeting Western audiences mentions Erdogan. Aside from 
the aforementioned Turkish coup attempt, which generated considerable activity, the only other notable spike in activity arose from the assassination of Andrey Karlov, the Russian Ambassador to Turkey in December 2016. ${ }^{121}$ Although the gunman's precise allegiances remain unclear, reports suggested that various jihadist circles lauded the attack. ${ }^{122}$ According to this dataset, so too did Englishlanguage IS sympathizers on Twitter. Lastly, as opposed to their interest in the U.S. election, this demographic gave little attention to the April 2017 constitutional referendum in Turkey.

Though slightly confounding, given Vladimir Putin's prominence in English-language IS propaganda, the Russian President is mentioned overtly in only 5,256 tweets throughout the tested timeframe. The highest peak in Putin-related discussion occurred during the week of the Russian elections in September 2016. However, this flux is arguably driven by proximally preceding events including the Syrian ceasefire, Trump's well-publicized praise of Putin during the U.S. presidential election, and Putin's meeting with Obama during the G-20 Summit. ${ }^{123}$ The second, and perhaps most interesting upsurge in tweets citing Putin, emerged around the aforementioned chemical attack in Syria, which occurred the day after a bombing in St. Petersburg, Russia. The compounding effects of these events led to a 455 percent hike in the number of Putin-related tweets during the week of April 3, 2017, compared to the week before. Providing more evidence of IS' lack of control over political narratives, it is useful to highlight the disconnect between IS' efforts to discuss Putin in English-language propaganda compared to the lack of content mentioning the politician on Twitter. A similar disconnect exists in discourse surrounding Trump, and still, substantive evidence of decay in the digital sphere.

Like other socio-political spheres on Twitter, IS sympathizers rally around incidents that are relevant to the group's base of supporters. Admittedly, however, some of the greatest hikes in activity are correlated with events IS cannot assert control over. This inability to dictate the outcome of current events is often two-pronged, manifesting both online and offline. The reopening of Incirlik Air Base to American forces offers a useful

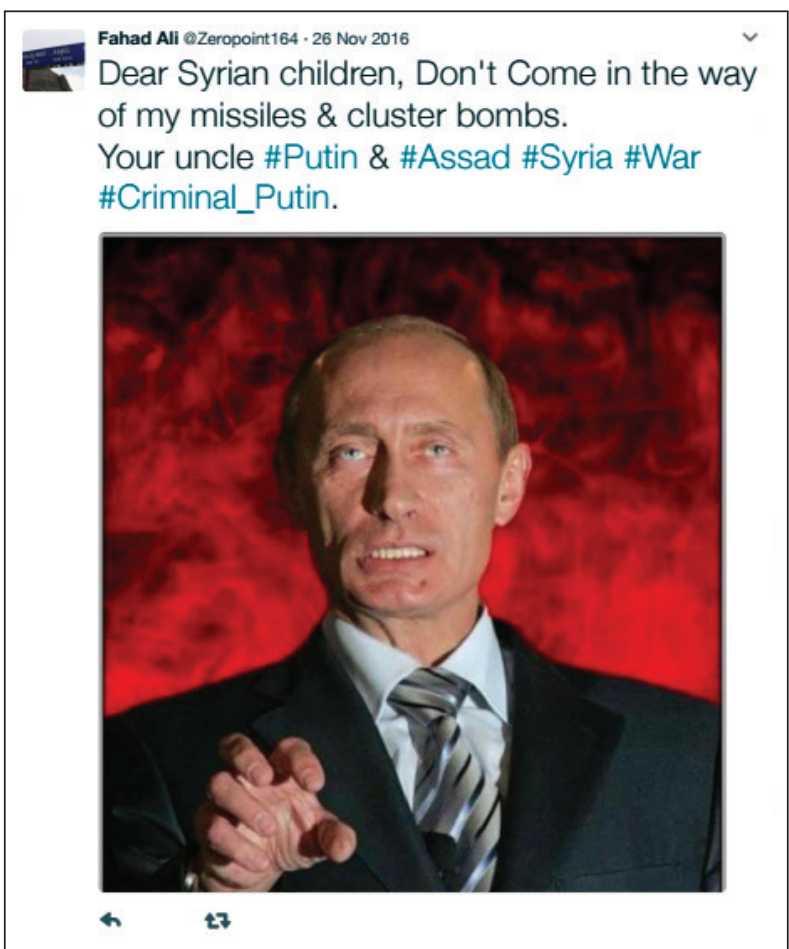

(Figure 23) This screenshot shows how accounts discuss various state leaders, sometimes mentioning more than one in the same tweet.

example of this phenomenon. After the July 2016 coup attempt in Turkey, the Turkish government allowed the U.S. to resume missions from Incirlik Air Base after a temporary shutdown. ${ }^{124}$ Incirlik is significant to IS because it houses critical infrastructure to the U.S.'s military efforts against fighters on the ground in Iraq and Syria. ${ }^{125}$ On Twitter, English-language IS followers rally without direction from IS-central in response to this event, as '\#CloseIncirlik' became the most popular hashtag during the week of July 18, 2016. Unexpectedly, this hashtag outshines every other top hashtag per week across the entire time series (see Figure 24). This vexing observation might reveal the efficacy of organic, bottom-up mobilization or point to the influence of other external factors. Either way, such findings hint at a dissonance between IS-central's messaging efforts for Western audiences and the rallying cries of Englishlanguage sympathizers on Twitter. 
This section cannot provide an exhaustive analysis of the range of global political events that drive the conversation online. Anecdotally, however, these matters often fall into two camps: those concerning the global Muslim community, and those regarding the group's adversaries. While this analysis focuses predominantly on the latter, it is crucial to note supporters' ongoing engagement with events around the world, especially in the Middle East, Africa, and Asia. The perceived and experienced persecution of Muslim communities, like the Rohingya in Myanmar, receive considerable attention from the broader base of English-language IS sympathizers. ${ }^{126}$ During the week of November 21, 2016, for example, "\#Rohingya" ranks within the top three hashtags used by adherents.

In short, some notable current events drive tweet frequency and discussion among English-language IS community on Twitter. Although a direct relationship between major political events and an increase in tweet frequency is nonexistent, a broad swathe of occurrences concern this demographic. While some events draw adherents in droves, others garner less attention. Though difficult to measure, the aggregation of political discussion accounts for the largest segment of content produced by English-language IS sympathizers on Twitter. No evidence suggests this dialogue is narrowing in the face of more stringent efforts to silence the movement. While relevant tweets have declined in absolute terms, like overall tweet frequency, the relative proportion of political discourse remains substantial.

\section{Notes}

1. Like geolocation, most accounts to not specify a time zone setting.

2. For example, and a notable segment of tweets use Somali, a language that is not supported by Twitter. "Twitter for Websites Supported Languages - Twitter Developers.” 2017. https://dev.twitter.com/web/overview/languages.

3. A derogatory term used by extremists to describe moderate Muslims. For more information, see: Bhogal, Gurwinder. 2017. "How Terrorists Are Creating a New Language." Medium. July 28. https://medium.com/@G_S_Bhogal/ how-terrorists-are-creating-a-new-language-595646a6e76d.

\section{Top Hashtag Per Week}

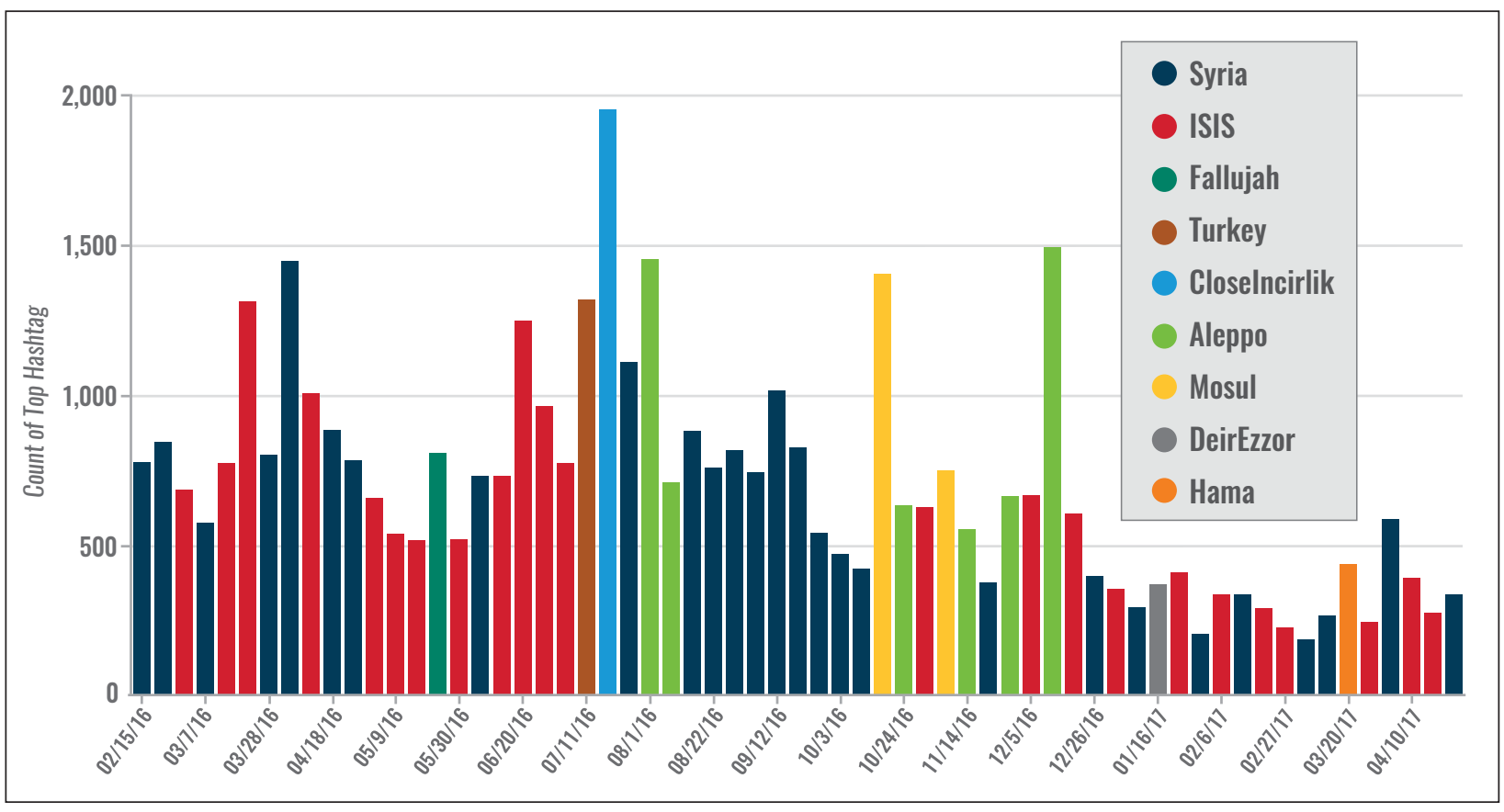

(Figure 24) This graph identifies the top tweet per week across the 63-week sample to identify key themes discussed by English-language sympathizers on Twitter. 
4. Part of IS' Arabic slogan "baqiya wa tatamaddad," which means "remaining and expanding." For more information, see: Zelin, Aaron. 2015. "The Islamic State's Model.” The Washington Institute: Improving the Quality of U.S. Middle East Policy. January 28. http://www.washingtoninstitute.org/policy-analysis/ view/the-islamic-states-model.

5. At its height during the week of April 4, 2016, this stream of IS sympathizers shared 26,733 tweets. Conversely, the enduring network of sympathizers reached its lowest point about a year later during the week of April 24, 2017, producing 6,298 tweets.

6. Fisher, Ali. 2016. "Interpreting Data About ISIS Online / USC Center on Public Diplomacy." Center on Public Diplomacy Blog. October 6. https://uscpublicdiplomacy.org/blog/ interpreting-data-about-isis-online.

7. “Government TOS Reports - July to December 2016.” 2017. https://transparency.twitter.com/en/gov-tos-reports.html.

8. “Combating Violent Extremism." 2016. Twitter

Blogs. February 5. https://blog.twitter.com/2016/ combating-violent-extremism.

9. According to an official blog post, Twitter "suspended over 125,000 accounts for threatening or promoting terrorist acts" from mid-2015 to February 5, 2016, prior to the dates used in this study. "Combating Violent Extremism.” 2016. Twitter Blogs. February 5. https://blog.twitter.com/2016/ combating-violent-extremism. A subsequent update by Twitter's public policy team said the company shut down an additional 235,000 accounts between February 5 and August 18, 2016. "An Update on Our Efforts to Combat Violent Extremism." 2016. Twitter Blogs. August 18. https://blog.twitter.com/2016/ an-update-on-our-efforts-to-combat-violent-extremism. The company's tenth \#Transparency Report notes that "During the reporting period of July 1, 2016 through December 31, 2016, a total of 376,890 accounts were suspended for violations related to promotion of terrorism." "Government TOS Reports - July to December 2016.” 2017. https://transparency.twitter.com/en/ gov-tos-reports.html.

10. The suspension of 235,000 accounts between February 5 and August 18, 2016 amounts to a rate of about 1,205 accounts per day. The suspension of 376,890 accounts between July 1 and December 31, 2016 amounts to a rate of about 2,060 accounts per day. In other words, various figures from 2016 show a 71 percent increase in the average number of accounts suspended per day for terrorism related activity. Though imperfect, as the dates overlap and Twitter's suspension rates likely vary from day to day, these figures are important because they support the claim that Twitter is increasing efforts to suspend accounts that threaten or promote terrorist attacks.

11. In this context, suspension is operationalized as a status change from active to inactive as per the API.

12. SFM pulls from a dynamic list of accounts that changes from week to week based on input and concurrent suspension.
13. Additionally, PoE researchers on Telegram have observed instances where IS supporters encouraged others to build a followership on broad-based platforms with innocuous activity, followed by an subtle escalation in extremist content. This could be another explanation for long-lasting accounts.

14. @erhabi35, @erhabi365, @erhabi37, and @Erhabi39.

15. Amarasingam, Amarnath. 2015. "What Twitter Really Means for Islamic State Supporters.” War on the Rocks. December 30. https://warontherocks.com/2015/12/what-twitter-reallymeans-for-islamic-state-supporters/.

16. Vidino, Lorenzo, and Seamus Hughes. 2015. "ISIS in America: From Retweets to Raqqa." The GW Program on Extremism. p.24; Amarasingam, Amarnath. 2015. "What Twitter Really Means for Islamic State Supporters." War on the Rocks. December 30. https://warontherocks.com/2015/12/what-twitter-reallymeans-for-islamic-state-supporters/.

17. The maximum value for each segment extends far beyond 600 , which is why they are not included on this chart.

18. Berger, J.M., and Heather Perez. 2016. “The Islamic State's Diminishing Returns on Twitter: How suspensions are limiting the social networks of English-speaking ISIS supporters." Program on Extremism. https://cchs.gwu.edu/sites/cchs. gwu.edu/files/downloads/Berger_Occasional\%20Paper.pdf; Larson, Selena. 2017. "Twitter Suspends 377,000 Accounts for pro-Terrorism Content." CNNMoney. March 21. http:// money.cnn.com/2017/03/21/technology/twitter-bans-terrorism-accounts/index.html.; Benner, Katie. "Twitter Suspends 235,000 More Accounts Over Extremism.” The New York Times, August 18, 2016, sec. Technology. https://www. nytimes.com/2016/08/19/technology/twitter-suspends-accounts-extremism.html.

19. "Security Manual Reveals the OPSEC Advice ISIS Gives Recruits.” 2017. Wired. https://www.wired.com/2015/11/ isis-opsec-encryption-manuals-reveal-terrorist-groupsecurity-protocols/.; "Several cyber security to protect your network communication SOCIAL." ISIS-OPSEC-Guide. September 14, 2015. https://www.wired.com/wp-content/ uploads/2015/11/ISIS-OPSEC-Guide.pdf.

20. Vidino, Lorenzo, and Seamus Hughes. 2015. "ISIS in America: From Retweets to Raqqa." The GW Program on Extremism. p.24; Amarasingam, Amarnath. 2015. "What Twitter Really Means for Islamic State Supporters.” War on the Rocks. December 30. https://warontherocks.com/2015/12/ what-twitter-really-means-for-islamic-state-supporters/.

21. At present, PoE does not use Twitter's API to identify each account's specific list of followers.

22. For clarity and more substantive analysis, researchers listed every single mention separately, identifying each instance where a account in the sample mentioned another username.

23. Please note that Abu Muhammad Al-Julani, the leader of Jabhat Al-Nusra, announced the rebranding of the organization (now Jabhat Fatah al-Sham) in July 2016, during 
PoE's data collection period. For more on the implications of this event, see Byman, Daniel. 2016. "What's in a Name? The New Jabhat Al-Nusra and the Future of Al Qaeda." Lawfare. October 24. https://www.lawfareblog.com/ whats-name-new-jabhat-al-nusra-and-future-al-qaeda.

24. Bastian M., Heymann S., Jacomy M. (2009). Gephi: an open source software for exploring and manipulating networks. International AAAI Conference on Weblogs and Social Media.

25. Rami (@RamiAlLolah) account bio as of July 28, 2017. https:// twitter.com/ramiailoiah?lang=en

26. Carter, Joseph, Shiraz Maher, and Peter Neumann. 2014. "\#Greenbirds: Measuring Importance and Influence in Syrian Foreign Fighter Networks." International Centre for the Study of Radicalisation. http://icsr.info/wp-content/uploads/2014/04/ ICSR-Report-Greenbirds-Measuring-Importance-andInfleunce-in-Syrian-Foreign-Fighter-Networks.pdf.

27. Although 'ShamiWitness' was deemed influential in an earlier study, the account received only 64 mentions in PoE's entire dataset. This pales in comparison to other accounts mentioned by English-language IS sympathizers. Jytte Klausen. 2015. 'Tweeting the Jihad: Social Media Networks of Western Foreign Fighters in Syria and Iraq,' Studies in Conflict \& Terrorism, 38:1

28. BBC News. 2016. "Radical Preacher Anjem Choudary Jailed for Five Years.” http://www.bbc.com/news/uk-37284199; Oakes, Dan, and Sam Clark. 2016. "Men Arrested in Queensland over Alleged Plan to Take Boat to Join IS.” ABC News. http://www. abc.net.au/news/2016-05-11/preacher-among-five-arrestedover-alleged-plan-to-join-is/7403344; Pegues, Jeff, 2015. “Using Social Media to Track Extremists Online." CBS News. http://www.cbsnews.com/news/using-social-media-to-trackextremists-who-advocate-jihad-online/.

29. Cronin, Audrey Kurth. 2009. How Terrorism Ends: Understanding the Decline and Demise of Terrorist Campaigns, 14-34.

30. Cronin, Audrey Kurth. 2009. How Terrorism Ends: Understanding the Decline and Demise of Terrorist Campaigns, 14-34.

31. Alkhouri, Laith, and Alex Kassirer. 2016. "Tech for Jihad: Dissecting Jihadists' Digital Toolbox.” Flashpoint. p.1 https:// www.flashpoint-intel.com/wp-content/uploads/2016/08/ TechForjihad.pdf.

32. Alkhouri, Laith, and Alex Kassirer. 2016. "Tech for Jihad: Dissecting Jihadists' Digital Toolbox.” Flashpoint. https:// www.flashpoint-intel.com/wp-content/uploads/2016/08/ TechForJihad.pdf.

33. Examples of protected encrypted messengers discussed by English-language sympathizers on Twitter include Telegram, Surespot, WhatsApp, Threema, Signal, WeChat, Viber.

34. Examples of mobile security applications discussed by English-language sympathizers on Twitter include F-Secure Freedome, VeraCrypt, Nextplus, and GPG4USB.
35. Examples of protected email services discussed by Englishlanguage sympathizers on Twitter include Tutanota, ProtonMail, and HushMail.

36. Examples of VPNS discussed by English-language sympathizers on Twitter include FlashVPN, TurboVPN, and SuperFreeVPN.

37. One speculative caveat is that Twitter's proprietary software might flag accounts that disseminate IS-related content and mention alternative means of online engagement. As the company does not make this information publically available, it is impossible to discern whether or not such factors affect the study's results.

38. Prucha, Nico. 2016. "IS and the Jihadist Information Highway - Projecting Influence and Religious Identity via Telegram." Perspectives on Terrorism 10 (6), p.54 http://www.terrorismanalysts. com/pt/index.php/pot/article/view/556.

39. "Combating Violent Extremism." 2016. Twitter Blogs. February 5. https://blog.twitter.com/2016/combating-violent-extremism.

40. Hosenball, Mark. "FBI Paid under $\$ 1$ Million to Unlock San Bernardino iPhone: Sources.” Reuters 4 May 2016. Reuters. Web.

41. Abdullah (@we_r_back64). “Hey kuffaar Worry about your belgium people, instead of suspending us . Lolzzzz.” 2017. Tweet.

42. Umm Radwa (@ummradwa3). "Without a doubt Twitter suspensions are biased against us. They hate us.” July 20, 2016. Tweet.

43. (@ssvvah). "It seems people were suspended. I would love to follow more but I can't. So I just hope not everyone gets suspended:/ Anyhow any tips how to." April 9, 2017. 10:42 AM. Tweet.

44. Lakomy, Miron. 2017. "Cracks in the Online "Caliphate": How the Islamic State is Losing Ground in the Battle for Cyberspace." Perspectives on Terrorism, 11 (3), p46.

45. Lakomy, Miron. 2017. "Cracks in the Online "Caliphate": How the Islamic State is Losing Ground in the Battle for Cyberspace." Perspectives on Terrorism, 11 (3), p47.

46. "Guidelines for Law Enforcement." 2017. Twitter Help Center. Accessed September 11. https://help.twitter.com/articles/41949?lang=en. "Transparency Report." 2017. Accessed September 11. https://transparency.twitter.com/en.html.

47. United States v. Haris Qamar Criminal Complaint and Affidavit (2016), p.3

48. United States v. Haris Qamar Criminal Complaint and Affidavit (2016), p.3.

49. Although PoE's database is not designed to connect social media accounts with real-world persons facing terrorism charges, researchers sometimes query usernames cited in Department of Justice press releases and legal documents, and courtroom transcripts. In instances where PoE finds social media records, staff members use them to better understand specific cases and trends.

50. According to a press release from the U.S. Department of Defense, Abu Muhammad al-Adnani was reportedly killed on August 30, 2016 by a precision airstrike. "Statement from 
Pentagon Press Secretary Peter Cook on Strike Against ISIL Senior Leader.” 2016. Department of Defense. September 12.

51. Milton, Daniel. 2016. "Communication Breakdown: Unraveling the Islamic State's Media Efforts.” Combating Terrorism Center at West Point, p.21.

52. Various works and tweets by subject matter experts suggest that these six campaigns received varying degrees of attention from IS-central and even Western mass media.

53. This section excludes analysis on tweets mentioning the town of Dabiq, a symbolically important front meeting the criteria for inclusion in this section, because the software's filter could not parse out references to the city versus the Englishlanguage propaganda magazine, skewing the data.

54. Winter, Charlie (@charliewinter). “Worth noting that \#IS’s approach to media \& battle of \#Fallujah is totally different to its media re battles for \#Ramadi/\#Palmyra/\#Tikrit." May 26 2016, 7:41AM. Tweet. https://twitter.com/charliewinter/ status/735843353556877312. On June 10, Winter, Charlie (@charliewinter). “\#Major discrepancies in how \#IS is reporting from \#Manbij, \#Sirt, and \#Fallujah.” June 10 2016, 9:09AM. Tweet. https://witter.com/charliewinter/ status/741301306032295937.

55. Winter, Charlie (@charliewinter).“\#Fallujah - pretty much live-blogging. \#Manbij - occasional mentions now \& then. Sirt - stony silence." 10 June 2016, 9:12AM. Tweet. https://twitter. com/charliewinter/status/741302122772369408.

56. Winter, Charlie (@charliewinter)."Instead of imposing media blackout (as it has done in the past), \#IS is issuing regular sitreps \& photo reports." 26 May 2016, 9:35AM. Tweet. https:// twitter.com/charliewinter/status/735872104055341056. Winter, Charlie (@charliewinter). “It can't be seen to abandon \#Fallujah - \#Is heavily invested in city for years. To give up w/o fight would fatally damage its narrative." 26 May 2016, 9:36AM. Tweet. https://twitter.com/charliewinter/ status/735872337002762241.

57. “Fallujah Declared 'Fully Liberated' from Isis by Senior Iraqi Army Commander" 2017. The Independent. http://www. independent.co.uk/news/world/middle-east/isis-fallujah-iraq -liberated-islamic-state-daesh-iraqi-army-a7103931.html.

58. Chulov, Martin. 2016. "Isis Kills Dozens and Seizes Hostages in Counter-Attack on Kirkuk." The Guardian, October 22. World news. https://www.theguardian.com/world/2016/ oct/21/isis-kill-dozens-and-seize-hundreds-in-counterattack-on-kirkuk.

59. Prickett, Ivor. 2017. "In Mosul, Revealing the Last ISIS Stronghold." The New York Times, August 1, sec. Middle East. https://www.nytimes.com/2017/08/01/world/middleeast/ mosul-isis-survivors-rights.html.

60. Shaheen, Kareem. 2016. "Isis Attacks Kirkuk as Concerns Mount over Fate of Civilians in Mosul." The Guardian, October 21, sec. World news. https://www.theguardian.com/world/ 2016/oct/21/kirkuk-police-compound-under-attack-militants- iraq-isis-mosul; Knights, Michael (@Mikeknightsiraq). "For general readers, the Kirkuk ISIL attacks are a couple of determined assaults on less well/protected/less critical sites." 21 October 2016, 3:03AM. Tweet. https://twitter.com/ Mikeknightsiraq/status/789406709659820032.

61. "ISIS Attack in Kirkuk Is Reality Check Amid Mosul Offensive - NBC News." 2017. http://www.nbcnews.com/storyline/ isis-terror/isis-attack-kirkuk-reality-check-amid-mosuloffensive-n670571.

62. Winter, Charlie (@charliewinter).“\#IS comms today re \#Kirkuk outnumber comms re \#Mosul by ratio of 4:1. These attacks in \#Kirkuk are about distraction, not territory." October 21 2016, 2:46AM. Tweet. https://twitter.com/ charliewinter/status/789402479460888576.

63. During the week of October 17 to 24, 2016, 2,884 tweets mentioned Mosul whereas 1,054 tweets referenced Kirkuk.

64. Loveluck, Louisa, and Liz Sly. 2017. "Turkey-Backed Rebels Seize Islamic State's Al-Bab Stronghold in Syria.” Washington Post, February 23. https://www.washingtonpost.com/world/ middle_east/turkey-backed-rebels-enter-center-of-islamicstates-al-bab-strongholdin-syria/2017/02/23/e389a506-f9c311e6-9b3e-ed886f4f4825_story.html.

65. Prickett, Ivor. 2017. "In Mosul, Revealing the Last ISIS Stronghold." The New York Times, August 1, sec. Middle East. https://www.nytimes.com/2017/08/01/world/middleeast/ mosul-isis-survivors-rights.html.

66. Winter, Charlie. 2017. "ICSR Insight: The ISIS Propaganda Decline." International Centre for the Study of Radicalisation. March 23. http://icsr.info/2017/03/icsr-insight-isispropaganda-decline/.

67. Arango, Tim, and Helene Cooper. 2017. "U.S. Investigating Mosul Strikes Said to Have Killed Up to 200 Civilians." The New York Times, March 24, sec. Middle East. https://www. nytimes.com/2017/03/24/world/middleeast/us-iraqmosul-investigation-airstrike-civilian-deaths.html.

68. "British Captive John Cantlie Appears in New Propaganda Video from Mosul." 2017. FDD's Long War Journal. http://www.longwarjournal.org/archives/2016/12/british-captive-john-cantlieappears-in-new-propaganda-video-from-mosul.php.

69. Zelin, Aaron Y. 2017. "New Video Message from The Islamic State: 'Knights of the Departments - Wilāyat Nīnawā."” January 24. http://jihadology.net/2017/01/24/new-videomessage-from-the-islamic-state-knights-of-the-departmentswilayat-ninawa/.

70. CNN, Kimberly Hutcherson and Faith Karimi. 2017. "Report: Syrian Forces Retake Palmyra from ISIS.” CNN. http://www. cnn.com/2016/03/27/middleeast/syria-forces-capture-palmyracity/index.html.

71. Winter, Charlie (@charliewinter). “Aside from those reports $\&$ these pics, practically * no* \#Mosul media over the weekend. Focus firmly on \#Palmyra (for obvious reasons)." December 
12 2016, 6:30AM. Tweet. https://twitter.com/charliewinter/ status/808318164442501120.

72. Dearden, Lizzie. 2017. "ISIS is driven out of ancient Syrian city of Palmyra for a second time." Independent. March 2. http://www. independent.co.uk/news/world/middle-east/isis-palmyrasyria-driven-out-second-time-islamic-state-ancient-romanruins-assad-executions-a7607351.html.

73. Jones, Seth G., James Dobbins, Daniel Byman, Christopher S. Chivvis, Ben Connable, Jeffrey Martini, Eric Robinson, and Nathan Chandler. 2017. "Rolling Back the Islamic State." Product Page. https://www.rand.org/pubs/research_reports/RR1912. html. Ogun, Mehmet Nesip. 2017. "ISIS: Less Territory, More Dangerous." Text. The National Interest. http://nationalinterest. org/feature/isis-less-territory-more-dangerous-18439.

74. Reuters. 2016. "Islamic State Calls for Attacks on the West during Ramadan in Audio Message," May 22. http://www. reuters.com/article/us-mideast-crisis-islamicstateidUSKCNOYCOOG.

75. Rumiyah, for example, contains a series titled, "Just Terror Tactics," which offers readers various modes of operation in consecutive issues of the magazine.

76. John, Tara. 2017. "Everything We Know About the Paris Knife Attacker Inspired By ISIS.” Time. http://time.com/4367986/ larossi-abballa-isis-paris-killed-police/.

77. Zelin, Aaron Y. 2016. "GUEST POST: An Interview with Rachid Kassim, Jihadist Orchestrating Attacks in France.” November 18. http://jihadology.net/2016/11/18/guest-post-an-interview-withrachid-kassim-jihadist-orchestrating-attacks-in-france/.

78. Hammadi, Saad, Rosie Scammell and Alan Yuhas. 2016. "Dhaka Cafe Attack Ends with 20 Hostages among Dead.” The Guardian, July 3. World news. https://www.theguardian.com/world/2016/ jul/01/dhaka-bangladesh-restaurant-attack-hostages.

79. BBC News. 2016. "Orlando Nightclub Shooting: How the Attack Unfolded,” June 15. http://www.bbc.com/news/ world-us-canada-36511778.

80. Defined as those killing 10 or more people excluding the perpetrators.

81. The author chose select spelling conventions to reduce error. For example, 'Brussels' instead of 'Bruxelles.'

82. BBC News. 2016. "Brussels Explosions: What We Know about Airport and Metro Attacks,” April 9. http://www.bbc.com/ news/world-europe-35869985.

83. BBC News. 2016. "Brussels Explosions: What We Know about Airport and Metro Attacks," April 9. http://www.bbc.com/ news/world-europe-35869985.

84. Henley, Jon, and Kareem Shaheen. 2016. "Suicide Bombers in Brussels Had Known Links to Paris Attacks.” The Guardian, March 23, sec. World news. https://www.theguardian.com/ world/2016/mar/23/belgium-awkward-questions-bomberslinks-to-paris-terror-cell.
85. Dabiq, 14. 2016. "The Knights of Shahadah in Belgium”, p6-7.

86. Ellis, Ralph , Ashley Fantz, Faith Karimi and Eliott C. McLaughlin. 2016. "49 Killed in Florida Nightclub Terror Attack." CNN, June 13. http://www.cnn.com/2016/06/12/us/orlandonightclub-shooting/index.html.

87. Like the other attacks discussed in this section, this figure offers only a sample of the number of tweets discussing the event as some tweets make no reference to the city.

88. "Ideology À La Carte: Why Lone Actor Terrorists Choose and Fuse Ideologies." 2016. Lawfare. October 2. https://www. lawfareblog.com/ideology-\%C3\%A0-la-carte-why-loneactor-terrorists-choose-and-fuse-ideologies. Ackerman, Spencer. 2016. "Omar Mateen Described Himself as 'Islamic Soldier' in 911 Calls to Police.” The Guardian, June 20, sec. US news. https://www.theguardian.com/us-news/2016/jun/20/ omar-mateen-911-calls-orlando-shooting-fbi-release-isis.

89. Zelin, Aaron Y. 2016. "New Video Message from The Islamic State: 'Manufacturing of the Illusions - Wilāyat Al-Khayr."' September 12. http://jihadology.net/2016/09/12/new-videomessage-from-the-islamic-state-manufacturing-of-the-illusionswilayat-al-khayr/.

90. Tuysuz, Gul, Holly Yan and Steve Almasy. 2016. "Istanbul Airport Attack: 42 Killed; Flights Resume.” CNN, July 6. http:// www.cnn.com/2016/06/29/europe/turkey-istanbul-ataturk-airport-attack/index.html.

91. Like the other attacks discussed in this section, this figure offers only a sample of the number of tweets discussing the event as some tweets make no reference to the city.

92. Smith-Spark, Laura. 2016. "Nice Attack Victims: France Pays Tribute 3 Months on." CNN, October 15. http://www.cnn.com/ 2016/10/15/europe/france-nice-attack-memorial/index.html.

93. Daly, Michael. 2017. "Terror Mag Praised Ramming Attacks Before Massacre in Nice.” The Daily Beast. January 30. http://www.thedailybeast.com/articles/2016/07/15/ terror-mag-praised-ramming-attacks.

94. Like the other attacks discussed in this section, this figure offers only a sample of the number of tweets discussing the event as some tweets make no reference to the city.

95. Though this challenge likely affects the broader number of 'Nice' mentions, the data show a notable uptick the day of the attack, and the precise content of the tweets shows that it is not a coincidence.

96. Rubin, Alissa J., and Aurelien Breeden. 2016. "ISIS Claims Truck Attacker in France Was Its 'Soldier.” The New York Times, July 16, sec. Europe. https://www.nytimes. com/2016/07/17/world/europe/isis-nice-france-attack.html.

97. Rumiyah Issue 5, January 2017

98. Hume,Tim , Isil Sariyuce and Joe Sterling. 2017. "Turkey Backtracks on Age of Wedding Bomber." CNN, August 22. http://www.cnn.com/2016/08/22/asia/turkey-gaziantep-blast/index.html; Al Jazeera. 2016. “Turkey: Suicide 
Bomber Kills More than 50 at Wedding," August 22. http:// www.aljazeera.com/news/2016/08/injured-blast-hits-wedding-hall-gaziantep-160820204150494.html.

99. Like the other attacks discussed in this section, this figure offers only a sample of the number of tweets discussing the event as some tweets make no reference to the city.

100. Letsch, Constanze. 2016. "Erdoğan Blames Isis for Suspected Suicide Attack at Wedding in Turkey”, The Guardian, August 22. https://www.theguardian.com/world/2016/aug/20/severaldead-in-suspected-terrorist-blast-at-wedding-in-turkey.

101. Pleitgen, Frederik, , Angela Dewan, James, Griffiths and Catherine E. Shoichet. 2016. "Berlin Attack: ISIS Claims It Inspired Truck Assault.” CNN, December 20. http://www. cnn.com/2016/12/20/europe/berlin-christmas-market-truck/ index.html.

102. Like the other attacks discussed in this section, this figure offers only a sample of the number of tweets discussing the event as some tweets make no reference to the city.

103. Frederik Pleitgen, Angela Dewan, James Griffiths and Catherine E. Shoichet. 2017. "Berlin Attack: ISIS Claims It Inspired Truck Assault.” CNN. http://www.cnn.com/2016/12/20/europe/ berlin-christmas-market-truck/index.html.

104. Weise, Zia. 2017. "Istanbul Nightclub Attack: Man Suspected of Killing 39 in New Year's Eve Massacre Captured by Police." The Telegraph, January 16. http://www.telegraph. co.uk/news/2017/01/16/istanbul-nightclub-attacker-killed39-new-years-eve-nightclub/.

105. McCallister, Doreen. 2017. "ISIS Claims Responsibility In Turkish Nightclub Attack; U.S. Man Among Wounded.” NPR. org, January 2. http://www.npr.org/sections/thetwo-way/ 2017/01/02/507848348/isis-claims-responsibility-inturkish-nightclub-attack-u-s-man-among-the-wounded.

106. Like the other attacks discussed in this section, this figure offers only a sample of the number of tweets discussing the event as some tweets make no reference to the city.

107. There were 2,092 tweets on the day of the attack on Istanbul's Ataturk Airport. There were 1,001 tweets on the day of the attack on Istanbul's nightclub.

108. Rumiyah Magazine, 5, January 2017.

109. Nechepurenko, Ivan, and Neil MacFarquhar. 2017. "St. Petersburg Metro Attack Included Many Students Among Victims." The New York Times, April 5, sec. Europe. https:// www.nytimes.com/2017/04/05/world/europe/st-petersburgmetro-attack-russia.html.

110. Amarasingam, Amarnath (@AmarAmarasingam). “6/6. So, from April 3-7, we have attacks in Saint Petersburg, Australia, and Stockholm - all of which have thus far gone unclaimed by ISIS.” April 8 2017, 5:04PM. Tweet. https://twitter.com/AmarAmarasingam/ status/850861931820974080.
111. Like the other attacks discussed in this section, this figure offers only a sample of the number of tweets discussing the event as some tweets make no reference to the city.

112. BBC News. 2016. "Turkey's Coup Attempt: What You Need to Know," July 17, sec. Europe. http://www.bbc.com/news/ world-europe-36816045.

113. The highest number of tweets per day in the dataset was 4,694 , on July 16, 2016, the day after the attempted coup in Turkey.

114. Researchers selected these individuals based on an initial survey of the data. Mentions of leaders like Angela Merkel and Francois Hollande were notably absent from content by English-language sympathizers.

115. Perry, Tom. 2016. "Syria Ceasefire Takes Effect with Assad Emboldened, Opposition Wary." Reuters, September 13. http://www.reuters.com/article/ us-mideast-crisis-syria-idUSKCN11I1BX.

116. Barnard, Anne. 2016. "How Omran Daqneesh, 5, Became a Symbol of Aleppo's Suffering." The New York Times, August 18, sec. Middle East. https://www.nytimes.com/2016/08/19/ world/middleeast/omran-daqneesh-syria-aleppo.html.

117. BBC News. 2017. "Syria Chemical 'Attack': What We Know," April 26, sec. Middle East. http://www.bbc.com/news/ world-middle-east-39500947.

118. Gordon, Michael R., Helene Cooper, and Michael D. Shear. 2017. "Dozens of U.S. Missiles Hit Air Base in Syria." The New York Times, April 6, sec. Middle East. https://www.nytimes. com/2017/04/06/world/middleeast/us-said-to-weighmilitary-responses-to-syrian-chemical-attack.html.

119. "Executive Order Protecting The Nation From Foreign Terrorist Entry Into The United States." 2017. Whitehouse.gov. March 6. https://www.whitehouse.gov/the-press-office/ 2017/03/06/executive-order-protecting-nation-foreign-terrorist-entry-united-states.

120. In an October 2016 interview, Charlie Winter explained, "Unofficially, there has been a few instances in which Trump has appeared in pro-ISIS propaganda. In terms of official ISIS propaganda, though, there hasn't been one mention of him; he's not appeared a single time. And that is quite incredible really, that someone who so perfectly encapsulates ISIS's view of the world, has been routinely ignored in any of its propaganda is very significant indeed, because this isn't happening by accident." The ISIS Propaganda Slowdown. 2017. http://www.wnyc.org/story/isis-propaganda-slowdown.

121. Malsin, Jared. 2016. "Russian Ambassador to Turkey Is Shot Dead in Ankara.” Time. December 19. http://time.com/ 4606600/russian-ambassador-turkey-ankara/; CNN, Catherine E. Shoichet, Nick Thompson and Emanuella Grinberg. 2017. “Gunman Shouted 'Do Not Forget Aleppo!' as He Shot Ambassador." CNN. http://www.cnn.com/2016/12/19/ europe/turkey-russian-ambassador-shot/index.html. 
122. "Pro-JFS Groups Laud Assassin of Russian Ambassador to Turkey, Distribute List of Russian Embassies.” 2017. https:// news.siteintelgroup.com/Jihadist-News/pro-jfs-groups-laudassassin-of-russian-ambassador-to-turkey-distribute-list-ofrussian-embassies.html.

123. MacFarquhar, Neil. 2016. "Vladimir Putin Tightens Grip on Russia's Parliament With Election Rout." The New York Times, September 19, sec. Europe. https://www.nytimes. com/2016/09/20/world/europe/vladimir-putin-unitedrussia-parliament-elections.html.; Browne, Ryan, and Elise Labott. 2016. "Kerry Announces US-Russia Deal on Syrian Ceasefire - CNNPolitics.com.” CNN Politics. September 10. http://www.cnn.com/2016/09/09/politics/syria-ceasefirekerry-lavrov/index.html.; Kaczynski, Andrew, Chris Massie, and Nathan McDermott. 2017. "80 Times Trump Talked about Putin.” CNN Politics. http://www.cnn.com/ interactive/2017/03/politics/trump-putin-russia-timeline/; Liptak, Kevin. 2016. “Obama Has 'Blunt' Meeting with Putin.” CNN. September 5. http://www.cnn.com/2016/09/05/ politics/barack-obama-g20-summit-asia/index.html.

124. The New York Times. 2016. "Turkey Allows Resumption of U.S. Missions From Incirlik Air Base,” The New York Times, July 17. https://www.nytimes.com/2016/07/18/world/middleeast/turkey-allows-resumption-of-us-missions-fromincirlik-air-base.html.

125. The New York Times. 2016. "Turkey Allows Resumption of U.S. Missions From Incirlik Air Base," The New York Times, July 17. https:/www.nytimes.com/2016/07/18/world/middleeast/turkey-allows-resumption-of-us-missions-fromincirlik-air-base.html.

126. Zelin, Aaron Y. 2017. "New Video Message from The Islamic State: 'Then Fight The Leaders Of Disbelief - Wilāyat Al-Khayr." February 11. http://jihadology.net/2017/02/11/ new-video-message-from-the-islamic-state-then-fight-theleaders-of-disbelief-wilayat-al-khayr/. 


\section{CONCLUSION}

The findings in this report chart an uncertain future for existing policies geared towards dismantling IS online. At first glance, declining tweet frequency, mounting account suspensions, and falling follower count initially indicate that English-language IS sympathizers suffer at the hand of the Twitter's efforts to counter the group online. Ultimately, however, growing evidence reveals a complex, nonlinear portrait of decay, showing that the fight against IS on Twitter is far from over. These results have significant implications for many government-endorsed approaches to countering violent extremism in the digital sphere.

This report analyzed 845,646 tweets produced by 1,782 English-language pro-IS accounts from February 15, 2016, to May 1, 2017. Through analyzing these accounts, and the broad range of content they disseminate, the study found that this sample of adherents was angry, agile, resilient, and committed to vocalizing their support for IS on Twitter, despite online and offline efforts to weaken the movement. After discussing the ambiguity of demographics, language trends, and the overarching decline in tweet frequency demonstrated by the dataset, the first analytical section worked to answer the question, "How have Twitter's counter-extremism policies affected Englishlanguage IS sympathizers on the platform?" This examination concluded that Twitter's policy hampered the efficacy of English-language supporters on-

\section{Counter-terrorism practitioners} and scholars must acknowledge the dexterity of sympathizers and work to understand the challenges posed by platforms other than Twitter. was not only the product of Twitter's policy, but also IS strategic shift from Twitter to platforms with encryption technology, including Telegram. While some accounts rallied in the face of shutdowns, others expressed interest in migrating to online environments that were more hospitable or optimal for extremist users. Those tasked with countering IS online must recognize the agency of actors in the movement. Swift moves to silence IS supporters may inadvertently produce side effects that challenge the efficacy of law enforcement in gauging and detecting the threat posed by violent extremists. Moreover, such actions do not necessarily affect the core of the movement and its leadership.

At the same time, however, counter-terrorism practitioners and scholars must acknowledge the dexterity of sympathizers and work to understand the challenges posed by platforms other than Twitter. Despite offering some benefits, namely regarding operational security, apps like Telegram and file sharing services like JustPaste.it offer fundamentally different methods for interaction with like-minded individuals. Furthermore, the reach of such tools varies significantly from broad-based platforms like Twitter, which is less optimal for extremists and counter-messaging practitioners alike.

Ultimately, these observations undermined the classification that line but argued that tech companies, policy makers, and other counter-terrorism practitioners should not equate such results with conventional notions of success. Although this sample of adherents struggled to keep their grip on Twitter, findings revealed their propensity to adapt to changing media landscapes.

This dataset aptly confirmed that the degradation in Twitter activity by English-language IS sympathizers
IS or its adversaries could concretely 'win' the war on Twitter, much less anywhere else online. Though narrow in scope, data gleaned from English-language IS sympathizers on Twitter suggest that this battlefield extends far beyond the reach of major tech companies and Western governments. This point is particularly concerning given the West's overwhelming reliance on tech enterprises in the fight against IS online. 
To expand upon these findings, the second section of the analysis posed three ancillary questions to investigate how English-language IS sympathizers engage on Twitter with real-world events. The first of these examined how adherents on Twitter engage with IS activity on the ground. This discussion revealed that IS' endeavors on the battlefield are still a unifying theme among sympathizers on Twitter and suggested that IS' strategic messaging output is a noteworthy, yet unreliable component linking followers on Twitter to military engagements in the region. Paired with existing research on IS' propaganda, particularly products geared towards Western audiences, the data indicates that the group's efforts to set the agenda among English-language followers on Twitter yielded mixed results. While protracted media campaigns attract and sustain some conflict-related discourse, short-lived messaging initiatives fail to divert supporters' focus in the desired direction. Although additional research is necessary, this tendency might point to a particular and perhaps growing cleavage between IS' efforts on the ground and its base of English-language supporters on Twitter. Once IS loses military engagements in its remaining strongholds in Syria, especially around Raqqa and even Deir Ezzor, it is unclear what specific topics will occupy the feeds of English-language IS sympathizers on Twitter.

The second of these supplementary questions interrogated the manner in which IS-claimed terror attacks drive discourse among English-language IS supporters on the platform. Contrary to popular belief, the effect of terrorist operations on this demographic was proportionally small and mostly unpredictable. This trend was feasibly due to the fact that the majority of IS-related violent activity occurs within IS-controlled territory. Though a rise in tweet frequency accompanied some attacks, variables like plot complexity and lethality did not consistently influence the sample of attack-related discussion among English-language sympathizers on Twitter. The clearest trend that emerged was that Western targets - those in Europe or North America - often garnered more attention than attacks elsewhere. Over time, there was a numerical and proportional decline in attack-related tweets that followed critical attacks, which suggests that terrorist operations' effect in mobilizing English-language IS supporters on Twitter is diminishing. Aside from notable spikes on the dates of attacks, terrorist violence does little to drive a sustained conversation among this demographic of supporters on Twitter, despite substantive attention from IS leadership, central propaganda, and even Western mass media. The engagement of online adherents is unsustained, indicating a disjunction between IS' reliance on the tactic and English-language sympathizers, who are apathetic to terrorist episodes in the long term.

Finally, the third question discussed how current events influence the activity of English-language sympathizers on Twitter. Ultimately, real-world events affect IS adherents whether they are inside or outside the IS-controlled territory. In a similar fashion to other socio-political spheres on Twitter, IS followers rally around incidents that resonate with its base of supporters. Some of the greatest hikes in activity correlated with events IS cannot control, and its inability to dictate the outcome of current events manifests both online and offline. While some events drew adherents en masse, others garnered less attention; though difficult to quantify with precision, the sum of these discussions accounted for the largest segment of content produced by English-language IS supporters on Twitter. No evidence suggested this dialogue is narrowing in the face of more stringent efforts to silence the movement. Although relevant tweets have declined in absolute terms, the proportion of political discourse remains substantial.

Data in this study showed that English-language IS sympathizers on Twitter defy straightforward analysis and convenient solutions. These accounts and their content are volatile, diverse, and continuously influenced by the competing agendas of IS-central, states, Twitter, and the users themselves. On Twitter, IS fights to be heard as the company strives to silence violent rhetoric. While embracing alternative platforms, especially Telegram, IS followers lack coherence but ensure a future for the organization online. In the meantime, the window of opportunity for effective, far-reaching strategic communication is closing for IS-central as supporters spread to various platforms. This challenge is further compounded by a decline in central media output, which is likely the product of IS' territorial losses and the death of propagandists like 
Abu Muhammad al-Adnani, the organization's former chief strategist of communications. ${ }^{1}$ Consequently, although IS-central attempts to communicate its priorities with a global base of supporters, some evidence suggested that its English-language adherents on Twitter stray from the path that is paved in targeted and tailored propaganda.

Like earlier iterations of the organization and many of its competitors, IS faces many contemporary challenges that will define its future in the political arena. At present, the group's ability to mobilize a base of supporters worldwide is confronted by counter-terrorism efforts both online and offline, ranging from content-based regulation on Twitter to targeting killings in Syria. In the face of such obstacles, IS' media strategy remains "intentional, broad, comprehensive and most of all - patient." 2 Like the organization's proclivity for "trial and error," ${ }^{3}$ English-language sympathizers on Twitter exhibit an uncanny aptitude for problem-solving in the digital sphere. Rather than ruminating over losses, adherents fight to be heard, whether on Twitter or one of the myriad communications technologies embraced by the organization.

To more effectively confront the threat posed by demographics like English-language IS supporters on Twitter, and the digital sphere writ large, counter-IS practitioners must show a similar willingness to adapt and explore alternative options. First and foremost, relevant entities should reconfigure their aims and definition of efficacy because total elimination of extremists on platforms like Twitter, and the Internet in general, is an unattainable goal. As terrorists continue to use communications technology to plan attacks, dialogue advocating for bans, shut-downs, and back doors across various mediums is escalating; these are "misguided" and counterproductive approaches. ${ }^{4}$ Telegram, along with other social media companies, is increasingly following in Twitter's footsteps with another iteration of content-based regulations via shut-downs. ${ }^{5}$ As anticipated, the cycle continues as IS sympathizers adapt accordingly with rebounding channels and alternative means of communication.

Although the private sector is critical to the fight against IS online, it is not the solution. The government should collaborate with various industries, but it cannot rely on the efforts of the tech industry to counter IS and its supporters in the digital sphere. Understandably, collaboration is attractive when the interest of tech companies and states align. Realistically, however, the benefits of such a relationship may be short-lived, particularly when respective interests diverge. In the case of Twitter and the U.S. government, for example, the promotion of counter-narratives and swift expulsion of IS sympathizers from the platform appealed to both parties. Over time, this approach remained marginally favorable for Twitter, but proved counterproductive to the U.S. government's fight against IS online, since many IS supporters migrated to other, less accessible channels of communication. To its detriment, the U.S. government's emphasis on social media providers' enforcement of their respective terms of service also counteracts the government's simultaneous requests for the same providers to promote counter-messages. These dynamics suggest that states must account for long term considerations in their development and appraisal of collaborative policies with the tech industry.

Without sacrificing their autonomy, supporting large scale information sharing, or relying on backdoors, social media companies can do more to undercut the reach of violent extremists without hindering conventional investigative processes. For example, social media companies should stop monetizing radical content and re-examine algorithms that optimize the connectivity of extremist users. Enterprises in the private sector, including Twitter, should continue to explore approaches that complement content-based regulation and counter-messaging initiatives. Alternative models might consider behavior-based incentives within the platform or draw upon the various strategies companies are developing to flag fake news and other disreputable sources. Rather than silencing users online, organizations can implement safeguards that make it difficult, not impossible, for users to gain traction if they violate a company's prescribed terms of service. These tools can be applied to mitigate the impact of online extremists of various persuasions.

Existing initiatives to counter IS online have also inadvertently made it difficult for law enforcement to detect and disrupt plots, whereas threats made on social media, 
including Twitter and Tumblr, were previously used in criminal cases. ${ }^{6}$ While legal redress is a fundamental consideration, steps forward by all parties must seek to balance security and civil liberties. Along these lines, policymakers and practitioners must remain cognizant of the online-offline synergy that affects the mobilization of violent extremists worldwide. Policies that fail to traverse the space between the two environments ignore the climate that dominates this arena.

IS' future in the digital sphere is amorphous but undeniable. Observations concerning English-language adherents on Twitter suggest that the company's counter-terrorism policy, in tandem with IS' strategic shift away from Twitter, facilitated the decay of the organization's presence on the platform. While focusing on a small sliver of the IS supporters, this report highlights contemporary challenges to countering online extremism. Ultimately, IS is the amalgamation of central leadership and a broad base that arose in support of its agenda. Through strategic and digital communications, particularly social media, these two components have synergistically fused into an elusive but proactive global movement. In the face of losses, IS and its English-language sympathizers demonstrate resilience, casting a wide net to guarantee survival, and live to tweet another day.

\section{Notes}

1. According to a press release from the U.S. Department of Defense, Abu Muhammad al-Adnani was reportedly killed on August 30, 2016 by a precision airstrike. "Statement from Pentagon Press Secretary Peter Cook on Strike Against ISIL Senior Leader." 2016. Department of Defense. September 12.

2. Whiteside, Craig. 2016. "Lighting the Path: The Evolution of the Islamic State Media Enterprise (2003-2016).” International Centre for Counter-Terrorism - The Hague. p.22.

3. Whiteside, Craig. 2016. "Lighting the Path: The Evolution of the Islamic State Media Enterprise (2003-2016).” International Centre for Counter-Terrorism - The Hague. p.4.

4. Brantly, Aaron, 2017. "Banning Encryption to Stop Terrorists: A Worse Than Futile Excercise” CTC Sentinel 10 (7).

5. See section regarding content deletion, "Telegram F.A.Q." 2017. Telegram. Accessed September 13. https://telegram. org/faq.“Telegram, Once More Repeating Twitter's Mistakes, Suspended ISIS' Main Arabic Channel, but New One Is Already up." 2017. News from War on ISIS in English from Iraq, Syria - Deir Ez-Zur Operation, Raqqa Operation - Isis. liveuamap.com. https://isis.liveuamap.com/en/2016/13-apriltelegram-once-more-repeating-twitters-mistakes-suspended.

6. Consider, for example, the aforementioned case of Safya Yassin. More recently, Terrence McNeil was sentenced to 20 years for soliciting the murder of U.S. service members on social media. United States Department of Justice. 2017. “ISIS Supporter from Akron Sentenced to 20 Years in Prison for Soliciting Murder of U.S. Service Members." Accessed August 8. https://www.justice. gov/usao-ndoh/pr/isis-supporter-akron-sentenced-20-years-pri son-soliciting-murder-us-service-members. 



\section{Program on Extremism}

THE GEORGE WASHINGTON UNIVERSITY

GW Program on Extremism · extremism.gwu.edu · @gwupoe 